\title{
Diuretic drug cessation in general practice : withdrawing diuretic drugs prescribed for ankle oedema
}

Citation for published version (APA):

de Jonge, J-W. (1993). Diuretic drug cessation in general practice : withdrawing diuretic drugs prescribed for ankle oedema. [Doctoral Thesis, Maastricht University]. Rijksuniversiteit Limburg. https://doi.org/10.26481/dis.19931201jj

Document status and date:

Published: 01/01/1993

DOI:

10.26481/dis.19931201jj

Document Version:

Publisher's PDF, also known as Version of record

\section{Please check the document version of this publication:}

- A submitted manuscript is the version of the article upon submission and before peer-review. There can be important differences between the submitted version and the official published version of record.

People interested in the research are advised to contact the author for the final version of the publication, or visit the DOI to the publisher's website.

- The final author version and the galley proof are versions of the publication after peer review.

- The final published version features the final layout of the paper including the volume, issue and page numbers.

Link to publication

\footnotetext{
General rights rights.

- You may freely distribute the URL identifying the publication in the public portal. please follow below link for the End User Agreement:

www.umlib.nl/taverne-license

Take down policy

If you believe that this document breaches copyright please contact us at:

repository@maastrichtuniversity.nl

providing details and we will investigate your claim.
}

Copyright and moral rights for the publications made accessible in the public portal are retained by the authors and/or other copyright owners and it is a condition of accessing publications that users recognise and abide by the legal requirements associated with these

- Users may download and print one copy of any publication from the public portal for the purpose of private study or research.

- You may not further distribute the material or use it for any profit-making activity or commercial gain

If the publication is distributed under the terms of Article $25 \mathrm{fa}$ of the Dutch Copyright Act, indicated by the "Taverne" license above, 
DIURETIC DRUG CESSATION IN GENERAL PRACTICE 
De tot standkoming van dit proefschrift werd mede mogelijk gemaakt door een financiële bijdrage van:

de firma E. Merck Nederland B.V. te Amsterdam; ORHA Verzekeringen te Amhern; de firma ZYMA Nederland B.V. te Mijdrecht. 


\section{DIURETIC DRUG CESSATION IN GENERAL PRACTICE}

WITHDRAWING DIURETIC DRUGS PRESCRIBED FOR ANKLE OEDEMA

\section{PROEFSCHRIFT}

ter verkrijging van de graad van doctor aan de Rijksuniversiteit Limburg te Maastricht, op het gezag van de Rector Magnificus, Prof. Dr. H. Philipsen, volgens het besluit van het College van Dekanen, in het openbaar te verdedigen op woensdag, 1 december 1993 om 16.00 uur

door

Jan-Willem de Jonge geboren te Warder 
Promotores:

Prof. Dr. J.A. Knottnerus

Prof. Dr. H.A.J. Struijker Boudier

Beoordelingscommissie:

Prof. Dr. J. Urquhart (voorzitter)

Dr. A.P.M. Gorgels

Prof. Dr. F.W.J. Gribnau (Katholieke Universiteit Nijmegen)

Dr. K.M.L. Leunissen

Prof. Dr. R.A. de Melker (Universiteit Utrecht) 
....But the doctors were hardly wiser then than they are now, and after prescribing rest and exercise, starvation and nourishment, sociery and solitude, that he should lie in bed all day and ride forry miles berween lunch and dinner, together with the usual sedatives and irritants, diverisfied, as the fancy took them, with possets of newt's slobber on rising, and draughts of peacock's gall on going to bed, they left him to himself....... 


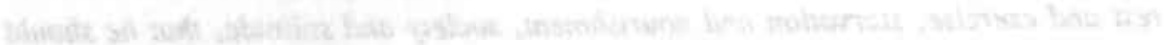

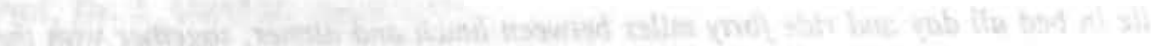

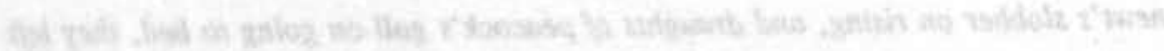

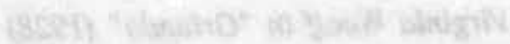

Aan Esther

Aan mijn ouders 
1.1 Introduction 3

1.2 Research questions 4

1.3 Structure of the thesis 6

2 General backgrounds 9

2.1 Introduction 11

2.2 Drug use in the elderly 11

$\begin{array}{lll}2.3 & \text { History of diuretic drugs } & 12\end{array}$

2.4 Mechanisms of actions of diurerics $\quad 14$

2.5 Indications for diuretic use 16

2.6 Adverse effects of diureric drugs $\quad 18$

2.7 Diuretic-induced oedema 23

2.8 Diuretics and ankle oedema 24

3 Diuretic drug withdrawal trials, a review 32

3.1 Abstract 33

3.2 Introduction 34

3.3 Methods 34

3.4 Results 37

3.5 Results of merhodological evaluation of the wirhdrawal studies 43

3.6 Discussion 44

4 Treatment of elderly patients with ankle oedema in general practice When and how often are diuretics used?

4.1 Summary

4.2 Introduction 
4.3 Method 53

4.4 Results $\quad 54$

4.5 Discussion 56

5 Methodological issues of withdrawal trials $\quad 60$

5.1 Methodological issues in withdrawal trials 61

5.2 The objective 61

5.3 The length of the follow-up period 61

5.4 Patient selection criteria 62.

5.6 Exclusion criteria 183

5.7 Use of placebo $\quad 64$

5.8 Conclusions 64

6 Research methods 67

6.1.1 Introduction $\quad 69$

6.2.1 The prevalence study. $\quad 69$

6.2.2 Phase one, identifying patients in general pracrice aged 65 or older 70

6.2.3 Phase no, the patient mail questionnaire 71

6.3.1 Design of the trial 72

6.3.2 Selection criteria for participanrs 13

6.3.3 Observations $\quad 75$

6.3.4 Performing of the definitive selection of the parients 77

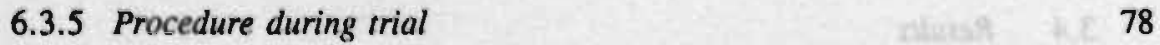

6.3.6 Monitoring 81

6.3.7 Criteria for congestive heart failure 82

6.3.8 Volumerry $\quad 84$

6.4.1 Non-experimental follow-up after the trial 85

6.5.1 Statistics 86 
7.1 Introduction 91

7.2 Results of the first phase of the selection procedure: selection according to age and use of diuretics 91

7.3 Practice-based prevalence of diuretic use $\quad 94$

7.4 Results of second phase of the selection: patients available for further investigation, and patients who were not sent a questionnaire, did not respond or refused further participation 95

7.5 Indicarions for diuretic use 97

7.6 Results of the third phase: further investigation of the questionnaires $\begin{array}{ll}\text { and patient records } & 98\end{array}$

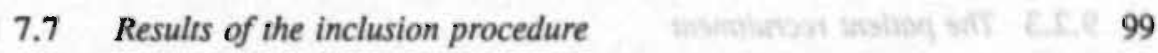

$\begin{array}{lll}7.8 & \text { Overview of resulss of selection method } 101\end{array}$

7.9 Comparison and discussion regarding sex and age distribution of trial population and all patients selected on age and diuretic use 106

7.10 Discussion

\subsection{Ineroduction}

8.2 Patients participaring in the trial

8.3 Patients who restarted diuretic therapy during the irial

8.4 Complaints of patients during the trial

8.5 Compliance to the iniervenion

8.6 Course of oedema index after withdrawing diuretic drugs 125

8.7 Degree of pedema during the follow-up period

8.8 Weight, peak flow and blood pressure during follow-up

8.9 Influence of withdrawing diuretics on electrolytes, haematocrit. crearinine and urea

8.10 Questionnaires about quality of life and functional status

8.11 Post-experimental follow-up 
9 Genera! discussion $\quad 149$

9.1.1 Introduction 151

9.1 .2 Diuretic withdrawal studies
9.1 .31

9.1.3 Questionnaire on treatment of ankle oedema 152

9.1.4 The prevalence study $\quad 153$

9.1.5 The withdrawal trial 153

9.2 Mechodology 154

9.2.1 The literature review method 154

9.2.2 The questionnaire $\quad 154$

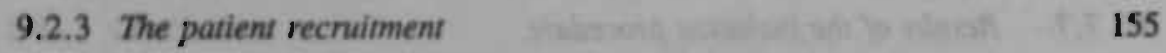

$\begin{array}{ll}\text { 9.2.4 Design of the trial } & 155\end{array}$

9.3 Recommendations for further research 158

$\begin{array}{ll}9.4 & \text { Recommendarions for clinical practice } \\ \end{array}$

10 Summary 163

$\begin{array}{ll}\text { Samenvatting } & 170\end{array}$

\begin{tabular}{l|l} 
Appendix & 177
\end{tabular}

$\begin{array}{ll}\text { Curriculum vitae } & 179\end{array}$

Dankwoord 180 
Chapter 1

Introduction 


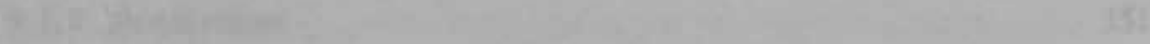

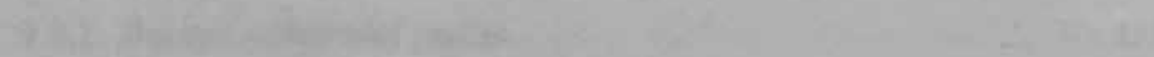

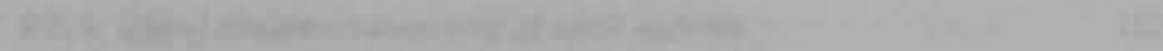

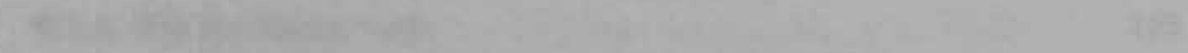

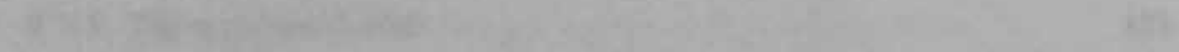

$$
\begin{aligned}
& \text { 17.7. }
\end{aligned}
$$

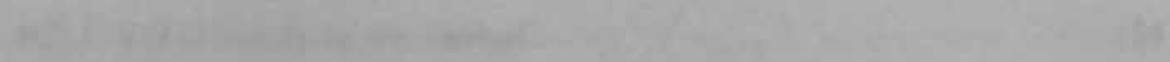

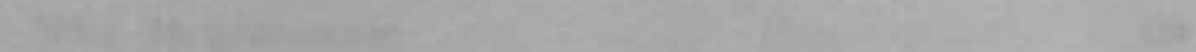

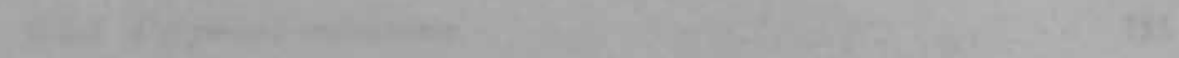

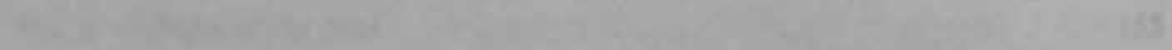

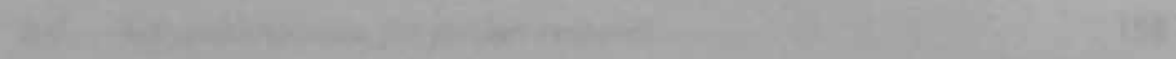

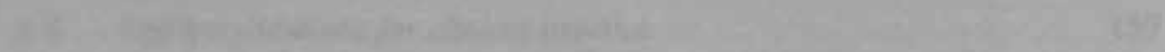

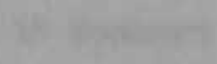

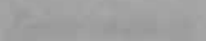

$$
\begin{aligned}
& x^{2}+2 x+25=
\end{aligned}
$$

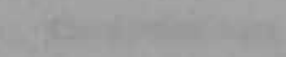

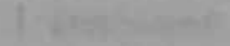


The general practitioner (GP) can have an important role in overseeing long-term drug use. In numerous situations the GP must decide whether to stop or to continue drugs that are being used chronically. Of course unnecessary drug use should be prevented. One of the ways to achieve this is to withdraw drugs whenever they are not useful (any more) in a given situation. Unfortunately there has as yet been little investigation of the effects of withdrawal of most therapies. This is in sharp contrast to the vast literature on the effects of starting therapies. Also the methodological aspects of studying the effects of drug withdrawal are undeveloped as compared with the methodology of trials on introducing new drugs. Therefore little is known about effects of stopping therapies in many circumstances. This might mean that withdrawal of drugs does not take place in situations where it would be appropriate. In this context diuretic drugs are of importance. In the Netherlands, and also in other countries such as the United Kingdom, about one in five people older than 64 are prescribed diuretic drugs for long-term use.(1)(2)(3) Disadvantages of this extensive use, in terms of adverse effects or unfavourable interactions with other drugs, are frequently mentioned in medical literature.(4)(5)(6) In cases where there is uncertainty about the rationality of diuretic therapy, it seems useful to attempt to withdraw diuretic therapy. This situation can occur when diuretics are prescribed to patients presenting with observed ankle oedema or complaining of it. Indeed several studies have advocated that the withdrawal of diuretics in elderly patients can be appropriate in certain circumstances, such as when patients are using diuretics for ankle oedema, given that the oedema is not caused by cardiac, renal or hepatic insufficiency.(1)(7-12) However, there has been no research purely on the effects of withdrawal of diuretic drugs in elderly people in the general practice population to whom diuretics were prescribed for ankle oedema. In this thesis we will describe the results of a research project focused on this subject.

We reviewed the literature concerning withdrawal of diuretic drugs in the elderly. We performed a questionnaire survey among general practitioners regarding their therapeutic options in a case of an elderly patient with the symptom ankle oedema. 
In addition a prevalence study was carried out on the use of diuretics by the elderly. Finally, in a randomized controlled trial we studied the effects of withdrawal of diuretics on the degree of ankle oedema in patients who were using diuretics because of ankle oedema.

\subsection{Research questions}

The review of diuretic drug withdrawal trials

Several publications have advocated that withdrawal of chronically used diuretic drugs in elderly patients is safe and appropriate in a number of situations.(1)(7-12)

A literature review was carried out to determine whether withdrawal of diuretic drugs in general practice is safe and adequate in elderly patients who use diuretics chronically and who do not have high blood pressure or show symptoms of cardiac, hepatic or renal failure.

The main research questions were the following:

1 To what extent do the trials on this subject meet the methodological criteria that gre important for their validity?

II What are the results of the studies especially regarding morbiclity, the development of cardiac failure and ankle oedema?

\section{The questionnaire survey}

A controversy between theory and practice seems to exist regarding the use of diuretics for the treatment of ankle oedema that is not caused by cardiac, renal or hepatic insufficiency. There are indications that they are prescribed for this complaint in day-to-day care, although in the Netherlands diuretics are not listed for use in ankle oedema that is not caused by cardiac, renal or hepatic insufficiency.(13), We used a questionnaire survey to obtain information on the opinions of general practitioners about their differential diagnosis and treatment in this situation. We 
were especially interested in whether diuretics were considered as a therapeutic option in patients with ankle oedema without strong evidence for cardiac insufficiency.

The research questions were as follows:

1 Which differential diagnoses ranked in order of likelihood are made, when general practitioners consider a case of a patient with ankle oedema without strong evidence for cardiac insufficiency?

II What treatment is proposed for the presented case?

The prevalence study

To assist in determining the selection of patients with the indication ankle oedema who would be eligible for withdrawal of diuretics, a prevalence study was conducted. In this study we collected information concerning patients aged 65 years and older who were prescribed diuretic drugs during the preceding half-year.

The research questions were the following:

I How large is the proportion of patients in general practice aged 65 years or older, who were prescribed diuretic drugs in the half-year preceding the experiment?

II For which indications and in what frequencies, according to patients, are diuretics prescribed?

III For which indications and in what frequencies, according to the doctors, are diuretics prescribed?

IV How large is the proportion of patients who use diuretic drugs for ankle oedema, without having indications for heart failure? 


\section{The withdrawal tria!}

There are no clear research results available about the effects of withdrawing diuretic therapy in elderly patients in general practice who are using diuretics for ankle oedema and in whom no strong indications are found for cardiac, hepatic or renal failure. Knowledge about this could lead to a more rational use in future, and the withdrawal of unnecessary diuretic drugs in elderly patients with ankle oedema. For this reason a randomized controlled trial of diuretics withdrawal was conducted. The trial was designed to investigate the following research questions:

I What are the effects of withdrawing diuretic drugs on the degree of oedema in patients who were prescribed diuretic drugs for ankle oedema and who at the moment of cessation of the diuretic therapy have no indications for cardiac, hepatic or renal insufficiency?

II If diuretic therapy has to be resumed, what are the reasons for this resumption?

\subsection{Structure of the thesis}

Chapter 1 provides a general introduction, with the research questions.

Chapter 2 (General background) contains background information about diug use of the elderly, focussing on diuretic drugs.

Chapter 3 (Diuretic drug withdrawal trials: a review) is a review of trials on the effects of discontinuing diuretic therapy in elderly patients.

Chapter 4 (Treatment of elderly patients with ankle oedema in general practice. When and how often are diuretics used?) reports on a mail questionnaire, which we used to investigate which therapeutic options GPs would use for ankle oedema without symptoms of cardiac, hepatic or renal failure. 
Chapter $S$ discusses methodological issues in research into the withdrawal of drugs.

Chapter 6 (Research methods of the prevalence study and the withdrawal trial) gives a detailed description of the design and the practical execution of both the prevalence study and the withdrawal trial.

Chapter 7 (Results of the prevalence study) presents the results of the prevalence study on diuretic use by the elderly patients in general practice. We discuss the number of patients who were eligible for withdrawal of diuretics in our trial.

Chapter 8 (Results of the withdrawal trial) reports on our trial on the withdrawal of diuretic therapy in elderly patients in general practice who were using diuretics for ankle oedema and in whom no strong indications were found for cardiac, hepatic or renal failure.

Chapter 9 (General discussion), here the findings are summarized and discussed in relation to methodological issues and practical consequences. Recommendations for health care and further research will be presented.

Chapter 10 (Summary), gives a summary of the whole thesis. 


\section{References}

1. Walma EP, Boukes FS. Print A, Vas, der Does E. Diuretica gebruik door 65 -plussers in een buisartspraktijk. Wie kunnen er atoppen? Huisurts Wet 1989; 32: 326-8.

2. Branbergen HCT. Welke pil alikt de 65-plusser? Huisarts Wet 1985; 28(suppl 9): 34-5.

3. Rhodes KE. Prescription of diuretic drugs and monitoring of long-term use in one general practice. Brit I Oen Pract 1992; 42: 68-70.

4. Diuretics in the elderly [editorial], Br Med I 1978; it 1092-3.

5. MacLenaan W]. Diuretics in the elderly; how safe? [editorial]. Brit Med I 1988; 296: 1551.

6. Need we poison the elderly so often?' [editorial], Lancet 1988: ii: 20-2.

7. Burr ML, King S, Davies HEF, Pathy MS. The effects of discontinuing long-term diuretic therapy in the elderly. Ago Ageing 1977; 6: 38-45.

8. Portnol VA, Pawlson LG. Abuse of diuretic therapy in nursing bomes. I Chron Dis $1981 ; 34: 363-5$.

9. Myer GM, Weingert ME, Fisher RH, Gryfe Cl, Shulman HS. Unnecessary tiuretie therapy in the elderly. Age Ageing 1982; 11: 213-21.

10. Thegart N. MeDevin DG. Diuretic withdrawal, a need for caution. Curr Med Res Ooin 1983: 8. Sol-8.

11. Koopmans RTCM. Gribnau FWI. Langdurige diureticumbehandeling bij verpleeghuisbewoners. Ls stoppen mogelijk? Tijdschr Gerontol Geriatr 1988; 19: 55-60.

12. Wilson JA, Thompson D, MacLennan WJ, Marshall I. Stasis oedema in the elderly: Are diuretics necessary? Geroutology 1991; 37: 289-92.

13. Anonymus. Tractus Uropolticus Diuretica. In: Nelemans FA ed. Farmacotherapeutisch Kompas. Amstelveen: Centrale Medisch Pharmaceutische Commissie van do Ziekenfondsraad, 1989: 362-5. 


\section{Chapter 2}

General backgrounds 


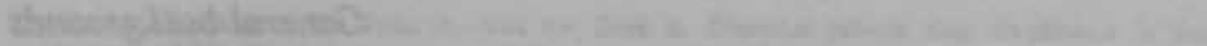

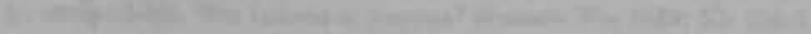

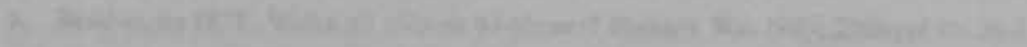

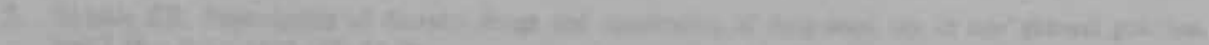

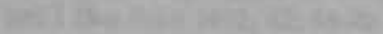

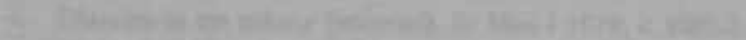

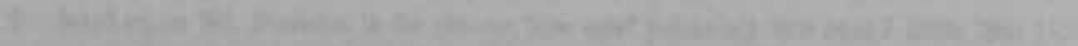

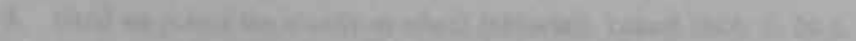

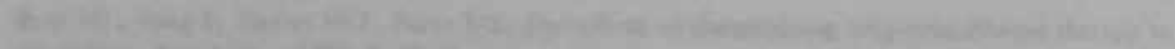

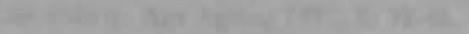

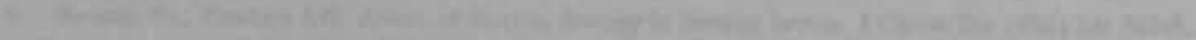

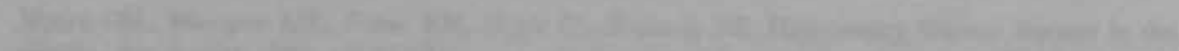

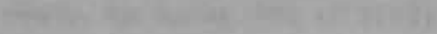

(1)

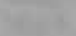

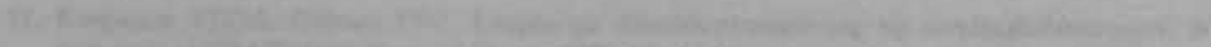

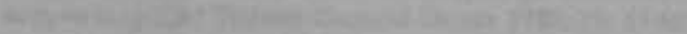

13.

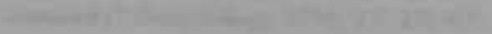

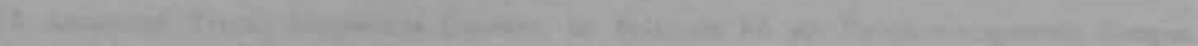

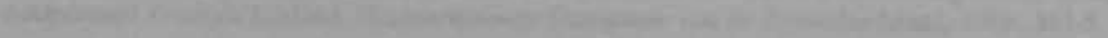




\subsection{Introduction}

This chapter contains background information concerning the research project. An overview is given of the problem of high and long-term drug use by the elderly. Diuretics are dealt with especially, since they are among the drugs most frequently prescribed to the elderly. A short history and the mechanisms of action of the diuretic drugs in current use is included. Further, indications for diuretics in relation to the mechanism of action are reviewed.

The major drawback of high diuretic use by the elderly concems the adverse effects. Therefore, a short review of adverse effects of diuretic drugs is given with special focus on problems that affect the elderly. Particular attention is paid to the rebound phenomenon of oedema and weight increase that may occur after withdrawal of diuretic drugs.

Ankle oedema is an important indication for prescription of diuretics in the elderly. Since this is of prime importance to the research project, a paragraph is specifically focused on this indication.

\subsection{Drug use in the elderly}

An item of concern to which attention is repeatedly paid in medical literature is the problem of the high prescription rate and often chronic use of drugs in elderly patients.(1) (2) Figures from a Dutch survey show a strong increase in the number of prescriptions per patient with the advancement of age. Regarding repeat prescriptions the figures show an increase from 275 prescribed daily doses (PDD)/1000/day for people between 20 and 50 years of age to $2104 \mathrm{PDD} / 1000 /$ day for people of 80 years and older.(3) Cardiovascular drugs and psychotropic drugs are responsible for the greatest part of this increase. Although patients will benefit from appropriate prescription, the danger of iatrogenic illness increases with the number of prescribed drugs. In a British study it was shown that in 209 of 1998 consecutive hospital admissions of elderly patients, adverse drug effects could have 
attributed to the hospital admission.(4)

Elderly patients are more prone to meet side effects because of sometimes unpredictable changes in pharmacokinetic and -dynamic behavior of drugs. Another reason for unfavourable drug effects in the elderly is the problem of multiple pathology which can lead to polypharmacy, with interactions between drugs as a consequence. Also non-pharmacologic factors may be of influence in causing unfavourable effects of drugs prescribed to elderly patients. The doctor-patient communication can be inadequate, leading to the patient having inappropriate ideas concerning the use of the prescribed drug. Appropriate use of drugs can be hindered by visual or memory disability of patients.(5) Often the compliance with drug use of elderly patients might be insufficient. However, Cartwright and Smith showed that non-compliance mainly occurred in medicines which the patients thought were not very helpful for their complaints. They found that on average $75 \%$ of patients reported using the prescribed drugs as advised.(6) Others estimate that $35 \%$ of patients taking chronic-use medicines substantially undercomply. (7)

The situation where elderly patients are prescribed too many drugs is unfavourable and requires attention. Attempts to diminish over-use of medicines appear to be important. In this context diuretic drugs are especially of interest. A survey carried out in the Netherlands showed that diuretics are the most frequently used drugs in patients aged 60 years and older.(3) In both Britain and the Netherlands the prevalence of diuretic drug use in persons aged 65 and older is approximately $20 \% .(6)(8)(9)(10)$ The prevalence increases strongly with the advancement of age. There is an increase from less than $30 \mathrm{PDD} / 1000 /$ day for people of 45 years of age up to $400 \mathrm{PDD} / 1000 /$ day in persons of 80 years and older.(3)

\subsection{History of diuretic drugs}

Diuretics are substances which increase the rate of urine output. Their principal aim is to reduce the total amount of fluid in the body. Treatment of oedema caused by cardiac, hepatic or renal insufficiency and hypertension are the main indications. 
Although nowadays hardly imaginable, potent orally administered diuretic drugs. without serious side-effects were not available until the end of the 1950s when clinical application of the first thiazide diuretics was discovered(11)(12). Prior to this, diuresis was promoted using on the one hand parenterally administered osmotic active agents such as dextran, albumin and mannitol and on the other mercurial preparations whether or not combined with xanthines. The mercurial substances were found by coincidence to promote diuresis while used for treatment of syphilis.(13) In the early 1920s their use for diuretic purposes emerged, which led to an important therapeutic advance in treatment of oedema. The mercurials had several toxic effects and had to be administered parenterally and therefore, these were far from ideal diuretics. In the early 1950s a wide range of sulphonamide-like substances were investigated on their general pharmacotherapeutical actions. First acetazolamide was found to have a carbon anhydrase inhibiting, diuretic effect. However, at the same time it caused a metabolic acidosis that inhibited further diuretic action and thus limited the diuretic efficacy of the drug. Moreover acetazolamide has quite unpleasant side-effects. It's use creates the risk of formation of renal stones, can give an unpleasant diminution of appetite and distortion of taste sensations. By further testing related substances for their carbonic anhydrase activity, the benzothiadiazides were found to have a fairly strong effect on urine voided. The urine contained a relatively high amount of chloride. Subsequent studies showed that benzothiadiazides (or thiazides) had a direct effect on the renal tubular transport of sodium and chloride, causing a diuresis independent of any effect on carbonic anhydrase.(14) The first substance extensively studied was chlorothiazide having a pharmacologic action similar to other, thiazide like substances developed later.(15) Only seven years after the introduction of chlorothiazide 12 different thiazide diuretics were reported in a Goodman and Gilman edition of those days.(12)

In the early 1960s in Germany the biological activities of sulphonamide derivates, were tested. Frusemide emerged to have strong and rapid diuretic effect and in 1964 its properties were reported.(16) Related to frusemide, bumetanide was developed in Scandinavia having an even stronger effect per administered weight of 
the substance. In this decade also the potassium-sparing agents, triamterene: and amiloride, were also developed.(12)

\subsection{Mechanisms of actions of diuretics (11)(17)}

The following description is restricted to the diuretics that were subject of the investigation in the trial.

Renal adaptive mechanisms play an important role in regulating within narrow limits the salt and fluid content of the extracelluar fluid (ECF) of the body. The total amount of ECF is strongly connected to the total amount of extracelluar sodium ions. This sodium balance is influenced by active reabsorption of sodium in distal parts of the nephron, under control of aldosterone. The osmolality of the ECF is primarily determined by the sodium concentration in the ECF. The sodium concentration is strongly influenced by anti-diuretic-hormone (ADH) secretion by the neurohypophysis. Under influence of $\mathrm{ADH}$, renal water reabsorption takes place from the collecting ducts, which results in more concentrated urine.

The diuretic effect of diuretic drugs consist mainly of the inhibition of the sodium reabsorption in the nephron, causing water and salt diuresis. Approximately $65 \%$ of the reabsorption of sodium takes place in the proximal tubule, $25 \%$ in Henle's loop, 8 to $9 \%$ in the distal tubule and the remainder in the collecting duct. In the light of these figures the place of action of the different types of diuretics largely explairs their maximum diuretic effect. The loop diuretics, frusemide and bumetanide, act by inhibiting the active transport of chloride (and with this anion, the cation $\mathrm{Na}^{+}$) through the tubule wall in the ascending part of Henle's loop. In relation to the site of action, the diuretic effect of the loop diuretics has two components. First, by the direct inhibition of reabsorption of sodiumchloride from the filtrate, more sodium chloride remains in the urine (thus water). Second, normally if sodium chloride is reabsorbed, it contributes to the development of hypertonicity of the medullary part of the kidney. Under influence of loop diuretics sodiumchloride is not transported to the medullary interstitium. The ability to reabsorb water from the collecting ducts is 
impaired and water diuresis is promoted.

The thiazide type diuretics act on the reabsorption of sodium chloride in the first part of the distal tube. Since this part is situated in the cortex and not in the medulla, the inhibition of development of hypertonicity of the medulla is not achieved. This explains partly why the thiazide diuretics have a lesser diuretic effect than the loop diuretics.

The potassium-sparing diuretics act on the second, medullary part of the distall tubule, inhibiting the exchange of $\mathrm{Na}^{+}$ions against $\mathrm{K}^{+}$and $\mathrm{NH}_{4}^{+}$ions.

Based on the maximum effect of the diuretic substances expressed as the maximal fraction excretion (MFE) of sodium (i.e sodium excretion expressed as a percentage of the sodium filtered in the glomerulus), the following classification of diuretic drugs can be made:(11)

1. High efficacy diuretics (MFE $>15 \%$ ).

loop diuretics:

frusemide

bumetanide

2. Medium efficacy diuretics (MFE 5\%-10\%).

thiazide and related diuretics:

chlorthalidone

hydrochlorthiazide

chlorthiazide

indapamide

mefruside

3. Weak diuretics (MFE $<5 \%$ )

potassium-sparing diuretics:

amiloride

triamterene

(aldosterone competitive antagonist)

spironolactone

The start and duration of diuretic effects differ strongly between the various types of 
diuretics. In table 2.1 an overview is given of the average time periods of diuretic action after oral administration of the diuretics under study in our project.(18)

Table 2.1. Time intervals for diuretic effects after oral administration (diuretics. most frequently prescribed in our trial population).(17)

\begin{tabular}{|c|c|c|c|}
\hline & start diuretic effect & $\begin{array}{l}\text { period after which } \\
\text { maximum effect is } \\
\text { achieved }\end{array}$ & duration of effect \\
\hline frasermide & $<30 \mathrm{~m}$. & & $6-8 \mathrm{~b}$. \\
\hline bumetanide & $30.60 \mathrm{~m}$ & & $4-6 b$. \\
\hline chlorthiaxide & $2 \mathrm{~h}$. & $4 \mathrm{~b}$. & $6-12 \mathrm{~h}$. \\
\hline hydrochlorthiazide & $1.2 \mathrm{~h}$. & in. & $12-13 \mathrm{~h}$. \\
\hline chlortialidone & $2 \mathrm{~b}$. & $12 \mathrm{~h}$. & 3 days \\
\hline mefrusida & $2 \mathrm{~h}$. & $6-12 \mathrm{~h}$. & $20-24$ h. \\
\hline triamterene & $2 \cdot 4 \mathrm{~h}$ & $6 \mathrm{~h}$. & $12 \cdot 16 \mathrm{~h}$ \\
\hline amiloride & $<2 \mathrm{~h}$. & $6 \cdot 10 \mathrm{~b}$. & $24 \mathrm{~h}$. \\
\hline
\end{tabular}

(h. = hours, m. = minutes)

\subsection{Indications for diuretic use}

In general practice the two most important iisted indications for diuretic use are congestive heart failure and hypertension.

In chronic heart failure, cardiac output is reduced. Renal blood flow and glomerular filtration rate are lowered. The glomerulotubular balance is lost, with a net increase of water and salt reabsorption. The circulating blood volume expands, central venous pressure and ventricular end-diastolic pressure become elevated. A further deterioration of the cardiac output occurs. One of the consequences of the elevated circulating volume is the development of oedema. The basic function of diuretics is 
breaking through these physiologic mechanisms, thus promoting the elimination of the accumulation of water in the intravascular or interstitial compartment.

Diuretics also are indicated in acute left-sided cardiac failure with pulmonary oedema. If used intravenously, loop diuretics exert an instantaneous effect.(11) Administration results in a direct increase in the capacity of the systemic venous reservoir with reduction in venous return and left ventricular filling pressure. This is an extrarenal vascular effect that precedes diuresis.

Different opinions exist with respect to treatment of patients with mild heart failure concerning the use of thiazide diuretics. On the one hand thiazide diuretics are advocated because of their mild and relatively long lasting activity.(19) On the other hand loop diuretics are considered as first choice diuretic therapy, because of their stronger effect on salt excretion.(19)

Hypertension is the other main accepted indication for diuretic use in general practice. The mechanism of the antihypertensive effects of diuretic drugs is still not totally clarified. Initially diuretics cause a shrinkage of plasma and extracellular fluid volume; cardiac output falls. Following this, early phase extracellular fluid and cardiac output return to normal with accompanying decreases in peripheral resistance, thus the antihypertensive effect remains.(17) Low doses of thiazide diuretics are a first choice in treatment of hypertension.

Other indications for diuretic use which are rarer in general practice but are usually encountered in the hospital setting are:

- oedema in nephrotic syndrome;

- oedema in liver cirrhosis;

- hypercalciuria.(11)(18)(20)

In practice, more indications for initial prescription of diuretic drugs can be observed. A survey concerning diuretic usage in the United Kingdom reported the initial reason for prescription as, among others: leg oedema, premenstrual syndrome, weight reduction, carpal tunnel syndrome and thrombophlebitis.(21) However, those indications are controversial in most cases 


\subsection{Adverse effects of diuretic drugs}

In general it is important to keep in mind that severe adverse effects of diuretics are often founded on hospital-based observations concerning patients not representative of the general practice population. Little is known about the incidence of these adverse effects due to diuretics used in the out-patient population. On the other hand, much research on effects of diuretics has taken place in large hypertension trials in which adverse effects were also investigated. However, figures concerning incidences of adverse effects are still difficult to obtain. A disadvantage of figures from the large hypertension trials is that the investigated population mostly is not representative of the population under study in our research project, elderly who use diuretics because of ankle oedema.

Some well known adverse effects of diuretic drugs can be attributed directly to their pharmacologic action. Since diuretics act on the electrolyte and water balance, unfavourable effects on this balance can also occur.

It has been shown that from patients admitted to a geriatric ward in a Dutch hospital $43 \%$ of those using diuretics showed symptoms of dehydration compared to $12.5 \%$ of those not using diuretics (odds ratio 5.3, 95\% confidence interval 1.9-

\section{3).(22)}

Diuretic-induced hypokalaemia is frequently reported as a side-effect. However, much controversy exists about its clinical relevance and whether, and if so, how to prevent hypokalaemia in low and moderate diuretic use. As a reaction to the relative hypovolaemia induced by the diuretics, the renin-angiotensin-aldosterone system (RAAS) may cause a secondary hyperaldosteronism. Aldosterone promotes the reabsorption of sodium ions from the ultrafiltrate. This process occurs in exchange against potassium and hydronium ions, which contributes to hypokalaemia and a relative metabolic alkalosis that can occur during the use of diuretic drugs. An indication for the frequency of diuretic-induced hypokalaemia is given by a study in which diuretic use and biochemical parameters were studied in elderly patients who were admitted to hospital. Thiazide diuretics without potassium supplementy or potassium-sparing agents were used by 14 patients, of whom 3 had a potassium level 
below $3 \mathrm{mmol} / \mathrm{l} .(23)$ of course selection bias, namely admission to hospital because of diuretic use and low potassium level, may have influenced this figure. In the Medical Research Council (MRC) trial for treatment of mild to moderate hypertension, the mean potassium level of men on bendrofluazide (thiazide diuretic) decreased from $4.07 \mathrm{mmol} / \mathrm{l}$ at entry to $3.59 \mathrm{mmol} / \mathrm{l}$ after 3 years of therapy and in women from $4.03 \mathrm{mmol} / \mathrm{l}$ to $3.52 \mathrm{mmol} / \mathrm{l}$. For both sexes the change was statistically significant in comparison with the placebo group.(24) Cardiac arrhythmias are attributed to diuretic-induced hypokalaemia.(25)(11) A recent case control investigation showed an increased risk of sudden cardiac death among patients using non-potassium sparing diuretic anti-hypertensive therapy compared to patients using other anti-hypertensive therapies (odds ratio $2.2,95 \%$ confidence interval 1.1-4.6).(26)

On the other hand, diuretic-induced hyperkalaemia caused by inappropriate use of potassium sparing diuretic drugs is also considered to be a risk, which pleads for the use of potassium sparing diuretics only in patients at risk. The most important group of patients at risk for hypokalaemia are digoxin-using patients, where hypokalaemia is known to cause sometimes severe cardiac arrhythmias.(11)

Hyponatraemia is reported, especially in elderly patients, to be a possible consequence of chronic use of diuretics.(12)(27) As diuretics promote saluresis this adverse effect could be expected. Reported complaints caused by low sodium levels in the blood are lethargy, weakness and confusion. However, also in this case the incidence of the effect seems limited and reports are based on incidental case observations. Selection bias may have influenced the results in studies that show hyponatraemia to be an effect of diuretic use, as in studies about diuretic-induced hypokaleamia. The study of Sundram et al is based on populations of patients who were admitted to hospital.(27) It is not inconceivable that hyponatraemia is detected in the first place because patients are using diuretics (if diureties are used, it is advised to monitor blood electrolyte levels), and that they are for that reason admitted to hospital. If in this situation a case control study is executed in the hospital population a relation with diuretics and hyponatraemia will easily be found. Another study, by Borland et al, showed only one case of hyponatraemia (sodium < 
$120 \mathrm{mmol} / \mathrm{l})$ in 232 diuretic-using hospitalized geriatric patients.(23) In the MRC trial in none of the patients on diuretics did the sodium level decrease sufficiently to cause symptoms of sodium depletion.(24)

Hypomagnesaemia is also reported to be a possible consequence of diuretic use.(28) The clinical consequence of this phenomenon is uncertain. In situations when normalization of a low potassium level is needed, a normal plasma magnesium level has been demonstrated to be conditional for recovery of the plasma potassium level.(29) Further, it has been suggested that hypomagnesaemia has an important influence on the occurrence of arrhythmias in diuretic-treated patients, whether or not in combination with hypokalaemic effects.(30)

Inappropriate use of high efficacy diureties such as frusemide in the treatment of hypertension in the elderly may induce hypovolaemia and hypotension, resulting in cerebral ischaemia.(31)

Orthostatic hypotension is repeatedly mentioned as an adverse effect of diuretics that especially strikes the elderly.(27)(32) However, the reservation has been made that this problem occurs only in the very old, aged 90 or more.(33) Whether or not caused by orthostatic hypotension, falls have been associated with diuretic use. When old people fall, it may result in serious consequences and contribute to mortality in the elderly. Especially hip fractures and fractures of the spine in elderly osteoporotic woman are serious consequence of a fall. In a case control study, besides benzodiazepines, diuretics had been used more among people who had fallen than people who had not fallen.(34) However, this study did not take in account the extent to which patients were ill. It is conceivable that because people are ill, they use diuretic drugs. Thus whether the falling occurred because of diuretic use or because of the underlying illness could not be clarified by this study. On the other hand, in theory it can be argued that thiazide diuretics have such an influence on calcium metabolism that loss of bone density is diminished if thiazide diuretics are used. Some investigations showed an increase in bone density under thiazide use. However, contrary results have been shown concerning the association between hip fractures and use of thiazide diuretics.(35) A case control study in which important confounding factors were taken into account gave the following results. 
The estimated adjusted relative risk for hip fracture among thiazide users compared to non-thiazide users was possibly slightly elevated, $1.6 \quad(95 \%$ confidence interval $1.0-2.5$ ). Use of other diuretics appeared to bear a higher risk for hip fracture. For patients using frusemide the adjusted relative risk was $3.9(95 \%$ confidence interval $1.5-10.4)$.(35)

A number of studies have found the lipid metabolism to be influenced by use of thiazide diuretics. The main effect is a relative decrease of high density lipoprotein cholesterol against a relative increase of low density lipoprotein cholesterol which is reported to be a risk factor for coronary artery disease. It is still unclear whether the observed lipid changes after long-term diuretic therapy constitute a cardiac risk factor that counterbalances the benefit of a lowered blood pressure.(11)

There is also an influence of diuretics on the glucose tolerance. Early trials seemed to show a diabetogenic effect of thiazide diuretics. However, later research in which lower doses of diuretic drugs were used, showed no diuretic associated deterioration in glucose tolerance with thiazides. Still in the MRC hypertension trial 9.38 per 1000 men and 6.01 per 1000 woman were withdrawn because of an impaired glucose tolerance in the thiazide diuretic group compared to 3.65 and 0.82 per 1000 patients respectively in the placebo group.(24) It is advocated to be parsimonious in long-term use of diuretics in people with an impaired glucose tolerance. (36)

Uric acid retention is deseribed as an effect of diuretic use with hyperuricaemia as a consequence.(18) However, whether this elevated plasma urate is also responsible for a higher incidence of gout in diuretic users is not certain. It seems to be advisable not to use diuretics in persons with complaints of gout.

Subjective complaints associated with bendrofluazide use were also reported from the MRC trial. Complaints in which a significant difference was found between the placebo group and the diuretic group are summarized in table 2,2.(24) 
Table 2.2. Prevalence of complaints 12 weeks after start of antihypertensive treatment. Percentages of persons who gave affirmative answers in questionnaire considering the stated complaints.(22)

\begin{tabular}{|l|r|r|r|r|}
\hline \multirow{2}{*}{ complaint } & \multicolumn{2}{|c|}{ men } & \multicolumn{2}{c|}{ women } \\
\cline { 2 - 5 } & diuretic & placebo & diuretic & placebo \\
\hline dimisess & $13.7^{*}$ & 5.9 & $25.3^{*}$ & 16.8 \\
\hline beadaches & 19.6 & 27.1 & $31.9^{\circ}$ & 42.4 \\
\hline paraenthesis & 11.6 & 14.7 & $28.9^{*}$ & 18.4 \\
\hline impotence & $16.2 *$ & 8.9 & & \\
\hline
\end{tabular}

- Significant difference $(p<0.05)$ between diuretic group and placebo group.

Finally we will describe some adverse effects that mostly are of unknown aetiology, occur unpredictably and bear no obvious relationship to either the pharmacology or the dose of the drug.

Ototoxity of high dose loop diuretics is reported especially in combination with use of aminoglycosides. The effect of long-term low dose use of loop diuretics on hearing is unknown.

Micturition problems, especially retention of urine, has been observed in patients using diuretics who suffer from prostatic hyperplasia. In other patients incontinence of urine is reported to be a consequence of the rapid filling of the bladder when loop diuretics are used.(37) Figures concerning severity of this problem and frequency of occurrence were not found.

Other, relatively rare adverse effects have been attributed to use of diuretics, such as pancreatitis, interstitial nephritis, renal stones and thrombocytopenia. 


\subsection{Diuretic-induced oedema}

In this paragraph two articles are described that gave strong indications that the occurrence of oedema could be a result of cessation of diuretic therapy.(38)(39) In the articles, one reporting about 2 patients and one case series of 10 patients, this phenomenon was described. The case series dealt with the effects of withdrawal of diuretics in patients with so called "idiopathic oedema". "Idiopathic oedema" has been described as a form of oedema that occurs often cyclically, in female patients and for which diuretics are prescribed. Patients were often paramedical workers who were concerned about their weight and appearance. In these case series the effects on some clinical and laboratory parameters were reported in hospital withdrawal of diuretic therapy. In the first article, based on observations of two female patients aged 22 and 45 years, it was reported that after withdrawal of diuretics in those otherwise healthy women, oedema developed in one case and got worse in the other case accompanied with \& weight increase after stopping diuretic use. In both cases oedema spontaneously disappeared and weight returned to the base line level within approximately three weeks. In the other article the experiment was repeated in 10 women (mean age 44 years, standard deviation 10 years). In those patients observations of not only oedema and weight were made but also of plasma renin activity and urinary aldosteron secretion. In all patients a weight increase after stopping diuretics occurred, with a peak level after 4 to 10 days. In 7 patients weight returned to normal within 20 days, in 2 patients this was achieved after use of a sodium restricted diet while one patient was not able to follow the diet prescriptions and kept the weight gained. Nine of ten patients became temporarily oedematous. The patients had high plasma renin and urinary aldosterone excretion levels while on diuretics. After withdrawal of diuretics both levels fell to norma! within 6 to 7 days.

On the basis of the observations, it was postulated that chronic diuretic use leads to stimulation of the RAAS (see paragraph 2.1.6), which leads to extra sodium and water retention. After stopping diuretic drugs, the high activity of the RAAS will continue for some days. The diuretic effect of the diuretic drugs ceases. Together 
these lead to temporary sodium and fluid retention resulting in weight increase and oedema. It was suggested that the phenomenon "idiopathic oedema" was iatrogenic oedema caused by inappropriate use of diuretics.

The experiments had no randomized controlled design. However, the magnitude of the effects and their reproducibility gave strong indications for the causal relation between the observations and the withdrawal of diuretics.

Although this research was carried out in healthy patients who used diuretics for the indication "idiopathic oedema" it can be expected that the rebound phenomenon described of weight increase and occurrence or aggravation of oedema may also occur if diuretics are stopped in patients who use them for other indications.

\subsection{Diuretics and ankle oedema}

This paragraph deals specifically with ankle oedema as an indication for diuretic drugs. Ankle oedema is frequently found an indication for diuretic use of elderly people.(21)(40) Venous insufficiency and chronic heart failure are likely to be the most common causes for chronic ankle oedema in general practice. Exact figures are not available concerning the prevalence of both illnesses in general practice. The figures from the Registration Network of Family Practice (RNF)(41)(42) show that ankle oedema is recorded in the cooperating practices as a prevalent medical problem in $0.7 \%$ of the patients of 65 years or older. It is likely that this figure gives too low an estimate of the prevalence. Many physicians might consider ankle oedema not an important medical problem worth recording, or consider it as a part of the symptoms of congestive heart failure in which case congestive heart failure will be recorded. The RNF prevalence figures for varicosis (including venous insufficiency) and congestive heart failure are given in tables 2.3 and 2.4 . 
Table 2.3. Prevalence (per age and sex category) of RNF patients registrated to have congestive heart failure (percentages).(38)(39)

\begin{tabular}{|l|c|c|c|}
\hline \multirow{2}{*}{\begin{tabular}{|c|}
$|c|$ \\
yeare caltegorie
\end{tabular}} & \multicolumn{2}{|c|}{ sex } & votal \\
\cline { 2 - 4 } & men & women & \\
\hline $65-74$ & 2.7 & 2.4 & 2.5 \\
\hline $75-8.4$ & 8.5 & 5.9 & 6.8 \\
\hline 85 and older & 14.2 & 12.5 & 13.0 \\
\hline total & 4.7 & 4.4 & 4.5 \\
\hline
\end{tabular}

Table 2.4. Prevalence (per age and sex category) of RNF patients registrated to have varicosis (percentage).(38)(39)

\begin{tabular}{|l|c|c|c|}
\hline \multirow{2}{*}{ age category (in years) } & \multicolumn{2}{|c|}{ sex } & \multirow{2}{*}{ votal } \\
\cline { 2 - 4 } & men & womea & \\
\hline $65-74$ & 5.5 & 11.3 & 8.7 \\
\hline $75-84$ & 4.5 & 11.7 & 9.2 \\
\hline 85 and olde: & 4.7 & 8.5 & 7.4 \\
\hline total & 5.2 & 11.2 & 8.8 \\
\hline
\end{tabular}

The figures show that the frequency of varicosis is more or less stable over the three age categories, while the frequency of congestive heart failure increases strongly in the higher age categories. This trend also emerges from the figures of the Nijmegen Continued Morbidity Registration (see chapter 4). The percentage of women recorded as having varicosis is almost twice that of the men. For congestive heart failure the percentages are almost equal for both sexes.

There is a broad consensus about the usefulness of diureties in case of ankle oedema caused by chronic heart failure (paragraph 2.1.5), we will not discuss this subject 
further. However, for use in venous insufficiency there is an important controversy between theory and practice (see also chapter 4). In this context we will discuss briefly the pathophysiology of oedema caused by venous insufficiency and its treatment options, including the place of diuretics.

Venous insuffiency is the expression for those conditions in which the physiologic entity "muscle pump" does not function adequately.(43) The muscle pump is a model for the mechanism that has a major role in the venous return blood flow to the heart from the legs against gravity. The mechanism includes the following elements.

- A venous system, consisting of a deep system situated in between the leg muscles flowing out in femoral veins, a superficial subcutaneous system situated external of the crural fascia, and a connecting venous system between the deep and the superficial system formed by the venae perforantes.

- The venous valves in the three venous systems force the direction of the blood flow from superficial to deep and from distal to proximal.

- Contractions of muscles provide, with the anatomy of the veins and their valves, the return blood flow. The major calf muscles have a tight fascia with a restricted volume. If a calf muscle contracts, it needs more space in the fascia, and because the fascia is tight the internal pressure in the muscle increases. The blood pressure in the veins in the muscle increases. The valves in the venae perforantes prevent blood flow out of the deep venous system into the superficial system, thus the blood is pumped out of the calf muscle in proximal direction inte the femoral vein, and eventually flows into the yena cava.

If one of these elements of the muscle pump dysfunctions, the venous drainage of the legs will be impaired. This can have the consequence that the hydrostatic pressure in the venous capillary system increases, and venous hypertension arises. This disturbs the 'Starling equilibrium' of fluid exchange over the capillary walls resulting in oedema. The venous hypertension will be aggravated by muscle contractions. On the longer term chronic venous insufficiency leads to morphological changes of capillaries, such as elongation, dilatation and leakage. As a consequence of the capillary leakage, transudation not only of fluid but also of proteins, fat or 
even erythrocytes occur into the pericapillary tissue. The lymphatic system, that normally provides the resorption of tissue fluid, becomes overloaded. The interstitial space becomes filled with fluid. One of the consequences of the resulting oedema is that it increases the distances for diffusional exchange between tissue cells and capillary blood. These events might eventually lead to venous, ulcers.(44) How important the role of oedema itself is as a risk factor for crural ulcers is not yet clear.

Three major problems can be determined that cause a dysfunctioning of the muscle pump. In elderly people an important one is lack of physical activity. When the muscles are not used because of a sedentary daily life, the muscle pump does not function and venous insufficiency develops leading to oedema. This is often referred to as stasis oedema or dependency oedema. Dysfunctioning of the valves, as a result of previous damage through deep venous thrombosis or dilated varicose veins, is another situation which leads to venous insufficiency. Further obstruction of the major veins in case of acute deep venous thrombosis or fumours compressing the veins can cause venous insufficiency.

Ideally, restoration of the function of the muscle pump should be aimed for in treatment of oedema caused by venous insufficiency. In some patients with dependency oedema this could easily be managed by promoting physical exercise and support venous drainage by elevation of the legs when patients are in a sitting position. In valvular insuffiency, repair of the valvular function is theoretically possible, but this treatment is still experimental and results are mostly disappointing.(44) On empirical grounds, the use of compressive bandages and stockings are considered as the best therapy to restore muscle pump function via a sort of external fascia. Elastic compression provides a raised local interstitial pressure, thereby reducing the leak of solutes and luids into the interstitial space. Evidence is not available, however, from double-blind randomized controlled trials concerning the efficacy of promoting physical activity, leg elevation and compression. Furthermore there is a range of perceptions of how these treatments should be applied.(45)(46)(47)(48)(49) Compliance in wearing of elastic stockings may be low. Patients often dislike the stockings because of the 
appearance. They can have difficulties in putting them on and taking them off, especially in case of stockings of a high pressure class (which is advised for venous insufficiency). If stockings are not properly fitted, they may fail to resolve the oedema, and cause extra discomfort.(50)(51)

Use of diuretics for venous insufficiency is controversial.(52)(18) Researchers in the early $1960 \mathrm{~s}$ advocated diuretics as effective for treatment of stasis oedema.(53)(54)(55) Theoretically diuretics can mobilize the oedema fluid and resolve ankle oedema. Advantages are:

- Diuretics are mostly well tolerated drugs with little discomfort for patients;

- Cheap, effective diuretics are available.

Disadvantages of diuretic therapy are:

- It is not a causal treatment;

- Diuretics use can have side effects;

- Diuretic dependency could develop, as a consequence of rebound oedema that can occur after cessation of diuretic therapy,

It is not clear whether long-term diuretic use is effective as a maintenance therapy in chronic venous insufficiency, when capillary darnage and leakage is more severe.

We conclude that diuretic use for treatment of ankle oedema of elderly patients is indicated if congestive heart failure is the cause of the oedema. However, when ankle oedema is caused by venous insufficiency, non-medical therapies are considered by the literature as treatment of choice. Still, on the other hand no clear evidence exists about the superiority of the non-medical treatment over diuretic treatment for ankle oedema from venous insuffiency. However, use of diuretic drugs by a high percentage of the elderly is unfavourable because of the risk for adverse effects and risk of interactions with other drugs. Complaints of ankle oedema without symptoms of cardiac, hepatic or renal failure are controversial as an indication for chronic diuretic use of elderly patients. The investigation of the effects of withdrawal of diuretics that are used in such circumstances seems worthwhile. This is a subject of interest for general practice, since prescription of drugs to the elderly often goes via the general practitioner.(6) In day-to-day care the GP is often the one who decides about continuation or withdrawal of chronically used drugs. 
1. Need we poison the elderly so often? [editorial], Lancet 1988: ii: 20-2.

2. World Health Organiation. Drugs for the elderly. Copenhagens WHO Regional Office for Europe. 1985.

3. Hanijer-Ruskamp FM. Geneesmiddelengebruik vaa ouderen. In: Goedhard WIA, Knook DL, editors. Ouderes eu geneesmiddelen. Houten/Antwerpen: Bohn Stafleu Van Loghem, 1991: 9-27.

4. Williansos J, Chopia JM. Adverse reactions to preseribed drugs in the elderly: in sulticenter investigation. Age Ageing 1980; 9: 73-80.

5. Offerhass L. Geneesmiddelen en bejarden; recente vorderingen in de geriatrische Klinische farmacologie. Ned Tujachr Geneeskd 1989; 133: 148-51.

6. Cartwright A, Smith C. Elderly people, their medicines, and their doctors. London: Routledge, 1988.

7. Kruse W. Patient compliance with drug treatment - new perspectives on an old problem. Clin Inveatig 1992; 70: $163-6$.

8. Rhoden KE. Prescription of diuretic drugs and monitoring of long term use in one general practice. Brit I Gen Pract 1992; 42: 68-70.

9. Walma EP. Boukes FS, Prins A, Van der Does E. Diuretica gebruik door 65 -plusern in een huisartspraktijk. Wie kunnen er stoppen? Huisarts Wet 1989; 32: 326-8.

10. Branbergen HCT. Welke pil slikt de 65-pluaser? Huisarts Wet 1985; 28(nuppl 9): 34-5.

11. Lant A. Diuretics, elinical pharmacology and therapeutic use, Drugs, 1985; 29: 162-88.

12. Tweeddale MG. Diuretic drugs. In: Dukes MNG editor. Meylers's Side Effects of Drugs. 9nd ed. Amsterdam: Exerpta Medica, 1980: 337-67.

13. Vogl A. The discovery of the organic mereurial diuretics. Am Heart J. 1980; 39: $881-3$.

14. Modge GH. Diuretics and other agents employed in the mobilization of edema fluid. In Boodman and Gilman ete. blz. 899

15. Novello FC, Sprague JM. Benzothiazine dioxides as novel diuretics. 1957; J Am Chem Soc 1957; 79: 2028-9.

16. Muschawek R, Hajdu P. Die salidiuretische Wirksamkeit det chlor-N-(2-furyimethyl)-5-sulfamyl anthranilsalire. Arzneimittel-Forsch 1964: 14: 44-7.

17. Weiner IM. Diureties and other agents employed in the mobilization of edema fluid. In: Gilman AO, Rall TW, Nies AS, Taylor P, editorn. Goodman and Gilman's; The Pharmocologieal Basis of Therapeuties. 8ch ed. New Yorks Pergamon Press, 1990: 713-32.

18. Anonymus. Tractus Uropotticus Diuretica. In: Nelemuns FA ed. Farmacotherapeutisch Kompas. Amstelveen: Centrale Medisch Pharmaceutische Commissie vas de Ziekenfondaraad, 1989: 362-5.

19. Kerremans ALM. Furosemide, Ned Tjjach Geneeske 1986; 130: 1588-90. 
20. Ramires IAF, Pileggi F. Diuretics in cardiac oedema. Drugs 1986; 31 (suppl 4): 68-75.

21. Rhodes KE. Prescription of diuretic drugs and monitoring of long-term tse in one general practice. Brit J Gen Pract 1992; 42: 68-70.

22. Haagama C, Gribnua FWJ, Bruyn E. De invloed van opname op de geriatrische afdeling van een algemeen ziekenhuis op het geneesmiddelengebruik van bejaardea. Ned Tijdscht Geseesk 1989; 133: 2341-44,

23. Borland C, Amadi A, Murphy P, Shalleross T. Biochemical and elinical correlates of diuretie therapy in the elderly. Age Ageing 1986; 15: 357-63.

24. Medieal Research Council Working Party. Adverso reactions to bendrofluazide and propanololl for the treatment of mild bypertension. Lancet 1931; ii: $539-43$.

25. Freis ED. The cardiovascular risks of thiazide diuretics. Clin Pharmacol Ther 1986; 39: 239-44.

26. Hoes AW. Non-potassium sparing diuretics and sudden eardiac death in hypertensive patienta: a pharnacoepidemiologie approach. [dissertation] Rotterdam: Erasmus Univerniteit Rotterdam, 1992.

27. Sundrum SG, Mankikar GD. Hyponatraemia in the elderly. Age Ageing 1983; 12: 77-80.

28. Dyckner $T$, Weater PO. Plasma and skeletal muscle electrolytes in patietns on long-termi diuretic therapy for arterial hypertension and/or congestive heart failure. Act Med Scand 1987; 222; 231-6.

29. Whang R. Flink EB, Dyckner T, Webster PO, Aikawe JK, Ryan MP. Magnesium depletion ^ a cause of refractory potasiium depletion. Arch Intern Med 1985; 145: 1686-9.

30. Lewis RV, Tregaskis B, McLay J, Service E, MeDevitt DG. Oral magnesium reduces ventricular ectopy in digitalised patients with chronie atrial fibrillation. Eur I Clin Pharmacol 1990; 38: 107-10.

31. Janseu PAF, Gribnau FWJ, Schulte BPM, Poels EFJ. Contributios of inappropriate treatment for hypertension to pathogenesin of stroke in the elderly. Br Med J 1986; 293: 914-17.

32. Lipsitz LA. Orthostatic hypotension in the elderly. N Eng J Med 1989; 321: 952-7.

33. Duken MNG, Aronson JK. Diuretics. In: Dukes MNG, editor. Meyler's Sido Effects of Drugs. IInd ed. Amsterdam: Elsevier, 1988: 416-36.

34. Prudham D, Grimley Evans J. Factors associated with falls in the elderly: a communmity study. Age Ageing 1981; 10: 141-6.

35. Heidrich FE, Stergachis A, Gross KM. Diuretic drug use and the riak of hip fracture. Ann Intern Med 1991; 115: 1-6.

36. Binsbergen JI van , Grundmeijer HGLM, Hoogen JPH van den, Kruijsdijk M van, Prins M, Ree JW van, Thomas S. Hypertensie, NHO-standaard. Huisarts Wet 1991; 34: 389-95.

37. Koopmans RTCM. Gribnaus FWJ. Langdurige diureticumbehandeling bij verpleeghuisbewoners. Is atoppen mogelijk7 Tijdschr Gerontol Geriatr 1988; 19: 55-60.

38. MacGregor GA, Markandu ND, Roulston IE, Jones IC, de Wardener HE; Is "idiopathic*" oedema idiopathic? Lancet 1979; 1: 397-400.

39. MacGregor GA, Tasker PRW, de Wardener HE; Diuretic-induced oedema. Lancet 1975; 1: 489-492. 
40. Brujine de GA. Het geneesmiddelengebruik in verzorgingstehuizen, een collectief probleem. Moderne Geriatrie 1984: 4: 151-2.

41. Höppener P, Knottnerus JA, Metsemakers JFM, Kocken RI, Limonard ChBG. Een geautomatiseerd steekproefbestand voor buisartsgeaeedkundig onderzock. Huisarts en Wetensachap 1990; 33: 66-9.

42. Metsemakers IFM, Höppener P, Knottnerus IA, Kocken RI, Limonard ChBC, Computerized health information in the Netherlands: a registration setwork of family practices, Brit J Oen Pract 1992; 42: $102-6$.

43. Kuiper JP Uleus cruris venosum. Behandeling naar hedendaagne inzichten. Het Medisch Jaar. Utrecht: Bohs, Scheltema en Holkema. 1978; 311.27.

44. Westerhof W. Mekkes JR. Pathogenese en behandeling vas het ulcus cruris venowam. Ned Tujdachr Geneesk 1991; 135: 1900-5.

45. Burnand KG, Layer GT. Graduated elastic stockings. Br Med J 1986; 293: 224-5.

46. Cornwall JV, Dore CI, Lewis JD. Oraduated compression and its relation to venous refilling time. Br Med J 1987; 295; 1087-90.

47. Horner J, Fernandes E, Fernandes J, Nicolaides AN, Value of graduated compression stockings in deep venous insufficiency. Br Med I 1980; 280; 820-1.

48. Partch H. Do we need firm compression stockings exerting high preasure? Vasa 1984; 13: 52-7.

49. Seott H, Coleridge Smith PD, MeMullin CM, Scurr IH. Venous disease: investigation and treatment, fact or fiction? Ann R Coll Surg Eng 1990; 72: 188-92.

50. Korntanje MI, Neumann HAM. Compresuietherapie door middel van elastische kousen. Ned Tujdachr Geneeskd 1990; 134: 799-802.

51. Withley A. Elastic stockings. Br Med J 1988; 296: 413-14.

52. Diuretics in the elderly [editorial]. Br Med 1 1978; it 1092-3.

53. Haeger K. Diuretic treatment of post thrombotic and varicose edema in the lower extremities. J Cardiovase Surg $1961 ; 2: 367-75$.

54. Haeger K. Further observations on the effects of diuretics on stasis oedema of the leg. Angiology 1964: 15: 417-29.

55. Bare WW, Baird HL. Hypertension and oedema in the aged: observations in the use of meprobamate-hydrochlorathalidone combination. I Am Geriatr Soc 1961; 9: 968-75. 
Chapter 3

Diuretic drug withdrawal trials, a review."

\section{Authors}

J.W. de longe, J.A. Knottnerus, W.M. van Zutphen, O.A. de Bruijne

J.W. de Jonge, MD, Assistant Researcher, Department of Ceneral Practice, University of Limburg. The Netheriands.

J.A. Knottnerus, Profestor, Department of General Practice, University of Limburs, The Netherlasds.

W.M. vas Zutphen PhD. Associato Professor, Department of General Practice, Univernity of Limburg. The Necherlands.

G.A. de Brujine. Assistant Professor, Department of General Practice, University of Limburk. The Netherlands.

Address for correspondence

I.W. de Jonge, Department of General Practice, University of Limburg, P.O Box 616, 6200 MD Maastricht, The Netherlands.

- Accepted for publication, by Age and Ageing. 
Objective: To determine, on the basis of literature, whether withdrawal of diuretic drugs in general practice is safe and adequate in elderly patients using chronic diuretics who do not have high blood pressure or symptoms of cardiac, hepatic or renal failure.

Data Sources: Literature in English and Dutch language, Index Medicus period 1983-1991 and additional snow-ball method.

Study selection: Seven studies on withdrawal of diuretic drugs in elderly patients who had used diuretics chronically are reviewed.

Data Extraction: Studies were assessed on their methodological validity on the basis of criteria for usefulness of interventions of Sackett et at. Consensus on the methodological judgement was sought between two observers on all criteria after independent assessment.

Data Synthesis: Relevant outcomes of individual studies are reported in the review. If appropriate, further statistical assessment was carried out. Pooling of data was not performed because of relevant differences between the studies.

Conclusions: No study fulfilled the methodological criteria for a clear judgement whether diuretic withdrawal is safe and worthwhile in the population of interest. Although the authors in the reported studies advocate that withdrawal of diuretics can be safe and appropriate in a number of situations, questions remain on the longterm effects especially on mortality, congestive hean failure and degree of ankle oedema.

key words: diuretic drugs, elderly, withdrawal, general practice, review. 


\subsection{Introduction}

It is often stated that the use of diuretic drugs by a high percentage of the elderly is unfavourable because of the risk for adverse effects and interactions with other drugs.(1)(2)(3) Several investigators have advocated that in elderly patients who use diuretics chronically, withdrawal is safe and adequate in many circumstances. This is a subject of interest for general practice, since prescription of drugs to the elderly often goes via the general practitioner.(4) In day-to-day care he or she decides about continuation or withdrawal of chronically used drugs.

In this review we describe the characteristics and results of studies in which the effects of withdrawal of diuretic drugs in elderly long-term diuretic using patients were studied. Further we discuss whether these investigations meet methodological criteria, in order to evaluate their validity.

\subsection{Methods}

Publications on the subject of withdrawal of diuretic drugs in the elderly, were sought by means of the so-called snow-ball method: publications which were referred to in publications previously found were collected. In addition a search in Index Medicus (period 1983 until 1991) on cd-rom on the key words diuretics and withdrawal was conducted.

For the methodological evaluation the following criteria, based on those of Sackett et al, were used.(5)

The first criterion checked is whether the trial had a randomized controlled design. Non-randomized investigations have a rather weak ability to prove efficacy of interventions, unless the effects of the intervention are extremely strong and occur quickly. In general, this is not to be expected where diuretics are withdrawn in clinically stable outpatients, thus the investigations should preferably have a randomized controlled trial design to obtain useful results.

The second criterion is whether all clinically relevant outcomes were reported. In the 
case of diuretic withdrawal, this means that the effect on the symptoms, initially leading to the preseription of diuretics should be reported. In addition, the study should describe whether patients suffered from important health problems after withdrawing diuretics.

The third criterion is whether the investigated patients are representative of patients in the general practice population. Conclusions inappropriate for general practice can be expected if a trial is performed in a population that differs significantly from the general practice population. For example, the elderly in a nursing home population have in general severe health problems that make withdrawal impossible or difficult, while withdrawal could be appropriate in the healtier persons in general practice.

The fourth criterion is whether both clinical and statistical differences were taken in account. If a statistical difference is found within the groups compared, this does not mean that this difference is clinically relevant. On the other hand, if no statistical difference is found, in reality an important clinical difference may exist while the power of a study is too low (mostly caused by a too few participants in the study). This problem is important in withdrawal studies. Modem medical assessment research is based on showing differences. Statistical methods are more appropriate to confirm differences in outcome between, for example, two treatment methods than to prove that the outcomes are equal. In withdrawal studies the hypothesis to prove will often be that result of continued treatment is equal to (or not worse than) the result of ceased therapy. The only way to handle this problem is to perform trials with sufficient power. Power is the statistical term for the chance to detect a statistically significant difference in outcome between two treatments in a trial, if in reality there is a relevant difference between the treatments.

Thus if no statistical difference between groups is reported as the result of a trial, which will often be the case in 'successful' withdrawal studies, it is important to know the power of the trial or at least to be able to make a judgement on the basis of confidence intervals. Only when a withdrawal trial has sufficient power, if no difference is found, can one have confidence in the results that withdrawal is not worse than continuation.

We carried out additional calculations if no statistical analysis had been performed 
but crude data were available. When needed, confidence intervals for rate differences were computed following the method described by Armitage.(6)

The fifth criterion also deals with feasibility. Is the intervention feasible in the general practice situation?

The last criterion is whether the conclusion is based on all the patients who entered the trial. Patients with unfavourable results may have been excluded from the analysis or lost to follow-up and not taken in account in the conclusion. As a result serious bias can occur.

Each diuretic withdrawal trial was checked on each item. A positive score was assigned for an item if the study fulfilled the criterion, a negative score if not. Scoring was based on the judgement of two observers made independently (J.W.J. and J.A.K.). The level of agreement achieved between the independent judgements was quite acceptable. Only in 6 of 56 cases was agreement not reached in the first instance. In the case of disagreement between the two observers consensus was reached after mutual consideration. In some cases no clear dichotomous judgement could be given because the study fulfilled partly the criterion, in that case the mark " \pm " was used in the results table. The sixth item was assessed for three separate categories: successful withdrawal, effects on ankle oedema and other clinical outcomes. This division was made because in most studies several outcomes were treated. In all studies the major outcome was the number of patients withdrawn of diuretic therapy without the need to restart diuretic use during the study period. Since ankle oedema is an important controversial indication for long-term diuretic use, this subject is treated separately. In some articles the effects on ankle pedema were not discussed, in these cases data for methodological judgement on this item were not available (notation n.a. in the table). All other outcome parameters such as blood pressure and laboratory measures are treated in the remainder category -other parameters". 
Seven studies were found on withdrawal of diuretic drugs in elderly patients. (7-13) Hereafter we will use the name of the first author when we are referring to one of those studies. The main objective in all the studies was to investigate whether it was possible to cease diuretic use for a certain period in patients on chronic diuretic therapy, without this causing medical problems that would force diuretics to be restarted. Since diuretics are often prescribed because of hypertension, heart failure or the symptom ankle oedema, in most studies special interest was given in the follow-up to these medical problems. As diuretics are known to have influence on laboratory parameters such as blood sodium, potassium level and renal function, these were often also recorded.

In all studies the main inclusion criterion was whether patients were using diuretic drugs.

The investigators, used different criteria 10 exclude patients whoose diuretic therapy they judged necessary or too risky to stop. All seven studies had in common that patients with diuretic use for severe heart failure or hypertension were excluded. In addition, Myers excluded patients with concomitant digoxin use, Koopmans patients with severe ankle oedema and Wilson patients with dementiall disorders. Only Walma supplied explicit criteria of how the diagnosis for heart failure was assessed.

All studies except those of Walma and Taggart took place in an intramural setting of nursing homes or geriatric wards of hospitals. The population of Walma's study consisted of elderly general practice patients, while Taggart enrolled outpatients attending a general or cardiologic hospital clinic.

In table 3.1 the most important patient characteristics and the main results of withdrawal are summarized. The percentages of screened patients who were included varies from $87 \%$ (Portnoi) to $28 \%$ (Myers). The item 'diuretics successfully withdrawn' concerns the numbers of patients who had stopped diuretic use and in whom diuretics had not been restarted during follow-up. The success percentage varies between $40 \%$ and $87 \%$. 
Table 3.1. Main results of diuretic withdrawal studies reviewed.

\begin{tabular}{|c|c|c|c|c|c|c|c|c|c|c|}
\hline \multirow[t]{2}{*}{ the } & \multirow[t]{2}{*}{ • } & \multirow{2}{*}{ 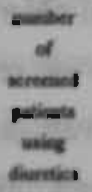 } & \multirow[t]{2}{*}{$\begin{array}{l}\text { aneber of } \\
\text { participents }\end{array}$} & \multicolumn{2}{|c|}{ ont } & \multirow[t]{2}{*}{ nest } & \multirow[t]{2}{*}{$\begin{array}{c}\text { dernile } \\
\text { of } \\
\text { follow-up }\end{array}$} & \multicolumn{2}{|c|}{ 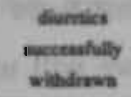 } & \multirow[t]{2}{*}{ 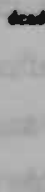 } \\
\hline & & & & fomale & mals & & & - & s & \\
\hline \multirow[t]{2}{*}{ Avrr } & , & 141 & 54 & 47 & 7 & 12 & 12 sods & 41 & 76 & 3 \\
\hline & $d$ & & 5 & 46 & 6 & $\mathbf{n}$ & & & & I \\
\hline Nortank & & $n$ & $n$ & ? & 7 & $\uparrow$ & 6 monchs & 23 & is & J \\
\hline \multirow[t]{2}{*}{ Mren } & 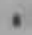 & ns & 38 & 9 & $x$ & 20 & 1 yar & $n$ & $n$ & 8 \\
\hline & 1 & & 39 & 1 & 31 & 82 & & & & 3 \\
\hline Tusen & & 105 & 38 & 12 & 26 & 6 & 12 weeks & $n$ & $n$ & I \\
\hline Keopowae: & & 24 & 16 & 4 & 2 & so & 17 tays & il & 69 & 1 \\
\hline Whatma & & 3 & is & 11 & 4 & 7 & 6 anonds & 6 & 40 & 0 \\
\hline Wilua: & & , & 13 & 3 & 12 & $\mathbf{M}$ & 28 ter & 13 & $n$ & 0 \\
\hline
\end{tabular}

An important outcome is whether patients developed heart failure that made restarting diuretic therapy necessary. In the study by Burr et al, $\mathbf{5}$ of the 54 patients on placebo were withdrawn because they developed symptoms of heart failure. No patient in the group using diuretics needed to be withdrawn because of heart failure. In Myers'study the situation was the opposite. In this study 2 of 38 patients in the placebo group and 6 of 39 patients in the diuretic group were withdrawn because of symptoms of heart failure. If, on the basis of these figures, the difference in rate of developing heart failure in both groups is calculated, Burr's study gives an excess rate in the withdrawal group compared to the diuretic group of $2.3 \%$ (95\% confidence interval $1.6 \%-17 \%)$. The corresponding figures for Myers' study are $-10.1 \%(95 \%$ confidence interval $-34.8 \%-14.6 \%)$; however, the confidence interval is very wide and includes 0 . In the other studies such a comparison is not possible due to the lack of a control group. In the study by Portnoi et al, no patients were withdrawn because of heart failure. Taggart reported withdrawing 8 of 38 patients from the trial because of symptoms of heart failure. Koopmans reported 
restarting diuretic therapy in 4 of 16 patients for the same reason, while Walma and Wilson each did so in 1 of 15 cases.

In all investigations a defined rise in blood pressure was set as a criterion for restarting active diuretic therapy. Actually in Myers' study 2 patients from the withdrawal group and in Walma's study 3 patients dropped out because of an elevated blood pressure.

In the last column of table 3.1 the numbers of patients who died in the follow-up period are given. The studies were carried out in a population of patients of high age. Therefore the occurrence of patients dying has to be taken into account. This makes it even more important that the studies have a randomized design since otherwise it cannot be shown whether or not there is a causal relation between patients dying and the intervention. In most cases diuretic withdrawal was not likely to have contributed to the cause of death in patients; however, this could not always be excluded. A causal relation between the intervention and the occurence of heart failure or stroke should be considered. The causes of death that were observed in the studies are summarized in table 3.2 .

Table 3.2. Specified causes of death of patients during the follow-up in the withdrawal studies.

\begin{tabular}{|c|c|c|c|c|c|c|c|c|}
\hline Author & - & $\begin{array}{l}\text { ceidlase } \\
\text { Miliare }\end{array}$ & wods & $\begin{array}{l}\text { yotro } \\
\text { Inestinal } \\
\text { Mineding }\end{array}$ & infarentiol & $\begin{array}{l}\text { mapirwery } \\
\text { diwcan }\end{array}$ & warinoes= & Lemin \\
\hline Burr & : & & & 1 & 1 & 1 & I & \\
\hline Porrear & & & & & 1 & 2 & & \\
\hline Merem & i & 1 & 1 & 1 & Habris? & 2 & $\begin{array}{r}3 \\
1\end{array}$ & 1 \\
\hline Treast & & 1 & & ta & & & & 7812 \\
\hline Koepana: & & & & 1 & & & & \\
\hline $\begin{array}{l}\text { Whine } \\
\text { whices }\end{array}$ & & & & & & & & \\
\hline
\end{tabular}

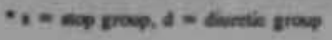


Although in most studies except Wilson's, the effect of the withdrawal of diuretics on ankle oedema was not a primary outcome measure, most authors had measured or recorded in some way ankle oedema in the patients. Ankle oedema was found to be the initial reason for prescription of diuretics in many patients, thus the follow-up of this symptom is important for diuretic withdrawal studies.

Burr provided information concerning the ankle oedema of the subgroup of patients who were not withdrawn from the study. Burr and colleages report the number of patients with increased, equal or decreased ankle oedema comparing baseline level to the level after 12 weeks of follow-up in both experimental groups. A slight trend was observed of there being more patients with increased oedema in the withdrawal group compared to the diuretic group, rate difference $22 \%$ ( $95 \%$ confidence interval $2 \%-42 \%)$.

Myers also provided information concerning the ankle oedema in patients who were not withdrawn from the study. In his study the oedema was assessed at base-line and at the end of the study by the ward sisters on a 5-point scale 10 : no oedema, 1: trace, 2: ankle, 3: mid-calf, 4: above mid-calf). In the diuretic group the mean oedema score decreased from 1.7 at base line to 1.1 at the final measurement. In the withdrawal group those figures were 1.9 (baseline) and 1.4 (final measurement). Myers reported a statistically significant difference in both groups if baseline measurement was compared to the final measurement. Thus in both groups a decrease of oedema was noticed during follow-up (a rate difference between both groups for the number of patients with increased oedema could not be calculated on basis of the data provided).

Taggart reported that in 3 of the 11 cases in which he was forced to re-instigate diuretic therapy the reason was ankle pedema. Nothing was reported concerning the extent of oedema or about ankle oedema in other patients.

Koopmans mentioned the development of the symptom ankle oedema in 3 of the 4 patients who dropped out from his investigation because of heart failure. In this study ankle oedema was recorded using the same scoring system as Myers had used. In the patients whe did not restart diuretics, the mean score for oedema was 1.6 at base line and 1.2 after 17 days of follow-up. Statistical evaluation was not reported. 
Walma reported that in 2 patients the development of ankle oedema was the reason for restarting diuretic therapy. He followed the degree of ankle oedema by measuring the ankle circumference at all follow-up moments. For all participants he compared the ankle circumference at baseline with the ankle circumference at the last measurement. In case of exclusion of a patient the last recorded measurement before drop-out was used. At baseline mean ankle circumference was $229 \mathrm{~mm}$ (standard deviation 23) compared to $235 \mathrm{~mm}$ (standard deviation 24) at the end of the study ( $t$-test for paired variables two-tailed $p<0.001$ ). Thus a slight increase in ankle circumference from elevated oedema was noticed.

Wilson specifically studied the effect on ankle oedema of withdrawing diuretics in patients who used them for stasis oedema. The degree of oedema was measured by determining the leg volume of the right leg of each patient at 4 consecutive followup times after a baseline measurement. Measurements were done at: day $0,1,7,14$ and 28 . Table 3.3 presents the measured volumes. An increase of leg volume can be observed reaching a peak 14 days after the withdrawal of diuretics. According to the author the elevation appeared to be statistically significant from $t_{2}$ and thereafter (paired t-test, $\mathrm{p}<0.01$ ).

Table 3.3. Measured lower leg volumes of patients in whom diuretics were withdrawn (Wilson et al).

\begin{tabular}{lccc}
\hline day & meun volume $(\mathrm{mi})$ & $95 \%$ confidence interval & relative increase $(\mathbf{\$})$ \\
\hline 0 & 2135 & $1937-2333$ & \\
1 & 2184 & $2006-2362$ & 2.2 \\
7 & 2276 & $2058-2494$ & 6.6 \\
14 & 2325 & $2130-2518$ & 8.9 \\
28 & 2324 & $2138-2510$ & 8.9
\end{tabular}

Most authors recorded additional data concerning some clinical parameters of withdrawing diuretics. In tables 3.4 and 3.5 the follow-up data of blood pressure and electrolytes are summarized whenever they were provided by the investigators. Some 
important remarks should be borne in mind when interpreting these data. All authors except Walma used only data of patients who did not restart diuretics during the follow-up period or did not drop out of the study for another reason. There is an important variation in the numbers of patients on which the figures are based (see table 3.1).

Table 3.4. Comparison of blood pressure in sitting position before and after withdrawal in patients in whom diuretics were successfully withdrawn. Mean and standard deviation are given when provided by the author.

\begin{tabular}{|c|c|c|c|c|c|}
\hline \multirow[t]{2}{*}{ Author } & & \multicolumn{2}{|c|}{$\begin{array}{l}\text { diantolic blood pressure } \\
\qquad(\mathrm{mmHg})\end{array}$} & \multicolumn{2}{|c|}{ systolie blood pressure $\left(\mathrm{mmH}_{\mathrm{g}}\right)$} \\
\hline & & baseline & final & baseline & final \\
\hline Burr & $\begin{array}{l}\text { stop group } \\
\text { diuretic group }\end{array}$ & $\begin{array}{l}75.2 \pm 10.3 \\
78.2 \pm 10.3\end{array}$ & $\begin{array}{l}82.4 \pm 8.3 \\
81.0 \pm 9.6\end{array}$ & $\begin{array}{l}126.4 \pm 15.2 \\
128.6 \pm 15.3\end{array}$ & $\begin{array}{l}136.3 \pm 12.7 \\
131.8 \pm 12.0\end{array}$ \\
\hline Myers & $\begin{array}{l}\text { stop group } \\
\text { diuretic group }\end{array}$ & $\begin{array}{l}74 \\
67\end{array}$ & $\begin{array}{l}76 \\
67\end{array}$ & $\begin{array}{l}129 \\
122\end{array}$ & $\begin{array}{l}136 \\
127\end{array}$ \\
\hline Taggart" & & $76.3 \pm 1.8$ & $75 \pm 2.1$ & $136.3 \pm 3.3$ & $136.5 \pm 3.7$ \\
\hline Koopmans & & $76.9 \pm 15.9$ & $82.4 \pm 11.9$ & $138.1 \pm 22.1$ & $137.5 \pm 18$ \\
\hline Walma** & & $74 \pm 11$ & $73 \pm 13$ & $150 \pm 18$ & $156 \pm 21$ \\
\hline
\end{tabular}

- Taggart provided mean and standard error of the mean.

- Walma provided data for all patients.

Concerning the blood pressure account of the fact should be taken that rise in blood pressure above a certain level was a reason for restarting, diuretic therapy in most investigations. This indicates an important drawback for interpretation, in that the, figures show that in most studies an elevation which was clinically not relevant in the mean diastolic and systolic blood pressure occurred after withdrawing diuretics 
Table 3.5. Recorded mean electrolyte levels.

\begin{tabular}{|c|c|c|c|c|c|}
\hline \multirow[t]{2}{*}{ Author } & \multirow{2}{*}{ 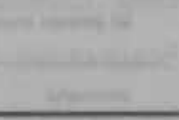 } & \multicolumn{2}{|c|}{ mean potassium $(\mathrm{mmol} / \mathrm{h})$} & \multicolumn{2}{|c|}{ mean sodium (mmol/) } \\
\hline & & baseline & final & baseline & final \\
\hline \multirow[t]{2}{*}{ Burr } & stop group & 3.90 & 4.25 & & \\
\hline & diuretic group & 4.11 & 4.19 & & \\
\hline \multirow[t]{2}{*}{ Myers } & stop group & 4.1 & 4.4 & 140.9 & 141.0 \\
\hline & diuretic group & 3.9 & 4.2 & 138.3 & 139.1 \\
\hline Tageart & & 4.1 & 4.1 & 141.3 & 141.5 \\
\hline Koopmans & & 4.1 & 4.3 & 141.3 & 139.5 \\
\hline
\end{tabular}

in the patients who did not drop out of the study.

Conceming the data of the electrolyte measurements interpretation is also difficult. The different authors did not have the same way of dealing with potassium supplements and potassium sparing preparations, which may have an important influence on potassium levels. However, in most studies a slight elevation of the potassium level was observed after diuretic withdrawal, as could expected. Sodium levels showed no relevant changes in the investigations. Myers and Koopmans both noticed a small decrease in creatinine level in patients from whom diuretics were withdrawn.

3.5 Results of methodological evaluation of the withdrawal studies

Table 3.6 presents the results of the methodological evaluation of the diuretic withdrawal studies. For each of the items treated in paragraph 3.2 the definitive score is given. No study completely fulfilled all criteria. Only two studies met the very important criterion of having a randomized controlled design. 
Table 3.6. Methodological characteristics of the diuretic withdrawal studies.

\begin{tabular}{|c|c|c|c|c|c|c|c|c|}
\hline \multirow[t]{2}{*}{ Aiens } & \multirow{2}{*}{ cendrobited trial } & \multirow{2}{*}{$\begin{array}{l}\text { All clinikal } \\
\text { melevant } \\
\text { oweones } \\
\text { mponed }\end{array}$} & \multirow{2}{*}{$\begin{array}{l}\text { smeral } \\
\text { practice } \\
\text { seltine }\end{array}$} & \multirow{2}{*}{ 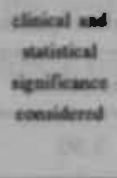 } & \multirow[t]{2}{*}{ fenale } & \multicolumn{3}{|c|}{ 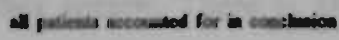 } \\
\hline & & & & & & 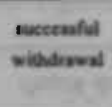 & andik & $\begin{array}{l}\text { other } \\
\text { clinical } \\
\text { Nacomes }\end{array}$ \\
\hline Mun & + & + & . & - & + & + & - & - \\
\hline Finted & - & + & * & ? & + & + & $\ldots$ & • \\
\hline men & + & + & . & 2 & + & + & . & • \\
\hline Terent & . & + & + & \pm & + & $=$ & $\ldots$ & - \\
\hline Kowgenase & - & + & 1. & - & + & + & $n . x \cdot$ & * \\
\hline Wales & • & + & + & \pm & + & + & + & + \\
\hline Wileve & . & + & * & $t$ & + & + & - & . \\
\hline
\end{tabular}

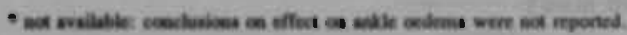

\subsection{Discussion}

Despite the importance of the issue, few articles concerning diuretic withdrawal in elderly patients who use diuretics chronically are available. If considered on methodological grounds, none of the reported studies can give a proper answer to the question whether diuretic withdrawal in elderly chronic diuretic users in general practice can be carried out safely and whether it is worthwhile. In adidition, most studies have been conducted in other settings. The only article that deals with a study in general practice reports a non-randomized experiment.

Most studies were based on before/after analysis. Only the studies of Burr and Myers were randomized controlled trials. Of these only Myers reported a statistical evaluation concerning several outcomes. Burr did provide data on the developmenit of heart failure and influence of withdrawal on ankle oedema, in such way that a brief additional statistical evaluation was possible.

In most studies only a small percentage of the screened patients were eventually included for diuretic withdrawal. This may imply that in a large number of patients contra indications for withdrawal were present. Although the figures originate from 
research settings which might give extra reasons for non-participation (for example meeting the exclusion criteria or refusal of consent), the figures show that if withdrawal is intended, quite often contra indications for withdrawal will be met.

When only the randomized studies are taken into account, no strong conclusions concerning the development of heart failure after withdrawal of diuretic therapy in the selected patients can be drawn on the basis of the information available. Burr's study shows a slight increase in the likelihood of developing heart failure after withdrawal of diuretic therapy if patients in whom diuretics were withdrawn are compared to patients who continued diuretic use. The estimation of the rate difference has a wide confidence interval; thus the size of the risk increase is not clear. In contrast, the study by Myers et al seems to show that patients who continued to use diuretic drugs had a slightly greater chance of developing heart failure than the patients in whom the diuretics were withdrawn. However, also in this study the confidence interval for the calculated rate difference is wide and includes 0 ; thus unambiguous conclusions cannot be drawn.

Furthermore, concerning the development of ankle oedema the randomized studies show conflicting results. In the study by Burr et al a slight increase in ankle oedema seemed to occur in patients who stopped using active diuretic drugs, while Myers et al reported a slight decrease in ankle oedema both in the placebo group (patients who stopped diuretic use) and in the active drug group. These conclusions are based on the patients who did not drop out of the study. However, some patients dropped out because of the development of ankle oedema. Thus different results could be expected if every patient were taken into account. From the other, uncontrolled studies it can be at best concluded that there are indications that on average a slight increase in oedema can occur after stopping diuretic use.

Another important issue is that no study enables us to predict the effect of stopping diuretics in patients who were prescribed diuretics for ankle oedema, since the populations under study consisted of patients with all kinds of indications, for diuretic use. Specific analyses of the population of patients with indication oedema are not available.

In general the articles reviewed suggest that withdrawal of diuretic drugs in elderly 
patients using diuretic drugs chronically appears safe and appropriate in patients without heart failure, hypertension, renal or hepatic failure. However, in several studies some patients died during the follow-up period. As mentioned earlier the studies were undertaken in a population of relatively advanced age where the possibility of natural death of the patients must be laken into account. In most cases. the cause of death was unlikely to be influenced by the diuretic withdrawal. However, in some instances such an influence could not be excluded. Because of inappropriate designs and lack of power (which is the case with the two randomized studies) no hard conclusions concerning this point can be drawn. But who has the burden of proof? In the articles reviewed an attempt was made to show the safety of net using a drug. In a way this is a paradoxal situation. If doubts exist about the safety of using a drug, it normally follows that those who prescribe or sell the drug. should prove that the drug is safe to use. In this light it is questionable whether it is the lask of those who have doubts about the usefulness of a drug in a given situation, to determinate the safety of its withdrawal.

From the withdrawal studies, ankle oedema appeared to be a controversial and frequent indication for long-term diuretic use. However, no randomized trials have been reported which address specifically the effect on ankle oedema of withdrawing diuretics prescribed for this indication. Thus it seems worthwhile to conduct a randomized trial to investigate the withdrawal of diuretics used in these circumstances. To perform this trial in the general practice situation would be useful since the general practitioner has often to decide whether to continue or stop longterm drug use. 
1. Diuretica in the elderly [editorial]. Br Med J 1978; i: $1092-3$.

2. MacLennas WJ. Diuretics in the elderly: how safe? (editorial). Br Med J 1988; 296: 1551

3. Rhodes KE. Preacription of diuretic drugs and monitoring of long-term use in one general practice. Brit J Gea Pract 1992; 42: 68-70.

4. Cartwright A, Smith C. Elderly people, their medicines, and their doctork, Losdon: Routledge, 1988.

5. Sacket DL, Haynes RB, Tugwell P. Clinical Epidemiology: A basic science for elinieal medicine. Boston: Little, Brown and Company, 1985.

6. Armitage P, Berry O. Statistical Methods in Medical Research. 2nd ed. Oxford: Blackwell Seientifie Publications, 1987.

7. Burr ML, King S, Davies HEF, Pathy MS. The effects of discontinuing long-term diuretic therapy in the elderly. Age Ageing 1977; 6: 38-45.

8. Portnoi VA, Pawlson LO. Abuse of diuretic therapy in nursing homes. J Chron Dis 1981: 34: 363-5.

9. Myers GM, Weingert ME, Fisher RH, Gryfe Cl, Shulman HS. Unnecessary diuretic therapy in tho elderly. Age Ageing 1982; 11: 213-21.

10. Taggart N. MeDevitt DO. Diuretic withdruwal, a need for caution. Curr Med Res Opin 1983; I: 501-8.

11. Koopman RTCM. Gribaau FWI. Langdurige diureticumbehandeling bij verpleeghuisbewoners. Is itoppen mogelijk? Tijdschr Gerontol Geriatr 1988; 19: 55-60.

12. Walma EP, Hoes AW, Prins A, van der Does E. Het staken van langdurige diuretica-medicatie bij 65-plussers in een huisartspraktijk. Huisarts Wes 1992; 34: 105-8.

13. Wilson 1A, Thompson D, MacLennan WI, Markhall L. Stasis oedema in the elderly: Are diuretics necessury? Gerontology 1991; 37; 289-92. 


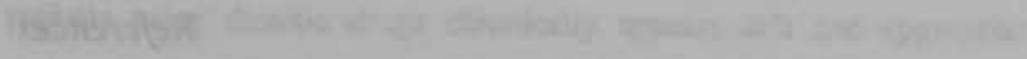

1 nach

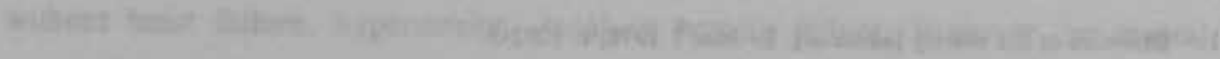

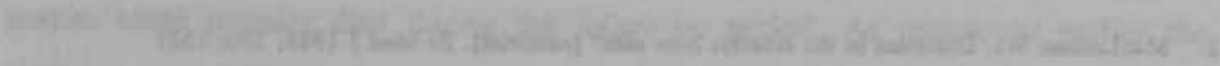

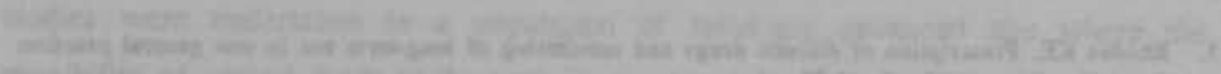

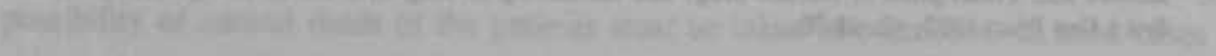

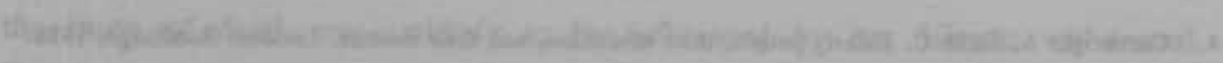

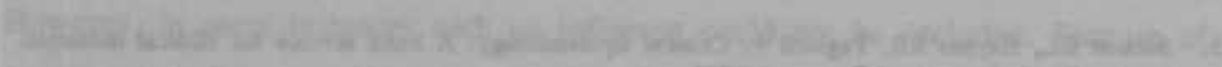

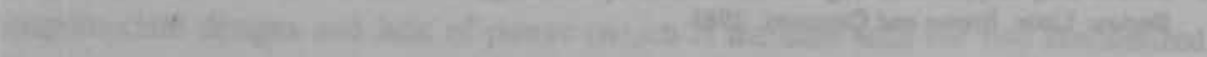

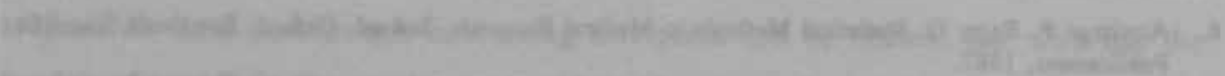

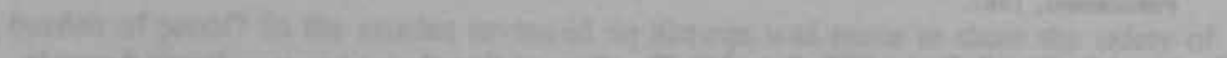

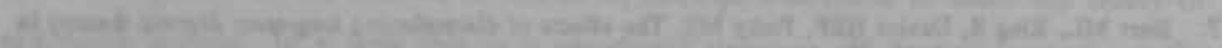
PHow

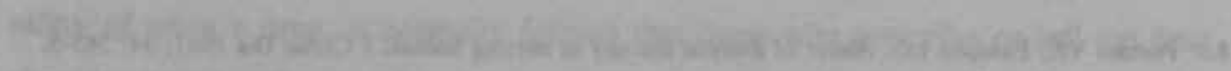

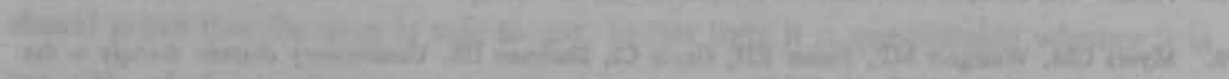

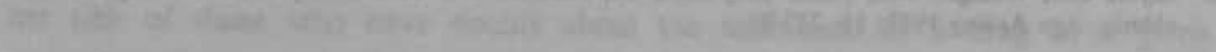

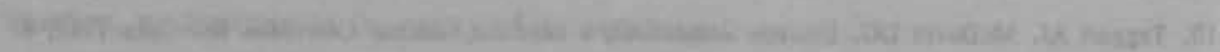

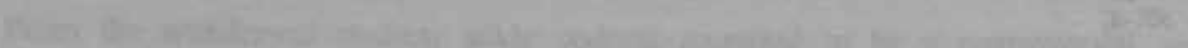

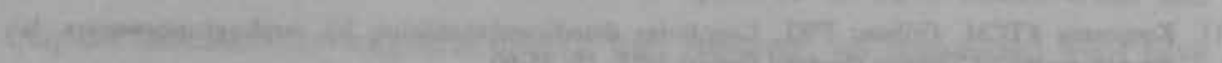

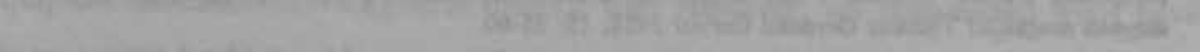

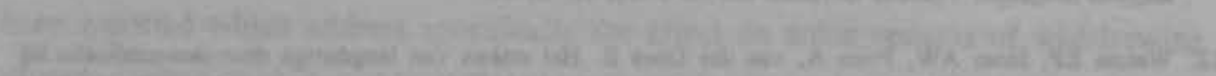

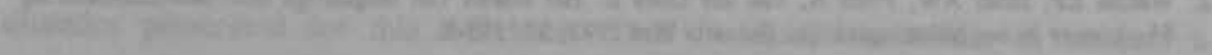

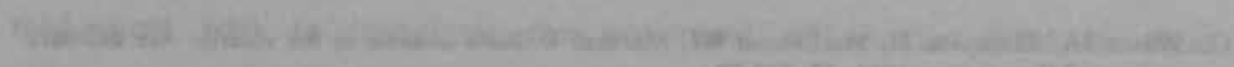

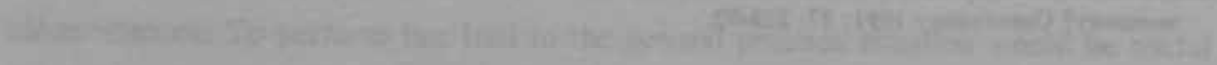

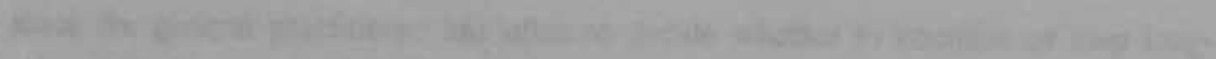

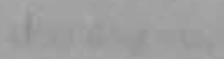


Chapter 4

Treatment of elderly patients with ankle oedema in general practice. When and how often are diuretics used? boe valk worden diuretica gebruiken Ned Tijdachr Ceneeskd 1990; 134: 1702-5. 
+hatpus

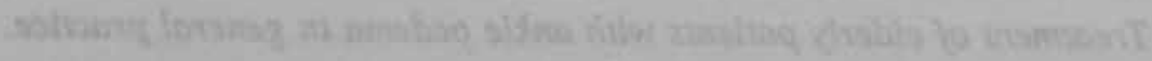

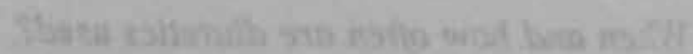

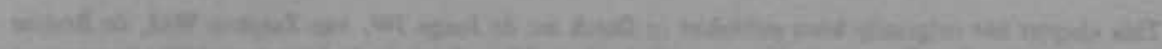

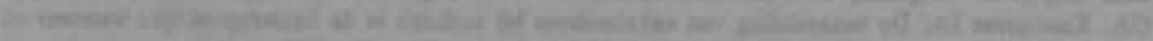

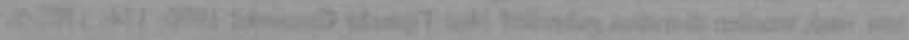


It has long been recommended that one should be careful and sparing in prescribing drugs for the elderly. However, it has been shown that more than $20 \%$ of people over 65 use diuretics. With advancing age this percentage increases. In the decision to prescribe diuretics, the symptom of ankle oedema appears to be an important factor. Where the oedema is not caused by heart failure, renal failure or hypoprotinaemia, the use of diuretics in ankle oedema is controversial. We used a questionnaire survey to obtain information on the opinions of Dutch general practitioners about the differential diagnosis and treatment of ankle oedema in the elderly. In the questionnaire we presented the case of a 68-year-old woman who complained of ankle oedema without any symptom or sign of heart failure. The questionnaire was sent to 200 Dutch general practitioners (response rate $64 \%$ ). Venous insufficiency was mentioned by $86 \%$ and heart failure by $12 \%$ of the responders as most probable cause of the oedema. The treatment proposed by $59 \%$ was advice and (or) compression therapy without drugs, while $40 \%$ would have prescribed diuretics.

\subsection{Introduction}

Elderly patients in general practice often use several medications simultaneously for multiple disorders or complaints. Many of them are prescribed diuretics. Studies in Dutch general practices reveal that about $20 \%$ of people of 65 years of aged and above take diuretics.(1)(2) In the oldest age group the figure seems to be more than $50 \%$.(3) However, the pharmacokinetic and pharmacodynamic properties in people change with ageing. Due to this mechanism elderly patients show more often side-effects from medication.(4)(5)

Many side-effects of diuretics have been described. The water and electrolyte balance is directly influenced. This can cause hyponatraemia, hypokalaemia, hypomagnesaemia and dehydration with risk of cardiac arrhythmia, orthostatic hypo- 
tension, weakness in the muscles and constipation. Moreover the thiazides influence glucose tolerance, cholesterol and lipid metabolism and uric acid concentration in the blood. Urine incontinence and urine retention can be provoked by a rapid filling of the bladder when using loop diuretics. An improper use of potassium sparing diuretics may cause hyperkalaemia. Elderly people are especially prone to disturbance of the water balance under the influence of a hot and dry atmosphere inside their homes, a reduced awareness of thirst and a low intake of fluids.(5)(6)

There is a broad consensus concerning the use of diuretics for oedema which results from (a) congestive heart failure, (b) cirrhosis of the liver, (c) chronic renal failure, or (d) hypo-albuminaemia and the treament of hypertension, tubular acidosis, glaucoma and idiopathic hypercalciuria.(7)

Investigation of reasons for the use of diuretics reveals a high prescription rate for oedema around the ankles or feet. (2)(8)(9)

In general practice many cases of ankle oedema are due to venous insufficiency (VI).(10) In VI the venous blood flow is decreased by failure of the muscular pump (MP). The MP is the physiological entity consisting of the crural veins, venous valves, muscular fascias and muscular contraction activities of the calf muscles assuring largely the venous blood retum out of the legs.(11) Hence the use of diuretics in ankle oedema is controversial.(12) There seerns to be no doubt about the relevance of postural measures (repeated elevations of the legs from lying position on the back several times a day) and the regular use of graduated compressive bandages or stockings.(13) However, these interventions have not been properly assessed in double-blind randomised controlled trials. There is a range of different perceptions of how these treatments should be applied.(14)(15)(16)(17)(18)

Ankle oedema in elderly people can be caused by congestive heart failure (CHF). However, in cardiology ankle oedema is considered as a late sign of CHF,(19) Nevertheless the literature shows that CHF in the elderly is frequently diagnosed by means of this sign.(9)(10) As a result some of the patients with ankle oedema based on VI are treated with diuretics as they are presumed to have a CHF.

The prescription and hence the use of diuretics in the elderly tend to be of long: 
duration. Doctors rarely advise their patients to stop to see whether they can do without. In some patients when diuretic intake is stopped after long-term use retention of water and salt occurs mainly due to a delayed adaptation of the renin angiotensin aldosteron system (RAAS).(20)(21) The consequent increase in oedema and weight after stopping diuretic therapy seems to underline apparently the indication for diuretics.

To get a better idea of the perception of Dutch general practitioners about the differential diagnosis and intervention conceming ankle oedema in the elderly, we performed a questionnaire survey.

\subsection{Method}

In the questionnaire a simulated case was presented with a number of open questions. The instructions did not mention our special interest in the indication for use of diuretics. In the medical history a patient was described having ankle oedemat most probably caused by VI according to the authors. Intentionally no allusions were made about the absence of indications of CHF. We only mentioned that physical examination did not reveal anything particular apart from ankle oedema, obesity and varicosis. The patient presentation was as follows:

Patient A, a 68-year-old woman is living in a home for elderly people. Since the recent death of her husband, she has been staying all day in her room leading a sedentary life. Now she comes to your surgery complaining of swollen feet and ankles. She asks you to treat the ankle oedema.

Her medical record shows no special remarks whatsoever. It is not easy to measure her exercise tolerance because of her inactivity. Physical examination reveals obesity, pitting oedema bilaterally at the ankles and varicosis.

Respondents were asked to:

a. make a differential diagnosis ranking in order of likelihood,

b. indicate what kind of treatment would be given. 
Intentionally no options for answers were given. In this way a wide range of perceptions could be gathered without influencing the respondents. As a consequence, for a proper analysis the answers had to be selected in a number of well-defined categories. The following categories were used:

- Referring to the question about the differential diagnosis:

1 VI, including all assessments which concerned MP dysfunctioning, insufficient venous drainage and oedema.

$2 \mathrm{CHF}$, including failure of the left or right ventricle.

3 Other.

- Referring to treatment:

1 Advice and counselling about physical activity "diet and compressive bandages.

2 Diuretic, long-term, temporarily or eventually.

3 Combination of 1 and 2.

4 Other, including all drugs other than diuretics or advices, other than that under 1.

The questionnaire was sent to a random sample of 200 Dutch general practitioners chosen by the Dutch Institute for Research of Primary Health Care. After two weeks. a reminder was sent to the non-responders. Collection and processing of the data. were done anonymously. Statistical analysis was performed using the chi-square test (two-tailed test, $\mathrm{p} \leq 0.05$ ).

\subsection{Results}

One hundred and twenty-seven forms were returned, giving a response rate of $64 \%$. No significant difference was found between responders, and non-responders concerning practice, urbanisation characteristics, and gender of the general practitioners.

The majority of the responders $(86 \%)$ held a diagnosis in the category of VI as most likely. Table 4.1 gives the first most likely diagnosis per category of the 127 GPs. 
Table 4.1. Most probable diagnosis as stated by 127 general practitioners, in the case of a woman of 68-year-old complaining of ankle oedema.

\begin{tabular}{lrr} 
diagnostic category & a & s \\
\hline venous insufficiency & 109 & 86 \\
congestive beart failure & 15 & 12 \\
other & 3 & 2 \\
\hline total & 127 & 100
\end{tabular}

In the total differential diagnosis a VI diagnosis was indicated by $126(99 \%)$ GPs and 2 CHF diagnosis CHF was mentioned by $104(82 \%)$ of the respondents.

The proposed treatments are presented in table 4.2. Diuretics whether or not in combination with other drugs were proposed by 51 (40\%) of the respondents. Sixteen GPs who intended to prescribe a diuretic indicated a restriction in the duration of use and further 10 respondents mentioned other conditions such as diuretic use only if compressive therapy was not sufficient or if further clinical investigations indicated $\mathrm{CHF}$.

Table 4.2. Treatment proposal of 127 general practitioners in the case of a 68-yearold woman complaining of ankle oedema.

\begin{tabular}{lcc} 
treatment & n & \% \\
\hline 1. advice & 75 & 59 \\
2. diuretics & 22 & 17 \\
3. combination 1 and 2 & 29 & 23 \\
4. other & 1 & 100 \\
\hline total & 127 & .
\end{tabular}

In table 4.3 the intention to prescribe diuretics has been correlated with the differential diagnosis (excluding the category "other"). 
Table 4.3. Differential diagnosis of 124 general practitioners in the case of a 68year-old woman with ankle edema, related to the intention to prescribe diuretics.

\begin{tabular}{|c|c|c|c|c|c|c|}
\hline \multirow{2}{*}{$\begin{array}{l}\text { firnt } \\
\text { diagnosis" }\end{array}$} & \multicolumn{6}{|c|}{ number of geseral practitioners (\$) } \\
\hline & \multicolumn{2}{|c|}{ diuretics } & \multicolumn{2}{|c|}{ no diuretics } & \multicolumn{2}{|r|}{ botal } \\
\hline CHF & 13 & (87) & 2 & (13) & 15 & $(100)$ \\
\hline $\mathrm{V}(\mathrm{CHF}$ in DD) & 32 & B6) & 56 & (64) & 88 & $(100)$ \\
\hline Vl(CHF not in DD) & 4 & (19) & 17 & (81) & 21 & $(100)$ \\
\hline total & 49 & $(40)$ & 75 & $(60)$ & 124 & $(100)$ \\
\hline
\end{tabular}

${ }^{\circ} \mathrm{CHF}=$ congestive heart failure, $\mathrm{VI}=$ venous insufficiency, DD $=$ differential diagnosis.

There is a statistical significance between the use of diuretics in the three categories (two tailed chi square test, $\mathrm{p}=0.0001$ ). The more CHF is considered to be present the more frequent diureties are chosen. However in the VI group without CHF in the differential diagnosis a diuretic was chosen in one of five cases.

\subsection{Discussion}

A considerable number of doctors propose the use of a diuretic as a proper treatment for the simulated patient problem. The majority of the respondents held VI as the most likely diagnosis, while CHF was quite often considered in the differential diagnosis. A relationship appeared between the ranking of CHF in the differential diagnosis and the intention to prescribe diuretics. It can be concluded from these results that quite a number of GPs believe diuretics to be effective in cases of ankle oedema as a consequence of VI. Some of them chose diuretics solely on the grounds of VI, while others took eventually CHF into account. We think the latter group overestimates risk and prevalence of CHF. This factor leads to the prescription of diuretics and may contribute to the fact that diuretics are among the most frequently prescribed drugs in the elderly.

The magnitude of overestimation of the risk of CHF cannot be given exactly. We do 
not know the predictive value of ankle oedema for CHF and VI in general practice. An indication is the ratio between the prevalence of the two disorders in the given age groups in general practice populations. The figures of the Nijmegen Continued Morbidity Registration show, among women, a five-fold frequency of varicosis including VI $(22.9 \%)$ compared to the prevalence of CHF $(4.5 \%)$ in the age groups 65 to 75 years of age. In the age category of 75 years and above the ratio is 24.3 : 16.5.(22) One should bear in mind that VI is recorded as being part of the category "varicosis", while CHF is recorded within the category "myocardial degeneration and cardiac insufficiency".

Although ankle oedema based on VI is officially rejected as an indication for the use of diuretics, it turns out that at least some of the GPs questioned consider their use as a valid option. It seems advisable to conduct further research on the clinical effects of the use of diuretics in people with ankle oedema based on VI as well as the effects of stopping the use of diureties in patients with ankle oedema and VI in which the presence of CHF has been carefully excluded.

Acknowledgement to all of the GPs who answered the inquiry and to Trudy Seegers who assisted in the data analysis. 


\section{References}

1. Branbergen HCT. Welke pil slikt de 65-pluaser? Huisarts en Wetenschap 1985; 28(uuppl. H en P 9): 34-5.

2. Walma EP. Boukes FS, Prins A, van der Does E. Diureticagebruik door 65-plusaen in eea huisartmraktijk. Huisarts en Wetenschap 1989; 32; 326-8.

3. Brujine de $\mathrm{GA}$. Het geneesmiddelengebruik in verzorgingstehuizen, een collectief probleem, Madorne Geriatrie $1984 ; 4: 151-2$.

4. Gribnau FWI. Het voorschrijven van geneesmiddelen bij bejaarden. In: Merkus FWHM, Gribnau FW]. eds. Het voorschrijven van jeneesmiddelen. 3th ed. Utrocht: Bohn, Scheltema en Holkema, 1986: $121-9$.

5. Rowe JW. Clinical research on ageing: strategies and directions. N Eng I Med 1977; 297: 1332:-6.

6. Hyams DE. The elderly patient, A special case for diuretic therapy. Drugs 1986; 31 (suppl.4): 13853.

7. Lant A. Diuretien, Clinical Pharmacology and Therapeutic Use. Drugs 1985; 29: 162-88.

2. Koopmans RTCM, Gribnau FWJ. Langdurige diureticum behandeling bij verpleeghuisbewoners is atoppen mogelijk? Tijdachr Gerontol Geriatr 1988; 19: 55-60.

9. Burr ML, King S, Davies HEF et al. The effects of discontinuing long-term diuretic therapy in the elderly. Age Ageing 1977; 6: 38-45.

10. Wilcock OK, Gray JAM. Pritchard PMM. Oedema of the enkles. Geriatric Problems in Oeneral Practice. In ed. Oxford: Oxford University Press, 1982: 64-7.

11. Kuiper JP Uleus ersris venosum. Behandeling naar hedendaage inzichten. Het Modisch Jar. Utrecht: Bohn, Scheltema en Holkemi. 1978; 311-27.

12. Anonymus. Tractus Uropoeticus Diuretica. In: Nelemans; FA ed. Farmacotherapeutisch Kompas. Amstelveen: Centrale Medisch Pharmaceutische Commissie van de Ziekenfondsraad, 1989: 362-5.

13. Whitley A. Elastic stockings. Bi Med J 1988; 296: 413-4.

14. Burnand KG, Layer $\mathrm{OT}$. Oraduated elastic stockings. Br Med I 1986; 293: 224-5.

15. Cornwall IV, Dore CI, Lewis JD. Graduated compression and its relation to venous refilling, timis. Br Med J 1987; 295; $1087-90$.

16. Horner J, Fernandes E, Fernandes J, Nicolaides AN. Value of graduated compression tockingı in Ieep venous insufficiency. Br Med II 1980; 280: 820-1.

17. Partch H. Do we need firm compression stockings exerting high pressure? Vass 1984; 13:52-7.

18. Scot H, Coleridge Smith PD, MeMullin GM, Seurr JH. Venous disease: investigation and treatment, fact or fiction? Ann R Colt Surg Eng 1990; 72: 188-92.

19. Westerhof PW, Klinische manifestaties van hartziekten. In: Dunning A, Mejlet FL, Verheugt APM, eds. Nederlands Leerboek der Cardiologie. 2th ed. Utrecht: Bohn, Scheltemat en Holkema, 1983: 199.228. 
20. MacOregor QA, Markandu ND, Roulaton JE, Jones JC, de Wardener HE; lu "idiopathic" oedema idiopathic? Lancet 1979; 1: 397-400.

21. MacGregor GA, Tasker PRW, de Wardener HE; Diuretic-induced oedema. Lancet 1975; 1: 489-492.

22. Hoogen van den HJM, Huygen FIA, Schellekens JWG, Straat IM, Velden van der HOM. Morbidity Figures From Geseral Practice, Nijmegen: N.H.U.I. 1985: 65-72. 
Chapter 5

Methodological! issues of withdrawal trials 


\subsection{Methodological issues in withdrawal trials}

On the basis of our problem definition, a withdrawal trial was chosen to be the most suitable method for investigation. Methodologically we considered withdrawal as an intervention. Therefore we applied the principles of intervention trials in our design.(1)(2)(3) However, a withdrawal trial has several methodological peculiarities compared with standard intervention trials. In this paragraph methodological characteristics of a withdrawal trial that differ from a common trial are discussed. We will treat characteristies of the objective, the length of the followup period, the patient selection criteria, the exclusion criteria and use of placebo.

\subsection{The objective}

In general, randomized clinical trials are performed to show a positive result, thus where one treatment is significantly better than another. However, the aim of our investigation is to show that regarding the degree of oedema, withdrawal of therapy is equally effective as continuing diuretic therapy. Thus we are interested in showing that there is no therapeutic difference between both regimens, which can be expressed as a negative trial result. This implies that it is even more important than in "positive trials" to avoid a type II error. In other words, when there really is a difference between the results of therapy, the probability of not detecting a significant difference should be small. This has implications for the required size of the study. The number of patients needed for a withdrawal trial is relatively high.

\subsection{The length of the follow-up period}

In a withdrawal trial choosing the length of the follow-up period can be more difficult than in a common trial. In a common trial a change in symptoms or complaints is expected. The time needed for a relevant or sufficient change can be a 
guide for choosing the length of the follow-up period. However, in a withdrawal trial eventually no change is expected. Therefore the length of the follow-up period cannot be chosen on the basis of the length of the period expected to be needed for a change.

\subsection{Patient selection criteria}

In common intervention trials, a restricted number of interventions is studied for a restricted number of indications - often one or two interventions for one indication. In this respect it seems obvious that in withdrawal research, restrictions of indications and type of drugs under study should be made. However, in our withdrawal research into diuretic drugs, we faced the problem that in the past different variations of diuretics were started for the same indication. Methodologically it would be preferable to restrict the variation in interventions. However, this would restrict the external validity of this first trial, which could be seen as a general exploration of the withdrawal effect. Furthermore, restriction would interfere with the feasibility of the trial, since in our basic population the number of different types of diuretics used for the indication under study is rather high. Separate trials for each individual diuretic, or a large trial with a complex stratified randomization procedure would be neccesary.

\subsection{Patient recruitment and informed consent}

Regarding the patient selection a withdrawal trial needs a different, more active, approach than normal trials do. To find eligible patients for participation in the trial can be difficult for two reasons:

- Firstly, patients can be satisfied with their medical treatment, thus unwilling to change something in it. In addition, withdrawal may not promise for the patients any short term therapeutic benefit, since the aim often is to demonstrate 
equivalence with the non-withdrawal group. It is therefore more difficult to convince patients to participate in a withdrawal trial. This is also the case for obtaining informed patient consent.

- Secondly, in traditional multi-centre trials, patients can be identified as eligible when a patient with the indication of interest consults the doctor. In a withdrawal trial, one deals with a status quo, for which patients do not consult their doctor. Therefore, patients must be identified by screening medical and/or pharmacy files for example, or they must be actively invited when they consult for an unrelated problem. This is a principally different starting position, both from a medical and an ethical point of view.

\subsection{Exclusion criteria.}

The exclusion criteria in a withdrawal trial are more demanding than in a normal trial. In our project, concern about overconsumption of a drug, regarding long-term adverse effects and interactions, was an important motivation. Therefore cessation of the therapy is expected to be beneficial for the patient on the long-term. However, in the short-term, withdrawal is supposed to be at best not worse for a patient than continuation of therapy. This implies that there are high demands for the exclusion criteria. In a positive trial the direct benefits for the patient might be regarded as putweighing the costs for the patient. Therefore unfavourable effects are sometimes accepted to some degree. In a withdrawall trial no benefits immediately observable on the health status might be expected, thus costs for patients are hardly acceptable. This is all the more so, since recruitment of patients for the trial cannot take place as a direct result of the presentation to the doctor of complaints or demands regarding the disorder under investigation. Thus the researcher has to try evert more than in a positive trial to exclude all patients at risk for unfavourable effects. 


\subsection{Use of placebo}

In a common trial the use of placebo is often required. In a withdrawal trial the use of placebo is not so obvious. In the evaluation of interventions, a placebo intervention is used to eliminate the effect of the act of being treated. This placebo effect is considered to be quite important.(4) However, in a withdrawal trial the intervention is cessation of treatment. Thus in the control group placebo cessation of treatment should be carried out. For example, in case of an investigation into the withdrawal of a drug, the controll group should have the idea that their medication is stopped while they are still being given medication without knowing it. This will hardly be feasible in most circumstances.

By changing the intervention group's medication from active medication in placebo medication while the control group continues medication as previously, withdrawal is. also not adequately tested, because the withdrawal group is still "placebo-treated" then. In that case the pharmaceutical effect of discontinuation is studied, without the effects of the withdrawal act as such. In day-10-day care, however, the withdrawal act itself may play an important role in successful or unsuccessful withdrawal.

\subsection{Conclusions}

The usual design for randomized clinica! trials is not perfectly suitable for the investigation of the withdrawal of therapy. Adaptation of elements, of the method is advisable. Depending on the research question, special attention should be paid to: the avoidance of type II errors in the analysis, restriction of the number of interventions and indications under study, the length of the follow-up period, patient selection and exclusion criteria, and the choice whether or not to use placebo therapy. Further development of research methods foi investigation of the withdrawal of therapies might be useful. 
1. Pocock SJ. Clinical trials; A practical approach. Chichester: Wiley, 1983.

2. Sacket DL, Hayes RB, Tugwell P. Clinical Epidemiology: A basie science for clinieal medicine. Boston: Little, Brown and Company, 1985.

3. Feinatein AR. Clinical Epidemiology: The Architecture of Clinical Research. Philadelphia: WB Saunders Company, 1985.

4. Gribbin M. Placebos: cheapeat medicine in the world. New Sci 1981: 89: 64-5. 


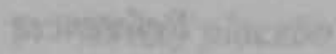

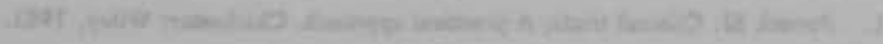

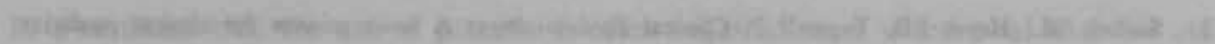

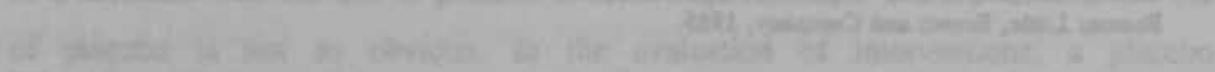

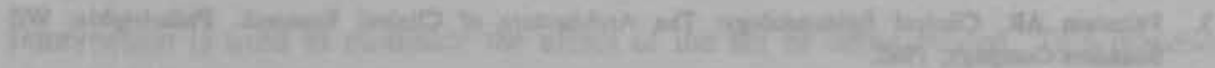

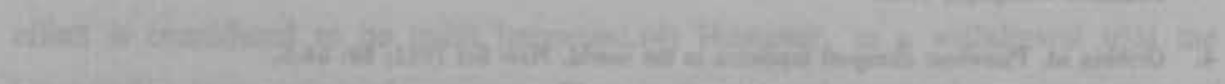

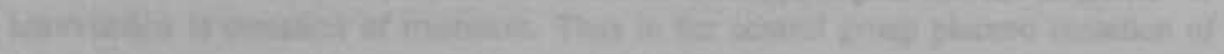

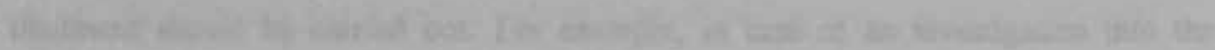

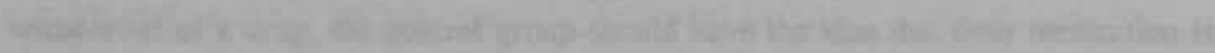

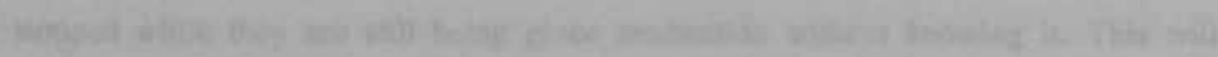

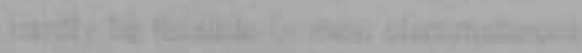

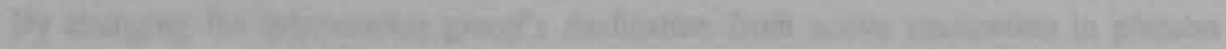

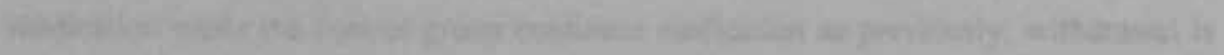

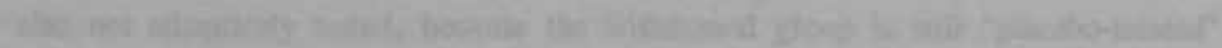

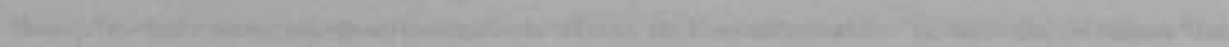

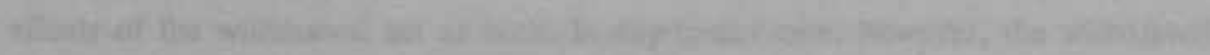

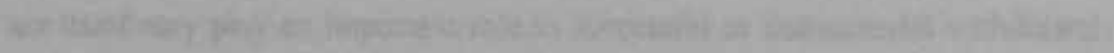

IS. $3 \mid$ bo

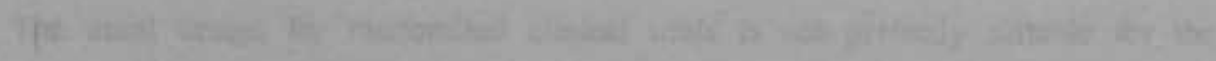
Imping,

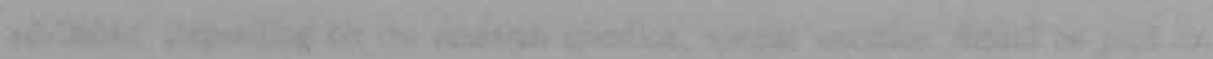

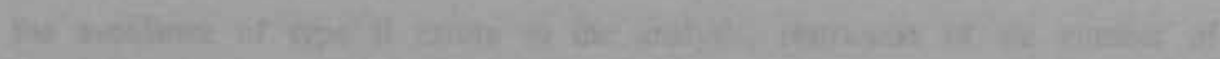

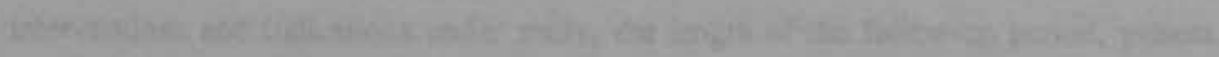

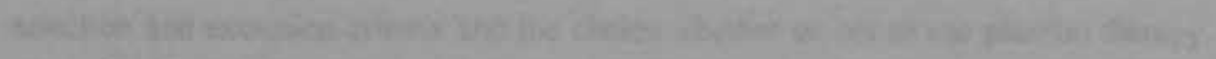
thather if

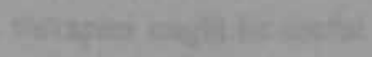


Chapter 6

Research methods 
Bnsyedo

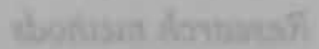




\subsubsection{Introduction}

This chapter describes the outlines of the experiment and the preceding prevalence study. In turn the designs and the practical execution are explained.

First, a prevalence study was carried out in several general practices. In this study we collected information concerning patients aged 65 years and older who were prescribed diuretic drugs in the preceding half-year. Following the prevalence study a randomized controlled trial was performed in which we studied the effect of withdrawing diuretic drugs, prescribed for ankle oedema not caused by heart failure, renal or hepatic insufficiency.

The study was reviewed and approved by the medical ethical commission of the AZM (University Hospital of Maastricht).

\subsubsection{The prevalence study}

The prevalence study served two purposes. It enabled us firstly to compose a group of patients eligible for the trial and secondly to describe some important characteristics of the population of patients aged 65 years or older who are prescribed diuretic drugs.

The prevalence study was carried out in four successive phases:

I An investigation to identify the patients aged 65 years or older, using diuretic drugs;

II A patient mail questionnaire;

III A medical file investigation from patients who cooperated with the questionnaire; IV An inclusion procedure, the definitive selection of patients eligible for the trial.

The methods of the first two phases are explained in the next two paragraphs, 6.2.2 and 6.2.3. The methods of phases three and four are described in paragraph 6.3.4, since proper understanding needs more knowledge about the design of the trial 
which is presented in paragraph 6.3.

\subsubsection{Phase one, identifying patients in general practice aged 65 or older, using diuretic drugs:}

The aim of this phase was to select patients within the participating practices who were aged 65 or older and were using diuretic drugs.

Two different strategies were followed to identify the eligible patients depending on whether a practice was computerized or not. A part of the project took place in six computerized practices in which the program "Micro-His" was used - this is a program specially designed for General Practice.(1) The program includes a socalled medical-module in which patients' medical information can be recorded. The files contain medically relevant data from patients attending the practice. The data include name, gender, date of birth, address, prescribed drugs, a. so-called problern list, and a patient journal. The problem list is an overview of the relevant medical "problems" patients have such as chronic diseases, risk factors and a short medical history. The patient journal contains the medical information from consultations and home visits. By means of this program we were able to conduct the selection in a computerized way. The general practitioners made a selection of all patients represented in the medical files who matched the criteria 65 years or older who had received in the preceding, half year a prescription for diuretic drugs, excluding the osmotic type of diuretics or fixed combination preparations of diuretic drugs with other drugs as ACE-inhibitors, beta-blockers that are not used for treatmenit of oedema.

In the case of practices in which the facility of computerized patients' medical files were not available, we used another strategy. Since most pharmacies, in the Netherlands use a computerized registration system of prescriptions, the selection could be compiled via the pharmacists. So in practices with the Dutch "green-card system", the cooperating general practitioners requested pharmacists serving the patients from their practice to make a selection of patients who had received diuretic 
drugs in the preceding half year. The types of diuretic drugs on the basis of which the selection was made were the same as in the case of the computerized practices.

\subsubsection{Phase two, the patient mail questionnaire}

The mail questionnaire served two aims. First we used the questionnaire to ask the patients themselves whether they were using diuretic drugs, for what reason they used the diuretics, and especially whether they used then for ankle oedema.

The questionnaire had another important goal. Since medical information concerning, patients is confidential, we wished to have the patients' permission before screening their medical files for our research project. The questionnaires were accompanied with a letter from the general practitioner. In the Jetter the patients were briefly told the aim of the questionnaire and the research project. By answering the first question of the questionnaire, patients were able to object to further use of their medical data for this project. To facilitate the response, a stamped reply-envelope was included. The practice nurses tried to contact patients by telephone when they had not replied within two weeks.

All the patients who were selected on the basis of their age and use of diuretics were sent the questionnaire, except in cases where the patients' general practitioner thought sending the questionnaire was not appropriate. For example, the guestionnaire was not sent to patients with a serious terminat iffness or to psychologically unstable patients, and naturally in the case of patients who had recently died, an event that has to be taken into account in the elderly population. In addition in cases where the physician knew the patients had a demential disorder rendering the patients unable to reply to the questionnaire independently, the questionnaire was not sent. 


\subsubsection{Design of the trial}

A randomized controlled design was chosen for the trial. During a period of six weeks, a group of selected patients eligible for diuretic withdrawal were followed. In the intervention group diuretic use ceased at start of the experimental period, while the control group continued to use the diuretics.

A placebo-controlled design was deliberately not chosen. We were interested in the gross effect of withdrawing diuretics compared with continuation of the treatment, as this is the intervention that would take place in practice. Furthermore, it is hardly possible to perform placebo withdrawal to the letter (paragraph 5.7). Finally a placebo-controlled trial was not feasible. In our target population a great variation of different types and combinations of diuretics are used. This would force us to make use of a lot of different placebo preparations, having major consequences for organizational and financial aspects of the trial.

Blinding of the observers did not take place. Our most important measurement was assessed in an objective way. This has the advantage that blinding of observers is not inevitable.(2)

Randomization was done, following prior stratification per practice. It was expected that the prescription habits of the general practitioners would have a major influence on the outcome of withdrawing diuretics. Equal distribution of patients from each type of practice in both the intervention and control group had to be ensured. Its importance can be illustrated by the following example.

If withdrawal of diuretics takes place in a practice where the general practitioner is accustomed to prescribing diuretics even in cases with little oedema, stopping diuretics will very probably show no important increase of oedema. Since the patients had little oedema before treatment with diuretics, it is unlikely that they would develop substantial oedema after ceasing diuretic therapy (assuming there is no rebound effect), irrespective of whether diuretic therapy has a decreasing influence on oedema. In contrast, if diuretics are effective, an observable effect in patients from a practice where diuretics are only prescribed for serious oedema, is that such patients are likely to develop grave oedema after ceasing diuretic therapy. 
If by chance a substantial majority of patients from the first type of practice were randomized to the intervention group, at best small differences between the control and the intervention group concerning the development of oedema would be expected. Vice-versa substantial differences in the development of oedema between both groups could be noticed if the intervention group contained mainly patients from doctors with a restrained prescription habit.

\subsubsection{Selection criteria for participants}

Participants were selected on the basis of the following inclusion and exclusion criteria.

inclusion criteria:

- age at least 65 years;

- use of diuretics for ankle oedema (according to patient or doctor).

exclusion criteria:

- less than one dose of diuretics per week;

- congestive heart failure;

- cardiac arrhythmia (atrial fibrillation);

- oedema caused by nephrotic syndrome or liver cirrhosis;

- hypertension, in those cases when the patient's general practitioner prefered treating this with diureties;

- terminal illness;

- hospitalization;

- decreased mental functioning;

- crural ulcus.

explanation of the exclusion criteria

Diuretics for ankle oedema are often prescribed only "if needed". We have chosen to exclude patients who used less than one dose a week. This choice is debatable but in our view at such a low dose or less, the pharmacological effect of ceasing the use 
of diuretics would not be detectable.

An important aspect of the selection was ruling out patients with congestive heart failure. We expected patients to be prescribed diuretics because they were suffering, from heart failure while they themselves reported that they were using diuretics for ankle oedema. In accordance with the research question we had to prevent such patients from entering the trial. On the other hand, we strived to include in the trial patients for whom the diagnosis heart failure in the past had been established on insufficient grounds. We expected that some of the patients whom the general practitioner reported using diuretics for heart failure, had been erroneously diagnosed to have cardiac failure (see chapter 4). It was very important to include these patients in the trial. Criteria used to exclude patients with an unacceptable risk of developing congestive heart failure after ceasing diuretic therapy were

- heart failure diagnosis assessed by cardiologist;

- history of complaints of severe dyspnoea treated by the general practitioner as cardiac failure;

- congestive heart failure diagnosis according to modified criteria of Carlson et al (see 6.3.7);

- patients with atrial fibrillation.

Reasons for the prescription of diuretics sometimes are ambiguous. Often diuretics were prescribed to treat hypertension and ankle oedema together. Previous research had shown that treatment of hypertension often can be withdrawn, without raising the blood-pressure to a level that makes resuming the treatment necessary.(3) Patients who were treated with diuretics for both hypertension and ankle oedema were also included in the trial to investigate the effect of ceasing diuretic therapy on the extent of oedema. Those patients for whom the general practitioner thought the diuretic therapy necessary for treatment of hypertension were excluded.

We did not attempt to include in the research project patients who were hospitalized during the inclusion period or were in a terminal stage of illness.

Participation in the trial demanded the active independent cooperation of the patients. Those who were unable to fulfill this condition were excluded. 
The measurements of oedema were made volumetrically with a water-filled box. The patients had to place their feet in this box. Because of the danger of contamination and disturbance to healing, patients with skin defects on the foot or ankle had to be excluded (see also 6.3.8)

\subsubsection{Observations}

This paragraph provides an overview, with explanation, of the observations that were made. How we made these observations is described in paragraph 6.3.4.

base-line observations $\left(\mathrm{C}_{0}\right)$ :

- weight(kg), blood pressure(mmHg), peak flow( $/ / \mathrm{min})$;

- laboratory: haematocrit(vol\%), $\operatorname{sodium}(\mathrm{mmol} / \mathrm{l})$, potassium(mmol/1), magnesium(mmol/l), creatinine $(\mu \mathrm{mol} / \mathrm{I})$, urea(mmol/1);

- determination of excretion of diuretic drug in urine;

- volumetry of ankles and feet;

- degree of oedema according to patient;

- degree of oedema in terms of pitting oedema

- questions about quality-of-life;

- functioning-score according to Nelson/Meyboom-de Jong.(4)(5)

follow-up observations I(assessed at house visits):

$\left(t_{1}, t_{2}\right.$, in the first week, $t_{3}, t_{4}, t_{5}$, and $t_{6}$, at the second, third, fourth and fifth weeks)

- weight(kg), blood pressure $(\mathrm{mmHg})$, peak flow(t/min);

- volumetry of ankles and feet;

- degree of oedema according to patient;

- degree of oedema in terms of pitting oedema;

- determination of excretion of diuretic drug in urine (only at $b$ ).

- general new complaints of patients 
follow-up observations II(reported by the patients themselves):

day 1 until day 22

- weight(kg);

- mobility;

- degree of oedema;

end-observations $(\mathrm{h})$ :

- weight(kg), blood pressure( $\mathrm{mmHg})$, peak flow( $(1 / \mathrm{min})$;

- laboratory: haematocrit(vol\%), $\operatorname{sodium(mmol/l),~potassium(mmol/l),~}$ magnesium(mmol/l), creatinine $(\mu \mathrm{mol} / \mathrm{l})$, urea $(\mathrm{mmol} / \mathrm{l})$;

- determination of excretion diuretic drug in urine;

- volumetry of ankles and feet;

- degree of oedema according to patient;

- degree of oedema in terms of pitting oedema

- short quality-of-life measurement;

- functioning-score according to Nelson/Meyboom-de Jong.(4)(5)

\section{Explanation}

As a measurement of water-retention after diuretic cessation the patients' weight was recorded both daily (by the patients themselves) and weekly (by the observers). The expiratory peak-flow was used as an indication of the lung-function in order to detect decrease of lung-function at an early stage.(6)(7)

In the literature disturbances in the body's sodium, potassium and magnesium balance are often mentioned as a consequence of using diuretics.(8) To investigate the effect of withdrawing diuretics the blood levels of these electrolytes were measured at the base-line and the end of the trial. As an indicator of hydration, the haematocrit and blood levels of urea and creatinine were assessed.

To sheck the degree of compliance with our instructions to stop or continue diuretic medication, urine samples were taken at $t_{0}, h_{2}$ and at the last visit. The urine samples were analysed for the presence of the diuretic drug used by the patient.

Changes in oedema were objectively assessed by measuring the volume of the foolt 
and ankle at the observation visits (see paragraph 6.3.8). To obtain a subjective judgement, the patients were asked to give their own opinion about the degree of oedema and it was assessed in terms of pitting oedema by the observer.

We expected the rate of physical activity of the patients to have an important influence on the degree of oedema. A person with a sedentary life-style has a greater chance of developing oedema, especially dependent oedema, than a person who is active and consequently activates 'the muscle-pump'. Assessment of mobility would enable us to correct for confounding that could appear when the mobility of the intervention group differed considerably from the control group.

To investigate whether withdrawing diuretics has influence on the patients' quality of life and functional status of the patients we performed short quality of life, and functional status measurements (appendices 1 and 2).

\subsubsection{Performing of the definitive selection of the patients}

This paragraph explains how the definitive selection of patients for the trial was performed. The selection of patients for the trial was carried out in four phases. Phases I and II have already been described in paragraph 6.2. To select the ultimate participants for the trial, two more phases were necessary, phase III, and phase IV, the inclusion procedure. In phase III, the medical files of all the patients who returned the questionnaire and had not objected to the use of their medical data were checked in cooperation with the patients' general practitioners. The indications for use of diuretics were recorded as far as possible and it was checked whether patients were potentially eligible for the trial, or were already to be excluded on the basis of the exclusion criteria.

Following this phase, the inclusion-procedure phase IV was performed. In this phase we contacted all the patients who met the inclusion criteria and were not excluded by meeting one of the exclusion criteria in phase III. The patients were contacted by telephone to arrange a consultation with the investigator. This was done by the practice-assistant or by the investigator or research-assistant, depending on the 
circumstances. In general the advantage of the practice-assistant phoning the patients was that people were more likely to cooperate because they trusted her. In contrast, when we phoned the patients directly, they sometimes tended to be suspicious. If it appeared from the phone contact that patients did not use diuretic drugs or did not use them for ankle oedema, they were already excluded. Depending on the possibilities, the consultations were arranged at the surgery of the cooperating, general practitioners or in the patients' own home.

At the first personal contact between the investigator and the participants, the informed consent procedure was started. Verbal explanation of the aims and the complete method of the trial was given. Patients were handed over written information about the trial. First a further check was made whether the patient used diuretics for ankle oedema at a rate of at least one dose per week. Secondly it was checked whether the diuretics were prescribed by a cardiologist for cardiac problems. When the patients seemed eligible and agreed to participate in the trial, we asked the patients to sign an informed consent form (approved by the medical ethical commission). Subsequently a standardized history taking and physical examination was performed. This examination focused primarily on ruling out. cardiac insufficiency. For this purpose we used the criteria for congestive heart. failure of Carlson et al., to which some additions were made for safety reasons (see paragraph 6.3.7). Laboratory measurements of total protein and albumen level were done to detect hypoprotinaemia. If necessary, a chest $\mathrm{X}$-ray was made. The request for the chest X-ray included a form in which we asked for, the results to be. presented in such terms that we could use the Carlson criteria. As soon as it was, certain which patients of a practice were definitively eligible for the trial, the randomization procedure was carried out.

\subsubsection{Procedure during trial}

The randomization procedure was executed using the program "Loting" of H. Schouten, biomedical statistician at the Department of Statistics of the University of 
Limburg. This program enabled us to randomize in blocks per practice with the result that the total number of participants in the intervention group would not differ much from the number of patients in the control group. After randomization, we made an appointment with the participants, for a home visit to make the base-line measurements. On this occasion we gave the patients instructions whether to cease or to continue diuretic medication. A schedule for visits and instructions as to which date to stop diuretic medication were discussed. We asked the patients to let the investigation have as little influence as possible on their daily habits. For example patients who used elastic stockings were asked to use them just as normal. Because patients were worried about getting swollen ankles, we advised every participant to maintain swollen legs as much as possible in an horizontal position when sitting, and to lie down for a while in the afternoon with their legs in an elevated position. Every participant received written as well as verbal instructions. The written instructions were included in a "diary". During the first three weeks of the trial the participants had to keep this diary every day. The items to be recorded were weight, physical activities, degree of oedema (subjective) and general feelings of well-being. For safety reasons patients from the intervention group were given instructions as to the circumstances in which they had to contact us or their own doctor (monitoring see 6.3.6).

During the experimental period the measurements were executed as follows. Each patients' weight was taken with his or her own pair of scales. We were primarily interested in individual fluctuations in weight. By letting patients, use their own scale we were able to detect changes in weight. In cases where patients had no adequate pair of scales, we provided one. We instructed the patients to take their weight directly after rising and under the same circumstances every morning.

Blood pressure was measured with patients in a sitting position with a calibrated sphygmanometer. Systolic blood pressure was defined as blood pressure at the moment of the first beat heard at 'Korotkoff phase $\mathrm{I}$ ', diastolic blood pressure as blood pressure at 'Korotkoff phase V'.

The peak expiratory flow was measured with the Wright Peak Flow mini-meter. Peak flow measurements were repeated at least three times (or more in cases of poor 
patient technique) with the highest achieved level of peak flow being recorded.

Laboratory measurements were done at the laboratories the participating general practitioners normally cooperated with. Thus the patients could go to laboratory facilities in their own area. In our opinion this facilitated participation. In cases where patients were unable to visit the laboratory, the blood samples were taken at home.

Compliance measurements were carried out by analysing urine samples of the participants. To prevent patients from anticipating the checks and altering their diuretic intake, they were not told that the urine was to be checked for the presence of diuretic drugs. The samples were obtained at 10,12 and 17 . They were analysed for the presence of the diuretic drug the patients used prior to the trial for during the trial in case of control patients). In case more than one diuretic drug was used, analyses for all the drugs were performed. The analyses were conducted at Department of Clinical Pharmacy of the University Hospital of Maastricht. Detection of diuretics in urine was performed by means of high pressure liquid chromatography. Depending on the type of diuretic an ultra-violet detection method or a fluorescence detection method was used. Test results were classified as positive, possible positive or negative.

For the measurements of the degree of oedema, we applied a volumetric method described in detail in paragraph 6.3.8. The degree of oedema for both ankles also was assessed by the 'classic' medical method. This involved examining for pitting oedema by pressing and rubbing a finger gently on the skin of the ankle, pre-tibial or retro-malleolar. A scale of four degrees was used: no oedema, dubious oedema, clear oedema and strong oedema. At every visit we also asked the patients theit own opinion about swelling of their ankles at that moment. We asked for degree of oedema and any increase or decrease, compared to the previous visit.

We recorded the complaints which patients reported us at the monitoring visits. Besides complaints concerning oedema, patients were explicitely asked about complaints of shortness of breath. Complaints of orthopnoea and severe dyspnoea d'effort, were monitored as important signs of unacceptable fluid retention, in which zase diuretic therapy was restarted. Other complaints were recorded after being 
mentioned spontaneously by patients.

For monitoring, the patients were visited frequently. In the first week of the six week follow-up period two visits were made. In the following period we examined the patients once every week, until the sixth week. To ensure good comparability of measurements, the base-line and end measurements were in every case performed by the investigator himself. Measurements in-between were made by the investigator or the research-assistant. For more detailed aspects of the monitoring see paragraph 6.3.6.

\subsubsection{Monitoring}

The nature of the trial obliged us to provide the patients with a good monitoring system. In the first place development of signs of congestive heart failure had to be noticed at an early stage. For this reason we made frequent home-visits. Because most diuretic drugs are eliminated within 24 hours unfavourable effects that would force us to restart therapy could be expected within a week. The schedule we used for the visits was as follows: first visit on second or third day after withdrawing diuretic therapy, second visit on fourth or fifth day, and in the following weeks one visit every week. An agreement was made with the participants that whenever they did not feel well or had complaints that they thought were caused by not using the diuretics, they could contact us or their general practitioner. We stressed that they should contact us in case they gained more than rwo talograms in weight or in case they had feelings of dyspnoea. The general practitioners were permitted to restart the diuretics if they felt it necessary, but we asked them to contact us for consultation in such cases. However, since we were aware that in some situations the decision had to be taken instantly, we could not insist on consultation in every case. Reasons for restarting diuretic therapy were to be recorded. It was impressed upon the patients not to change diuretic use without consulting their general practitioner or us. 


\subsubsection{Criteria for congestive heart failure}

Because of the type of intervention, it was very important that, before admitting participants into the trial, we could rule out patients with cardiac insufficiency. It would be unfavourable to disturb the equilibrium of patients suffering from heart failure who were just in balance with diuretic drugs. On the other hand we wanted to take into account the hypothesis formulated in literature, that was confirmed by the questionnaire survey we conducted among Dutch general practitioners, that some of the patients treated with diuretic drugs for heart failure were in fact being treated for venous insufficiency (Chapter 4). Thus some of the group of potential participant patients in the trial were selected even though the labelled indication for diuretic use was heart failure.

We had to find a way that could easily be conducted in General Practice without expensive or invasive diagnostic procedures to rule out patients with cardiac insufficiency. We chose criteria previously used by Carlson et al, in a research project investigating the prescription of digitalis in case of heart failure (table 6.1).(9) These criteria have the advantage that they have been validated (albeit in a highly selected population) against a "gold standard", namely the pulmonary wedge pressure. Another important advantage is that these criteria do not need more than routine physical examination procedures and as additional procedure only a Chest X-ray which can easily be arranged in the General Practice setting.

For reasons of safety and feasibility we used the criteria in a slightly modified way. Since a substantial number of patients under study were people of a very advanced age who would experience a hospital visit for an X-ray investigation as a burden, we decided to make a Chest X-ray only on indication. As indication we used a score of 4 points or more on the first two categories of the "Carlson criteria"

With or without chest radiography, we chose to admit only those patients in the trial who had a score of 5 points or less. Independent of the Carlson score, we decided following advice from the cardiologist of the Department of Cardiology, University of Maastricht, whom we consulted, to rule out in any case patients with the symptoms of right-sided heart failure, palpable right ventricular pulsations and 
Table 6.1. Criteria for congestive heart failure of Carlson et al.(9)

Point value*

\begin{tabular}{|c|c|}
\hline \multicolumn{2}{|l|}{ Category L: listory } \\
\hline Rest dyapnoea & 4 \\
\hline Orthopsoea & 4 \\
\hline Paroxysmal nocturnal dyspnoea & 3 \\
\hline Cyapnoes on walking on level & 2 \\
\hline Dyspnoea oa climbing & 1 \\
\hline \multicolumn{2}{|l|}{ Category II: physical examination } \\
\hline Heart-rate absormality (if $91-110$ beats/min, 1 point; if $>110$ beats/min, 2 points) & $1-2$ \\
\hline $\begin{array}{l}\text { Jugular-venous pressure elevation (plus hepatomegaly or oedema } 3 \text { points; otherwise } \\
2 \text { points) }\end{array}$ & $2-3$ \\
\hline Lung crackles (if basilar, 1 point; if more than basilar, 2 points) & $1-2$ \\
\hline Wheezing & 3 \\
\hline Third heart sound & 3 \\
\hline \multicolumn{2}{|l|}{ Category III: chest radiography } \\
\hline Alveolar pulmonary oedema & 4 \\
\hline Interatitial pulmonary oedema & 3 \\
\hline Bilateral pleural effusions & 3 \\
\hline Cardiothoracie ratio $>0.50$ & 3 \\
\hline Upper-zone flow redistribution & 2 \\
\hline
\end{tabular}

No more than 4 points are allowed in each of three sategories; the composite score (the sum of the subtotal from each category) has a possible maximum of 12 points. The diagnosis of heart failure is classified as definite for a jeore of 8 to 12 points, possible for 5 ts 7 points, and unlikely for 4 points or leas.

hepatomegaly. Also patients with cardiac arrythmia as noticed by pulse examination were excluded because we did not want to take any risk of their deterioration into the development of congestive heart failure, although strictly speaking cardiac arrythmia alone is not an indication for diuretic use. 
In the case of the patients who had the additional indication hypertension, blood pressure measurements were obtained at least three months after the end of the trial, independent of whether diuretics were restarted or not.

\subsubsection{Statistics}

For statistical Inalysis, the BMDP-90 statistical program was used.(13) For hypothesis testing, a significance level of $\alpha<.05$ was chosen. Ninety-five percent confidence intervals for the mean were calculated by using BMDP 2D. The chisquare test or, when appropriate, Fisher's exact test was used to compare proportions (BMDP 4F). For comparison of means, the BMDP 3D $\mathrm{T}$-test was used. If additional statistical analysis was performed this is stated in the chapter of concern. Percentages are often given for clarity even if they had to be calculated on the basis of a low number. In some tables percentages do not add up to exactly $100 \%$ because of rounding off error. 
1. Höppener P. Automatisering en wetenschappelijk onderzoek in le huisartspraktijk [Dissertatie]. Maustricht: Rijksuniverniteit Limbure. 1990.

2. Knottnerus 1A, Volovics A. Medische statistiek on onderzoek in de huisartsgeneeskunde, Utrecht: NHO 1990.

3. Kruijsdijk M van. Hypertensie opnieuw gemeten [Dissertatie]. Nijmegen: Katholieke Universiteit te Nujmegen, 1991.

4. Nelson EC, Wasson J, Kirk J, et al. Assessment of function in routine clinical practice: description of the COOP chart method and preliminary findings. I Chronic Dis 1987; 40: (Suppl D: 55s-64s.

5. Meyboom-de Jong B. Bejaarde patiènten: Een onderzoek in twaalf huisartaprnktijken [dissertatie\}. Groningen: Rijksuniversiteit Groningen 1989.

6. Veen van WA. De bruikbaarheid van de piekatroombepaling voor de buisarts. Huinarts Wet 1982; (uppl HAP 6): 69-75.

7. Dobbs SM, Kenyon WI, Dobbs RJ. Maintenance digoxin after an episode of heart failure: placebocontrolled trial is out patients. Br Med J 1977; is 749-52.

8. Tweeddale MO. Diuretic drugs. In: Dukes MNG nditor. Meylers's Side Effects of Drugs, 9nd ed. Amsterdam: Excerpta Medica, 1980: 337-67.

9. Carlaon $\mathrm{KJ}$, Lee DC, Goroll AH, Leahy M, Johnson RA. An analysis of physicians' reasons for prescribing long-term digitalis therapy in outpatients. J Chronic Dis. 1985; $38: 733-9$.

10. Thulesius O, Norgren L, Gjoeres JE. Foot-volumetry, a new method for objective assessment of edema and venous function. Vasa 1973; 2:325-29.

11. Wienert V, Kamps J. Volumetrische und venenverschlusaplechysmographische Unternuchungen am Unterschenkel mit Hilfe der computerunterntûtzten Videoplethysmographie. Phlebpl u. Proktod 1987; 16: 134.

12. Hübner K. Das Volometer - in neuartiges Gerili zur schnellen Volumenbestimmung von Extremithiten. Phleb u. Proktol 1987; 16: 40.

13. Dixon W], Brown MB, Engelman L, Jennrich RL. BMDP statistical software manual: to accompany the 1990 software relaese. Berkeley: University of California Press, 1990. 


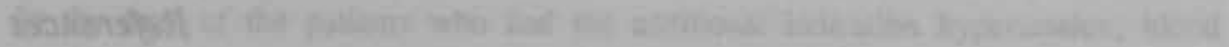

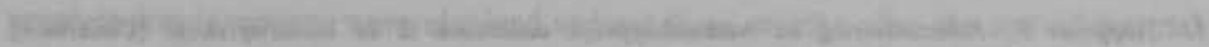

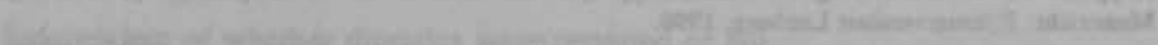

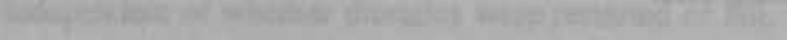

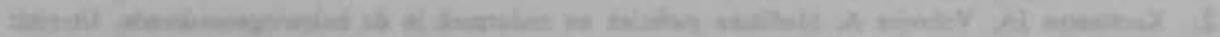

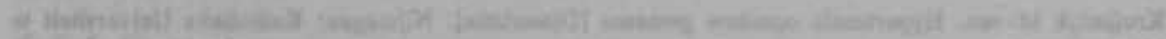

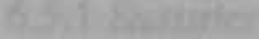

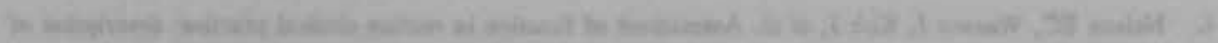

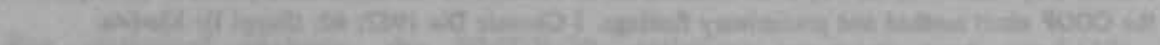

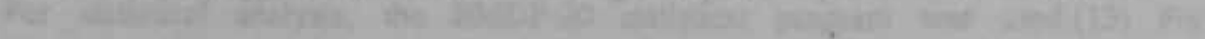

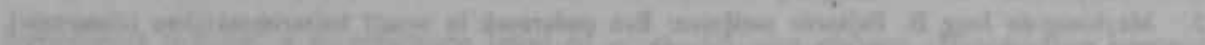

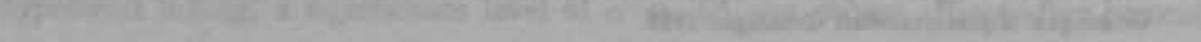

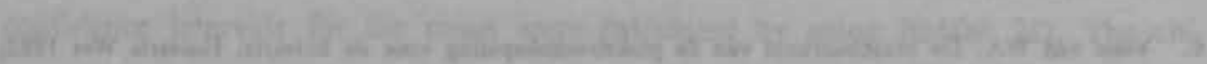

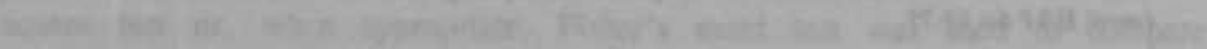

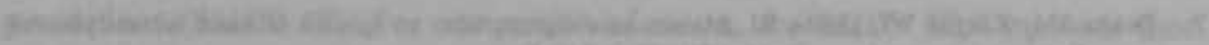

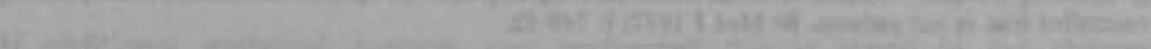
HF

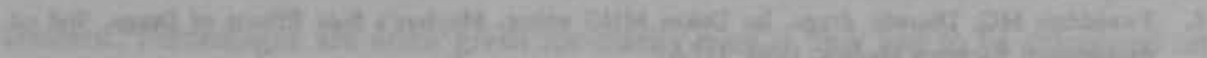

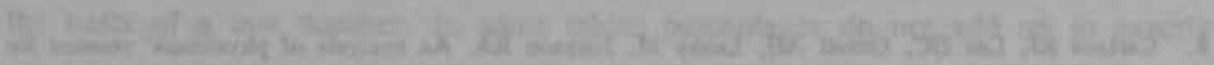

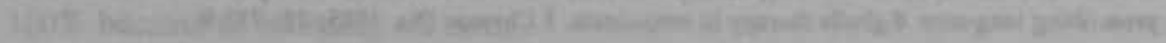

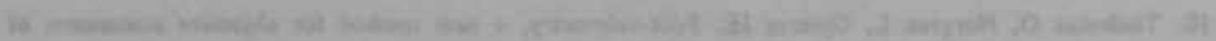

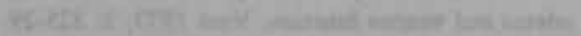

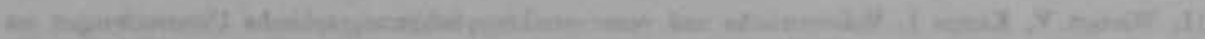

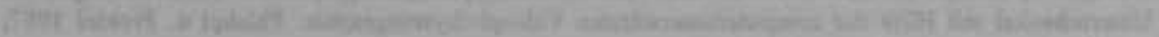
BII WH

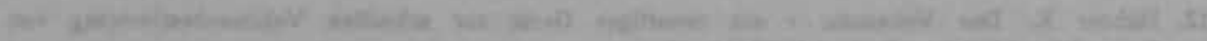

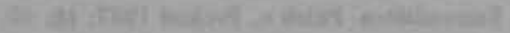

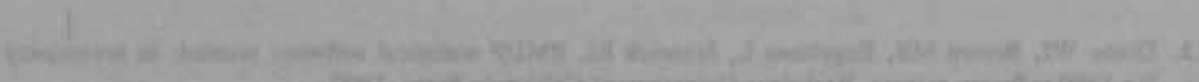

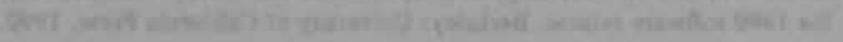




\section{Chapter 7}

Results of the prevalence study 
Timas

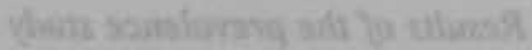




\subsection{Introduction}

This chapter presents the results of the prevalence study, on the basis of which we selected patients for the trial. We tried to conduct this survey in every practice in such a way that every potential participant for the trial could be screened. This enabled us to describe general characteristics of the source population and, in more detail, a selection of this population of people aged 65 years or older who were prescribed diuretics drugs. The chapter presents, in sequence, the results of the method to find elderly people who used diuretics; an estimation of the proportion of elderly people who use diuretics; the results of the second phase of the selection with a non-response analysis; the reported indications for using diuretics; the results of the third and fourth phase of our selection method; an overview of the complete selection method; a comparison of the selected trial population with the total elderly population using diuretics; and, finally, conclusions and recommendations.

\subsection{Results of the first phase of the selection procedure: selection according to age and use of diuretics}

The main purpose of the first phase of the selection was, to obtain a population of patients aged 65 years or older using diuretic drugs. We were able to screen the population in fifteen practices on these criteria. All these practices were situated in the province of Limburg. Nine practices were situated in Maastricht, two were in the town of Heerlen and four practices were situated in rural areas of Limburg in the villages Velden, Lottum, Well, and Berg en Terblijt. For the practices in Maastricht the selection of patients was obtained in cooperation with 11 of the 14 pharmacies in Maastricht. Three pharmacies were not able to cooperate. It is not likely that we missed a substantial number of the eligible patients as a consequence, because these pharmacies were located in other areas of the town than where the cooperating general practitioners had their practice. All the participating practices outside Maastricht were computerized, enabling us to perform the selection procedure 
independently of pharmacies.

As result of the first phase we traced 1202 patients from these practices who met the criteria: aged 65 years or older and being prescribed diuretic drugs (age and sex distribution is presented in table 7.1). In this population the highest recorded age was 99 years; median age 76 years; first quartile 70 years and third quartile 81 years.

Table 7.1. Age and gender distribution of patients of 65 years and older, using diuretic drugs. (column percentages)

\begin{tabular}{|c|c|c|c|c|c|c|}
\hline \multirow[b]{2}{*}{ age } & \multicolumn{2}{|c|}{ ment } & \multicolumn{2}{|c|}{ women } & \multicolumn{2}{|c|}{ total } \\
\hline & n & 8 & n & 5 & a & $\%$ \\
\hline $65-74$ years & 154 & 47 & 373 & 43 & 527 & 44 \\
\hline $75-84$ years & 137 & 42 & 371 & 42 & 508 & 42 \\
\hline 85 and older & 35 & 11 & 129 & 15 & 164 & 14 \\
\hline total & 326 & 100 & 873 & 100 & -1199 & 100 \\
\hline
\end{tabular}

- in 3 casea data were incomplete for incorporation in this table

The diuretics prescribed to the people whose medical data we were able to investigate further (see next paragraph) are listed in table 7.2. Since mariy patients were prescribed two diuretics in combination, the figures per diuretic do not add up to $100 \%$ because of category overlap. As can be read from the table, hydrochlorthiazide, frusemide, triamterene and amiloride are the substances most frequently used. What is striking is the relatively high use of potassium sparing fixed combination preparations in spite of the relatively rare indication for these preparations according to literature.(1) This phenomenon was also observed in a survey in Great Britain.(2) 
Table 7.2. Prescribed diuretics in sample of population $(n=772)$. The table gives figures per preparation. Since combinations of preparations are presented twice, percentages do not add up to $100 \%$.

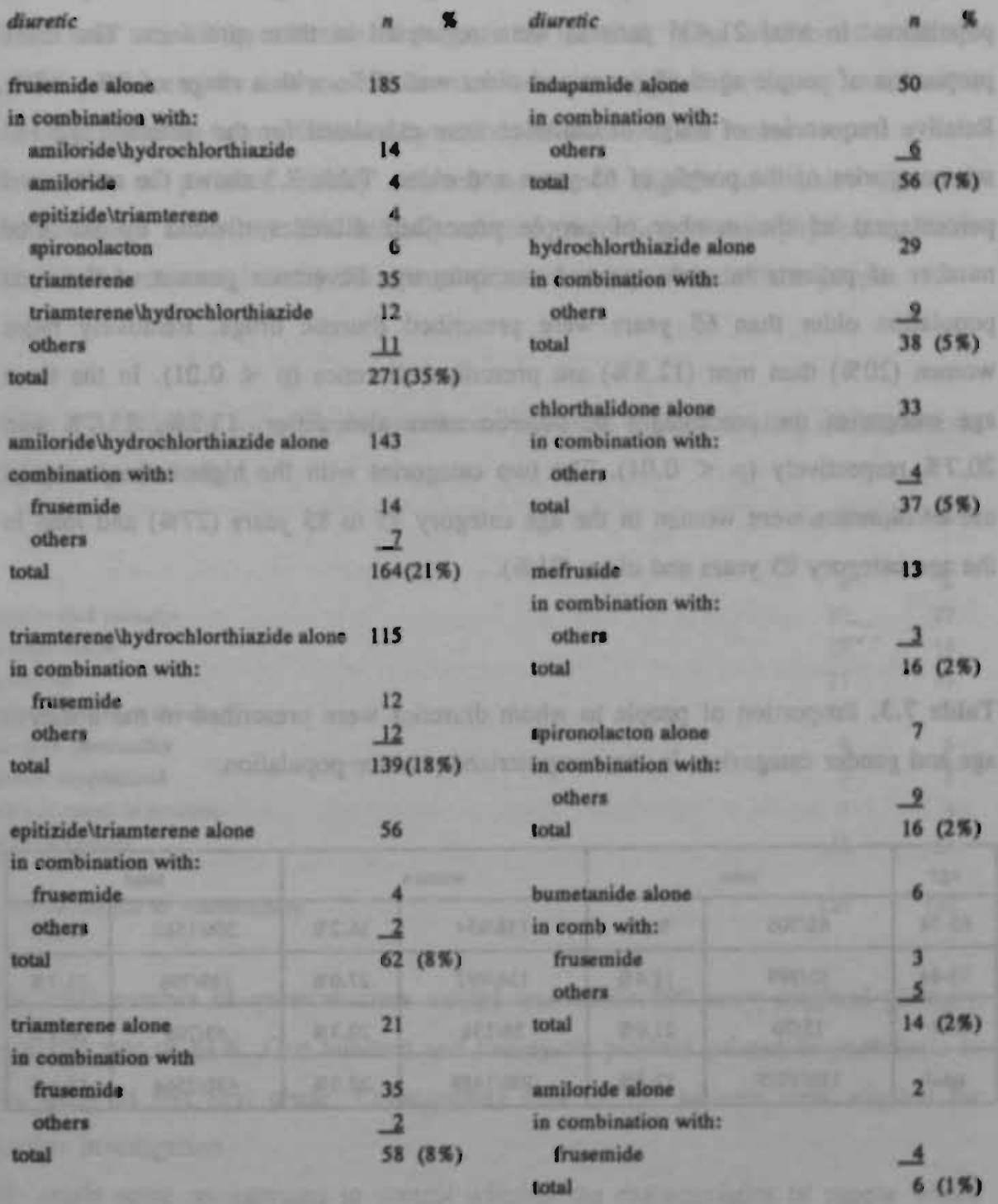




\subsection{Practice-based prevalence of diuretic use}

Six computerized practices cooperated with the study. From these practices we have background figures at our disposal, concerning sex and age of the total practice population. In total 21,435 patients were registered in these practices. The mean proportion of people aged 65 years and older was $12 \%$, with a range of $7 \%-17 \%$. Relative frequencies of usage of diuretics were calculated for the different age and sex categories of the people of 65 years and older. Table 7.3 shows the ratios (and percentages) of the number of people prescribed diuretics divided by the total number of patients in each age and sex category. Seventeen percent of the total population older than 65 years were prescribed diuretic drugs. Relatively more women $(20 \%)$ than men $(12.8 \%)$ are prescribed diuretics $(p<0.01)$. In the three age categories the percentages of diuretic users also differ, $13.2 \%, 23.7 \%$ and $20.7 \%$ respectively $(p<0.01)$. The two categories with the highest frequency of use of diuretics were women in the age category 75 to 85 years $(27 \%)$ and men in the age category 85 years and older $(21 \%)$.

Table 7.3. Proportion of people to whom diuretics were prescribed in the different age and gender categories, in the computerized-practice population.

\begin{tabular}{|c|c|c|c|c|c|c|}
\hline age & \multicolumn{2}{|c|}{ men } & \multicolumn{2}{c|}{ women } & \multicolumn{2}{c|}{ sotal } \\
\hline $65-74$ & $68 / 706$ & $9.6 \%$ & $138 / 854$ & $16.2 \%$ & $206 / 1560$ & $13.2 \%$ \\
\hline $75-84$ & $55 / 299$ & $18.4 \%$ & $134 / 497$ & $27.0 \%$ & $189 / 796$ & $23.7 \%$ \\
\hline $85+$ & $15 / 70$ & $21.0 \%$ & $28 / 13 \pi$ & $20.3 \%$ & $43 / 208$ & $20.7 \%$ \\
\hline total & $138 / 1075$ & $12.8 \%$ & $300 / 1489$ & $20.0 \%$ & $438 / 2564$ & $17.1 \%$ \\
\hline
\end{tabular}


7.4 Results of second phase of the selection: parients available for further investigation, and patients who were not sent a questionnaire, did not respond or refised further participation

In the next step of the selection of patients for the trial, those who met the criteria age 65 years or older and use of diuretics were investigated further by means of a mail questionnaire survey followed by a study of their medical record.

A number of patients initially selected were not eligible to receive the mail questionnaire: 137 of the 1202 initially selected, according to their physicians. Table 7.4 lists the reasons given by the general practitioners to exclude these people.

Table 7.4. Reasons by general practitioners reported for not sending questionnaires to particular patients.

number of patients

patient died recently

\begin{tabular}{rr}
8 & 5 \\
37 & 27 \\
25 & 18 \\
21 & 15 \\
16 & 12 \\
8 & 6 \\
7 & 5 \\
5 & 4 \\
18 & 12 \\
\hline
\end{tabular}

total not eligible for questionnaire

137

100

The total number of questionnaires mailed was 1065: 898 were retumed giving a response rate of $84 \%$. One hundred and twenty-six patients refused to participate in the study in this first phase. Consequently data of 772 patients were eligible for further investigation.

We made some comparisons to control whether the characteristics of people whose medical records were at our disposal differed from those whose medical records could not be investigated. The sex distribution of patients in both groups is 
represented in table 7.5. There is no statistically significant difference between the two groups. In table 7.6 the age distribution of the accessible group and not accessible group is represented. In this case there is a difference between the two groups. There were relatively more older people in the 'not accessible' group.

Figures in subsequent paragraphs refer to the $7 / 2$ patients whose medical records were accessible.

Table 7.5. Gender of patients whose medical records were accessible compared with patients whose records were not accessible and consequently were to be excluded.

\begin{tabular}{|c|c|c|c|c|c|c|}
\hline \multicolumn{3}{|c|}{ recorda aceessible } & \multicolumn{2}{|c|}{ ecords not accessible } & \multicolumn{2}{|c|}{ total } \\
\hline & s & 8 & $\mathrm{n}$ & \% & $\mathbf{n}$ & $\%$ \\
\hline mes & 216 & 28 & 110 & 26 & 326 & 27 \\
\hline women & 556 & 72 & 319 & 74 & 875 & 73 \\
\hline total & 772 & 100 & 429 & 100 & $* 1201$ & 100 \\
\hline
\end{tabular}

$p=.38$

- 1 patient gender unknown.

Table 7.6. Age of patients whose medical records were accessible compared with patients whose records were not accessible and consequently were to be excluded.

\begin{tabular}{|c|c|c|c|c|c|c|}
\hline & \multicolumn{2}{|c|}{ records accessible } & \multicolumn{2}{|c|}{ ecords not accessible } & \multicolumn{2}{|c|}{ total } \\
\hline & A & $\pi$ & $\mathbf{n}$ & \% & n & 5 \\
\hline $65-74$ & 363 & 47 & 165 & 39 & 527 & 4 \\
\hline 75.84 & 322 & 42 & 187 & 44 & 509 & 42 \\
\hline $85+$ & 88 & 11 & 76 & III & 164 & 14 \\
\hline total & $m$ & 100 & 428 & 100 & $\bullet 1200$ & 100 \\
\hline
\end{tabular}

$p<0.01$

* exact year of birth of two patients unknowa. 
The questionnaire asked patients why they were using diuretic drugs. High blood pressure was reported as indication by $315(40 \%)$ of the respondents. Use for swollen ankles was mentioned 302 times (39\%), and use for "fluid in the lungs" 92 times (12\%). Fifty-three patients (7\%) indicated their ignorance of why they were using diuretics. When interpreting these figures one has to bear in mind that respondents were able to state several reasons for using diuretics.

Besides asking the patients, we also asked their physicians the majos indication for prescribing these patients diuretics. Indications for diuretic prescription according to the general practitioners were as follows: hypertension: 426 (55\%); heart failure: 178 (23\%); foot or ankle oedema: 103 (13\%); unknown: 41 (5\%); others: 24 (3\%).

These figures reveal a striking difference between the opinion of the patients and the physicians about the reason of using diuretics. From both points of view hypertension is the most frequently mentioned indication, but oedema is far more often given as a reason by patients than by the general practitioners. In table 7.7 we compare the patient's and doctor's opinion about the reason of diuretic use regarding the indications hypertension and oedema separately. In both cases kappa values are low: for oedema agreement is poorer than for hypertension.

With respect to the 302 cases in which the patients reported using diuretics for oedema, the indications according to their doctors were hypertension in 118 cases (39\%), heart failure in 83 cases (28\%), pedema in 79 cases (26\%), 15. (5\%) unknown and 7 (2\%) other reasons for diuretic use.

The data obtained from the medical files were combined with those obtained from the questionnaire to investigate which patients were eligible for the trial. The results of the third stage of the selection procedure are given in the next paragraph. 
Table 7.7. Agreement between doctors and patients about indication for diuretic use.

\section{hypertension}

Cohens' kappa $=0,48$ oedema

doctor

Cohens' kappa $=0.24$ patient

\begin{tabular}{|c|c|c|c|}
\cline { 2 - 4 } \multicolumn{1}{c|}{} & + & - & Lotal \\
\hline+ & 268 & 158 & 426 \\
\hline+ & 47 & 299 & 346 \\
\hline total & 315 & 457 & 772 \\
\hline
\end{tabular}

patient

\begin{tabular}{|c|c|c|c|}
\cline { 2 - 4 } \multicolumn{1}{c|}{} & + & $\cdot$ & total \\
\hline+ & 79 & 24 & 103 \\
\hline$*$ & 223 & 446 & 669 \\
\hline total & 302 & 470 & 772 \\
\hline
\end{tabular}

\subsection{Results of the third phase:}

further investigation of the questionnaires and patient records

In the thind phase of the selection we were able to sereen those people aged 65 years or older who had a prescription for diuretics. The main objective was to find people who used diuretics for ankle oedema irrespective of the cause of the oedema.

The screening was conducted on the basis not only of information the patients provided in the questionnaire but also of information we obtained from their general practitioners. The total number of patients we were able to screen in this phase was $7 / 2$ (see paragraph 7.4). First patients who used diuretics for ankle oedema had to be identified. The following patients were selected:

1. those who reported in the questionnaire that they used diuretics for ankle oedema;

2. those whose general practitioners reported that the indication for diuretic use was 
ankle oedema;

3. those whose general practitioner reported that the indication was heart failure.

The third criterion was added because we assumed we would find patients with ankle oedema eligible for the trial in the group with the indication heart failure (see chapter 4 and paragraph 6.3.2).

In 427 cases at least one of these criteria was met. In table 7.8 the reasons are presented why patients from this group had to be excluded after further investigation of medical records or consultation of the general practitioner. In the first place some patients were identified who did not use diuretic drugs any more. These were patients who recently stopped using diuretic drugs or patients who had had an incidental prescription. As already mentioned in the previous paragraph the information obtained from the patients and doctors often differed. Especially in the case of patients who stated they used diuretic medication for oedema, the indication according to the general practitioner often was hypertension or heart failure (paragraph 7.5). In these cases we had to decide whether withdrawing diuretics was appropriate within the scope of the trial. Paragraph 6.2 .2 describes how the exclusion criteria were applied in these cases. In 16 cases miscellaneous reasons rendered patients ineligible at second instance, for example patients who were seriously ill or had recently moved. Also some patients appeared to have additional indications for diuretic use eg. prescription by a lung specialist in the case of pulmonary problems. Ultimately 141 patients met the criteria for phase IV, the inclusion procedure.

\subsection{Results of the inclusion procedure}

In this paragraph we present the results of the fourth phase of the selection, the inclusion procedure. Its aims and the way how it was carried out are described in paragraph 6.3.4. This procedure was used to select the eventual patients for the trial from the population previously defined on the basis of the preceding phases. 
Table 7.8. Results of second phase of the selection.

medical rocords of patients

checked on basil of the questionnaire

not eligible for trial:

diuretics not for oedema

345

no diuretica

excluded on grounds of exclusion criteriat

diuretics for hypertension

Jess than 1 dose/week

risk heart failore

arrhythmia

renal dyafunction

dementia

niscellaneous reasons

patients eligible for inclusion procedure

After phase III, 141 patients fulfilled the rough criteria for entering the trial. These patients were invited to meet the investigator. Table 7.9 presents the results of this procedure.

The table is divided in 4 categories of reasons why patients did not enter the trial after being screened with the inclusion procedure.

- Category A contains the group of patients who refused further participation after being informed about the procedure and the aims of the trial.

- Category B contains the patients who were wrongly selected because of obsolete or insufficient data. Since we intended to prevent incorrect exclusion, all the patients for whom we did not find strong reasons for their nonparticipation in the trial were a priori 'included'. As a result some patients were selected for phase IV in the preceding phases, who had used diuretics in the past but had stopped, or used diuretics for reasons other than ankle oedema.

- Category $\mathrm{C}$ contains the patients who met our a priori inclusion criteria but who after examination had to be excluded on grounds of the exclusion criteria.

- Category D contains, the patients who were eligible to enter the trial but 
eventually did not participate.

Those three patients from the last category did not participate in the trial for the following reasons. Two patients were clients in a large practice at one and a half hour's travelling distance from Maastricht. As we expected to find a substantial number of eligible patients there, the practice was initially incorporated in the group where the trial was to take place. However, since only two patients proved to be eligible, the trial was not conducted in this practice for reasons of efficiency. One eligible patient from another practice had stopped the diuretic therapy on his own initiative independent of the randomization.

Thus finally 63 patients started in the trial.

\subsection{Overview of results of selection method}

In table 7.10 and figure 7.1 an overview is given of the complete selection procedure, starting from the point where the patients were selected on the basis of age and use of diuretic drugs. In figure 1 a flow diagram of the selection procedure is presented. For each phase the number of patients who were not included can be identified. The corresponding reasons why patients were not included are mentioned on the left side of the figure. Besides the flow diagram, table 7.10 shows the selection procedure indicating the reasons for the exclusion in each phase of the number of patients from participating in the trial. The numbers at the head of each column represent the number of patients, at the start of each phase. In each row the reasons are given why patients did not enter the trial.

Detailed explanation of each exclusion reason have been dealt with in the previous paragraphs. The item "diuretics not for oedema" concerns the patients who did not fulfill the criterion: using diuretics for ankle oedema irrespective of its cause (see paragraph 7.6). The item 'no diuretics' indicates the number of patients that had to be excluded because they had stopped diuretic use or were taking an insufficient dose to be included.

The area of the table below the first double line concerns the patients of the target 
Table 7.9. Results of inclusion procedure.

patients invited for a consultation

reason for not entering the trial

A. refused cooperation

B. at eligible because:

no diuretica

reasons other than oedema for using diuretics:

diuretics for hypertension.

'prescribed by GP to prevent ulcus cruris"

'diuretics pressribed by luag specialist'

'regulation of miction'

C. excluded on grounds of exclusion criterin

lees than 1 dose/week

risk heart failure

cardiac arrhythmia

kidney dysfunction (ereatinine $>200$ )

dementia

crura! ulcus

1

1

Ireatment with compressive bandage

D. lost before start of the trial:

patients in withdrawn practice

patient stopped on his own initiative

population; patients of 65 years and older who used diuretics for ankle oedema, including the patients with the 'doctor's indication' heart failure, Of the 772 patients whose medical data were accessible, $383(49.6 \%)$ fulfilled that criterion. On the 
basis of the questionnaire and first screening of medical files alone, 427 patients seemed to meet this criterion (see also paragraph 7.6). However, in the third and fourth phase it appeared that 44 of those patients did not use diuretics or in a very low dose, or used them not because of ankle oedema. Thus the ultimate number of patients of the target population amounted 383 . Ultimately only in 66 cases (17\% of the target population) stopping diuretics for the trial appeared be possible without any contra-indication. The risk of developing problems of heart failure after withdrawing diuretic therapy according to our criteria was reason for exclusion in $53 \%((183+19) / 383)$ of the cases. In $18 \%(69 / 383)$ of the cases diuretic therapy could not be withdrawn because of current treatment for hypertension.

It is important to keep in mind that in this case hypertension, risk of heart failure, cardiac arrhythmia and renal insufficiency should not be considered as strong indications for not withdrawing diuretics, but as reasons for us to rule patients ineligible for the trial. In our opinion on the other hand, this illustrates the difficulty of withdrawing diuretics, once they have been prescribed for any reason. Although strictly speaking there might be no hard indications for the use of the diuretics, withdrawal often seems to yield a kind of risk.

Special attention was paid to the exclusion procedure considering the patients whose indication for using diuretics was heart failure. As described in chapter 4, we assumed that a considerable proportion of the patients with the diagnosis of heart failure may in fact have had ankle oedema caused by venous insufficiency and not by heart failure. In that case diuretic therapy could be withdrawn in the trial. In table 7.11 the results are presented of the exclusion procedure of patients with heart failure as indication for diuretic use. In the vast majority of the cases we had to decide not to stop the diuretics treatment. These were the cases in which the patients met our criteria to exclude patients because of the risk of developing heart failure. For this special category only 4 out of 178 patients were eligible to enter the trial. 
Figure 7.1 Flow diagram of exclusion procedure

$$
\begin{aligned}
& \text { patients } 65+\text { and } \\
& \text { prescribed diuretics } \\
& \text { patients } 65+\text { and } \\
& \text { prescribed diuretics }
\end{aligned}
$$

$\infty$ questionnaire

no responsa

refusal

w tratment for oedema

no diuretica

Important additional indication

other

no treatment for oedema

no diuretics

important additional indication

unauitable for trial

refusal to participate is trial

lost before start of trial

total participants in trial
PHASE I

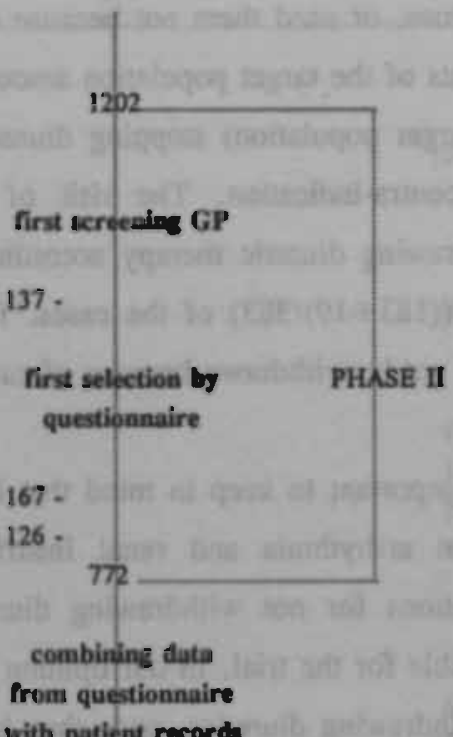

with patient record
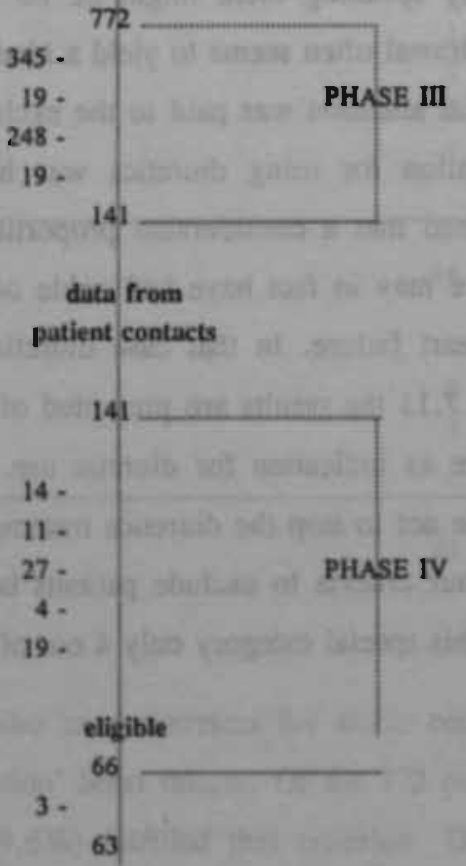

Chapter 7 
Table 7.10. Overview selection procedure, reasons why patients did not participate in the trial

PHASE

A at start

of each phase

1202

II

III

IV

bot.

\section{2}

14]

\begin{tabular}{|c|c|c|c|c|}
\hline no questionnaire & 137 & & & 137 \\
\hline no response & 167 & & & 167 \\
\hline objectioa & 126 & & & 126 \\
\hline diuretica not for eedema & & 345 & 14 & 359 \\
\hline no diuretics & & 19 & 11 & 30 \\
\hline
\end{tabular}

'Larget population' $n=383$.

$\begin{array}{lrrr}\text { riak heart failure } & 165 & 18 & 183 \\ \text { hypertension } & 69 & & 69 \\ \text { arthythmia } & 11 & 8 & 19 \\ \text { renal insufficiency } & 3 & 1 & 4 \\ \text { other } & 19 & & 19 \\ \text { unsuitable for trial } & & 4 & 4 \\ \text { refusal } & & 19 & 19\end{array}$

eligible for trial 66

last before start of tried 3

total participants 63

Chapter 7 
Table 7.11. Exclusion of patients with indication heart failure.

patients with indication heart failure: 178

Teasons for not entering the trial

\%

1. refused cooperation

4

2

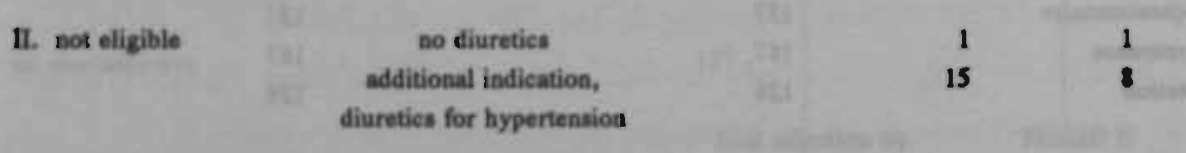

\begin{tabular}{|c|c|}
\hline $\begin{array}{l}\text { III. excluded because } \\
\text { of exclusion criteria }\end{array}$ & $\begin{array}{l}\text { risk for cardiac } \\
\text { insuffieiency } \\
\text { cardiae arrhythmia } \\
\text { kidney dyafunction } \\
\text { others }\end{array}$ \\
\hline
\end{tabular}

eligible

$136 \quad 76$

$\begin{array}{cc}12 & 7 \\ 1 & 1 \\ 5 & 3\end{array}$

7.9 Comparison and discussion regarding sex and age distribution of trial population and all patients selected on age and diuretic use

Due to the selection method we could expect that the characteristics of the population entering the trial would differ from those of the total population of patients aged 65 or older using diuretics. A comparison of the distribution of numbers of patients according to sex is represented in table 7.12. The lable shows that relatively more women than men were eligible to participate in the trial. On the basis of our data a definitive explanation cannot be given, but there are some reasonable hypotheses. Possibly more women use diuretics for ankle oedema. This can be due to a higher prevalence of ankle oedema in women or to the fact that women are more prone to consult their physician for the symptom ankle oedema than men. In the population investigated $66 \%$ of the women reported having 
Table 7.12. Comparison of gender of patients who participated in the trial with those who did not participate in the trial.

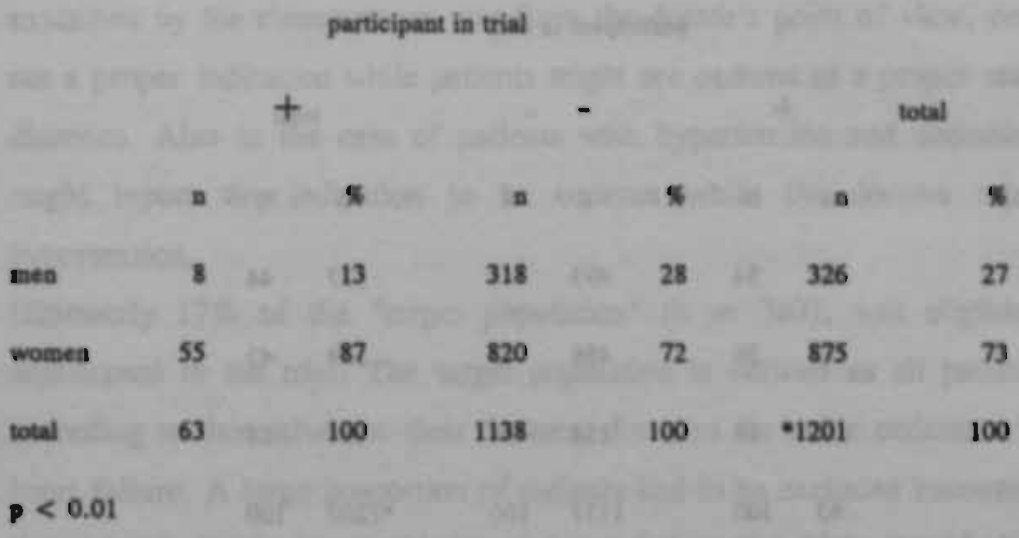

- 1 patient's gender unknown.

complaints of ankle oedema against $49 \%$ of the men (653 patients answered this question, $p<0.01)$. However, other reasons could have contributed to the fact that relatively more women than men were eligible for the trial. For instance, women could have been more cooperative about entering this research project.

In table 7.13 the age distribution of the entire group of diuretic users aged 65 or older is compared with the trial group. Participants in the trial were a slightly younger population than would be expected on the basis of the age distribution of the entire group. The most obvious reason is that as a result of our selection method relatively healthy subjects from the population of people aged 65 or older using diuretics were chosen. It is more likely to find no serious health problems in a 65 . year-old person than in a 90-year-old. Consequently the persons from the younger age category were more often eligible for the trial. 
Table 7.13. Comparison of age of patients who participated in the trial with those who did not participate.

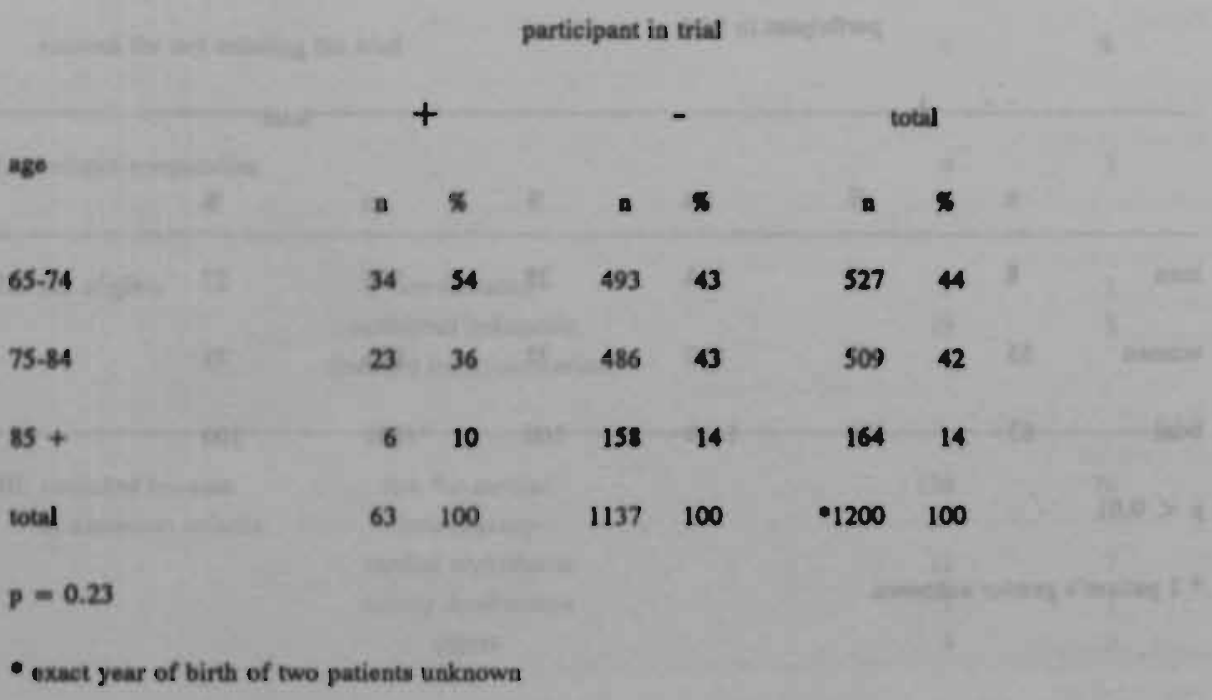

\subsection{Discussion}

On the basis of our research, we estimate that about $17 \%$ of the practice population aged 65 years and older are prescribed diuretic drugs. This figure is comparable to figures previous published based on the situation in the Netherlands.(3)(4) In our population, use of diuretics in the category women of 85 years and older is less compared to the sategory 75 to 84 years. Other studies (Walma et al, HaaijerRuskamp) showed an increase in the frequency of diuretic use with rising of age.(4)(5) Since it has been shown that in nursing homes the frequency of diuretic use is very high, our findings can possibly be explained by the circumstance that we screened a relatively healthy population who were not living in nursing homes.(6)

On being asked, $40 \%$ of the patients report using diuretics for hypertension and $39 \%$ for swollen ankles. If these patients' doctors are asked the indications for diuretic use, they state that in $55 \%$ of the cases the diuretics are prescribed for hypertension, in $23 \%$ for heart failure and in $13 \%$ for ankle oedema. By computing Cohen's kappa 
values for agreement regarding hypertension and ankle oedema, we demonstrated a considerable difference between the doctors and the patients about the reasons, for using the diuretic drugs. The low agreement in the case of oedema could be explained by the circumstance that from the doctor's point of view, oedema itself is not a proper indication while patients might see oedema as a proper reason for using diuretics. Also in the case of patients with hypertension and oedema, the patients might report the indication to be oedema while the doctors report it to be hypertension.

Ultimately $17 \%$ of the "target population" ( $\mathrm{n}=383$ ), was eligible for diuretic withdrawal in the trial. The target population is defined as all patients who used, according to themselves or their doctors, diuretics for ankle oedema with or without heart failure. A large proportion of patients had to be excluded because we estimated the risk of developing problems of heart failure too high should they stop using diuretic drugs. Another important group of patients used diuretics for hypertension also, in which case we had to exclude them too. Thus it appeared to be difficult to find patients in this population whose diuretic therapy could be stopped safely and appropriately. There are three additional explanations for this phenomenon.

- We acted very cautiously, since we did not want to take any risk that 2 patient would experience health problems as result of our trial.

- The problem of misuse of diuretics for ankle oedema is not as widespread as we thought based on literature and previous research.

- Once diuretic therapy is started it is difficult to withdraw diuretics because "contra-indications" for stopping diuretics are present in a substantial number of patients.

The last point illustrates why, once diuretic treatment is started, it is very difficult to cease the therapy. This appeared to hold also when the diuretics were used for a relatively weak indication as ankle oedema.

We should stress that our findings cannot be interpreted as a recommendation against the withdrawal of diuretics in cases where they are prescribed because of heart failure or hypertension. Several earlier research projects gave indications that withdrawing diuretics even in these situations can be done safely in selected patients 
(chapter 3). However, since this question fell beyond the scope of our research project patients with these indications had to be excluded (with the exception of a proportion of the patients who used diuretics because of ankle oedema and high blood pressure, see paragraph 6.3 .2 ). An answer to this problem probably will be provided by the work of Walma et al.

Another important conclusion can be drawn from the results of our selection procedure. In chapter 4 we discussed the case where diuretics are prescribed for the indication heart failure, and argued that the diagnosis in a number of cases was presumably made on insufficient grounds. We presumed ankle oedema caused by venous insufficiency to be a deceptive symptom that could erroneously lead to the diagnosis of heart failure. However, in the population we investigated, only 4 out of 178 of the patients with the indication of heart failure were eligible to participate in our trial. Even including 4 patients who refused informed consent, only 8 patients would be eligible. Thus in our study population only a small minority of patients with the indication of heart failure actually used diuretics for the symptom ankle oedema while the diagnosis of heart failure could not be confirmed.

We conclude that each doctor should make a thorough evaluation of the necessity of diuretic therapy before prescribing diuretics since withdrawal of the therapy will at least be complicated by several contra-indications, which could reinforce the undesirable situation of widespread chronic diuretic use in the elderly. 
1. Anonymus. Tractus Uropoêticus Diuretica. In: Nelemans FA ed. Farmacotherapeutisch Kompas. Amatelveen: Centrale Medisch Pharmaceutische Commissie van de Ziekenfondsraad, 1989: 362-5.

2. Cartwright A, Smith C. Prescribed nedicines taken and kept by the elderly people. Elderly people, their medicines, and their doctors. 1st ed. London: Routledge, 1988: 15-36.

3. Branbergen HCT. Welke pil alikt de 65-plusser? Huisarts en Wetenschap 1985; 28(suppl 9): 34-5.

4. Walma EP, Boukes FS, Prins A. Does E van der. Diureticagebruik door 65-pluasern in een buisartspraktijk. Huisarts en Wetenschap 1989; 32: 326-8.

5. Haaijer-Ruskamp FM. Geneesmiddelengebruik van ouderen. In: Goedhard WJA, Knook DL, editors. Ouderen en geneesmiddelen. Houten: Bohn Stafleu van Loghem, 1991: 9.25.

6. Bruijne GA de. Het geneesmiddelengebruik in verzorgingstehuizen een collectief probleem. Moderne Oeriatrie 1984; 4 : $151-2$. 


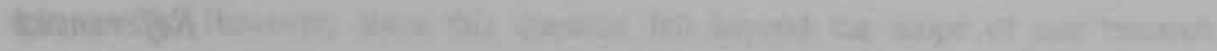

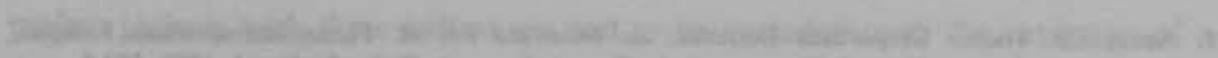

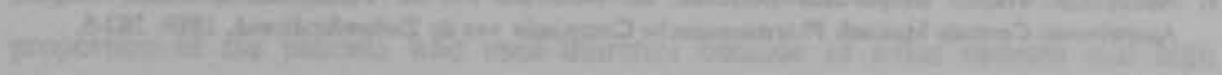

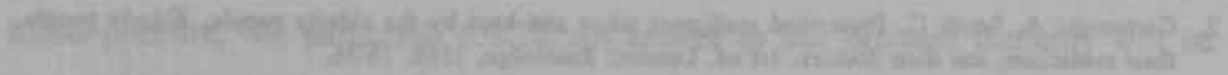

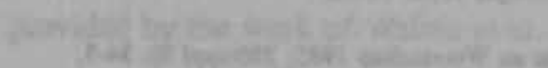

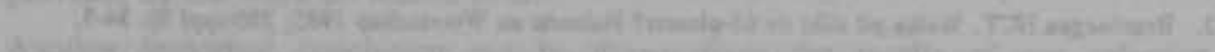
-

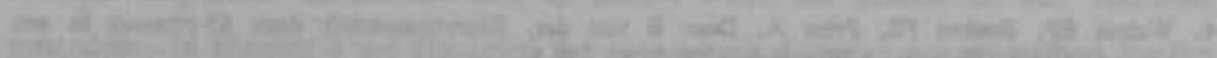
Wnity

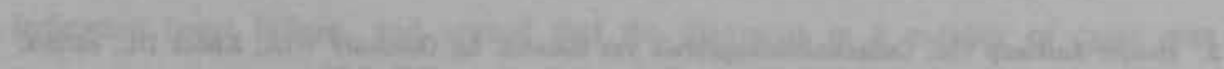

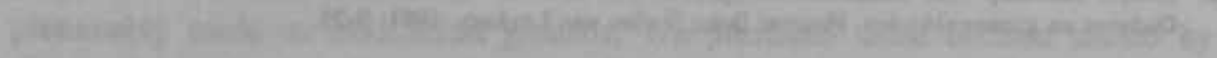

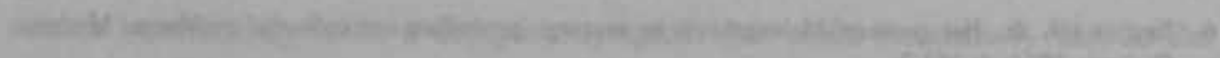

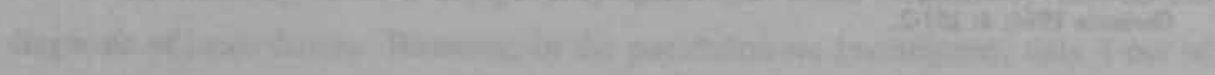

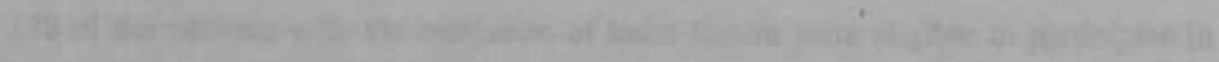

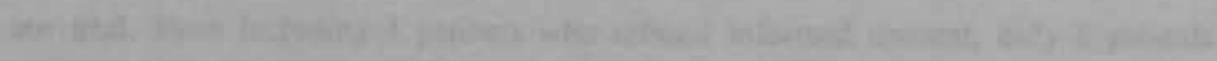

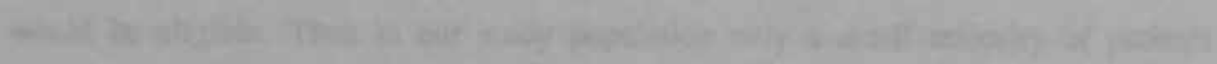

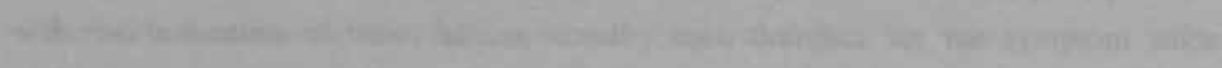

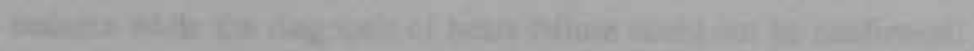

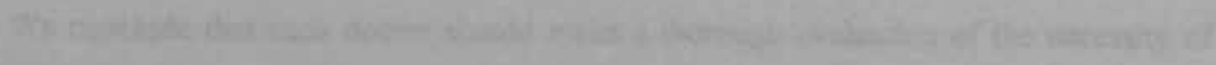

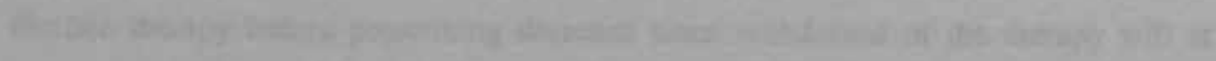

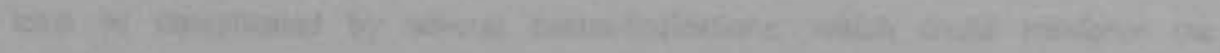

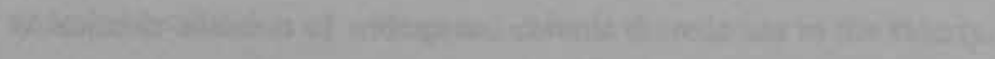




\section{Chapter 8}

Results of the trial 
8 Tathe

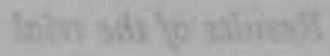


The results of the withdrawal trial and the additional follow-up procedure are presented in this chapter. The trial was performed to study the effect of withdrawing diuretic drugs, prescribed for ankle-oedema not caused by heart failure, renal or hepatic insufficiency. The chapter presents, in sequence, a description of the patients who participated in the trial; patients who dropped out during the trial; complaints of patients during the trial; compliance of patients to our instructions; effects of withdrawal on oedema in objective and subjective measures; additional measurements and the post experimental follow-up. In the final paragraph the results are discussed.

\subsection{Patients participating in the trial}

In this paragraph a description is given of the main characteristics of the patients participating in the trial. The aim of this paragraph is in the first place to provide a profile of the patients in this trial and in the second place, to check the withdrawal group and the control group on their main characteristics in order $\omega$ find out whether they are comparable.

The selection method described in the previous chapters has resulted in a number of 63 patients who entered the trial. As mentioned in paragraph 6.3 .1 it was important to randomize the patients to both groups per practice. The result of our randomization method is presented in table 8.1 , which indicates that the random allocation per practice has functioned satisfactorily.

Table 8.2 shows the main features of the people who participated in the trial. In this table the withdrawal group is compared to the control group.

Besides age and gender, items presented in the table are:

- Indication for using diuretics according to the information provided by the patient's general practitioner, classified as: unknown, hypertension, oedema, and heart failure. 
Table 8.1. Result of randomization per practice.

\begin{tabular}{|c|c|c|c|}
\hline \multirow{2}{*}{} & \multicolumn{2}{|c|}{ Randomization } & total practics \\
\cline { 2 - 4 } & practica & control & \\
\hline I & 3 & 0 & 6 \\
\hline II & 3 & 3 & 6 \\
\hline III & 2 & 3 & 4 \\
\hline IV & 2 & 2 & 3 \\
\hline V & 1 & 1 & 2 \\
\hline VI & 1 & 1 & 2 \\
\hline VII & 2 & 1 & 4 \\
\hline VIII & 2 & 2 & 4 \\
\hline IX & 2 & 2 & 4 \\
\hline X & 2 & 2 & 4 \\
\hline XI & 3 & 2 & 5 \\
\hline XII & 3 & 2 & 10 \\
\hline XIII & 3 & 5 & 4 \\
\hline XIV & 2 & 1 & 3 \\
\hline XV & 1 & 1 & 2 \\
\hline
\end{tabular}

- Actually five patients were randomized in this practice but pae patient (allocated to the withdrawal group) droppes out before the interventios period.

- The presence or absence of pitting oedema at the start of the trial. A patient was defined as positive with respect to the presence of oedema when at least in one ankle (pre-tibial andlor retro-malleolar) pitting oedema could be proven.

- Used type of diuretics: loop diuretics (frusemide or bumetanide) or others.

- Frequency of diuretic use, divided in at least one daily dose or less.

- Symptoms of chronic venous insufficiency (CVI). We have defined a patient as 
Table 8.2. Baseline characteristics of withdrawal - and control group.

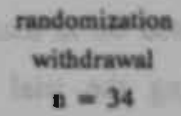

gender:

women

men

age:

$$
\begin{aligned}
& 65-74 \text { yeam } \\
& 75-84 \text { years } \\
& 84 \text { and older }
\end{aligned}
$$

indication:

$$
\begin{aligned}
& \text { unknows } \\
& \text { bypertenaion } \\
& \text { oedema }
\end{aligned}
$$

heart failure

pitting oedema:

present

absenit

type of diuretic:

loop diuretic

other

dosage:

1 daily dose

$<$ I daily dose

signs of chronic venous insuffiency:

present

absent

compression therapy:

$\begin{array}{ll}\text { used } & 3 \\ \text { not uaed } & 31\end{array}$

24

10

19

10

5

control

$\mathrm{B}=29$

30

25

4

4

15

13

-

2 I

1209

$19 \quad 16$

1 3

14

14

20

15

13

21

14

15

27

19

7

10

21

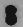

35

$31 \quad 24$

dietary salt:

$\begin{array}{lc}\text { restricted } & 9 \\ \text { not restricted } & 25\end{array}$

7

22

mobility:

inactive

8

2

26

No aignificant differences $(9<.05)$ were found betwees the groups on each characteristic. 
positive with respect to symptoms of CVI when at least in one leg, the symptoms ankle flare or hemosiderine pigmentations were observed.

- Compression treatment. Patients who used on at least one leg an elastic stocking (compression grade I, II or III) during the trial were considered as having compression treatment.

- Dietary salt intake, in categories high and low. Patients were considered as having a high salt intake when they reported eating meals in which salt was used during preparation. Patients who reported only eating meals in which no salt was used during preparation or even used unsalted products were considered as having a low salt intake.

- Mobility. It was expected that a part of the patients had dependent oedema caused by a sedentary daily life. During the visits of the patients we assessed this aspect. Patients with a sedentary life were classified in low mobility, others were classified normal.

No statistically significant differences in the observed frequencies of characteristics between the experimental groups were shown.

In total, pitting oedema was present at start of the trial in 28 patients $(44 \%)$. Signs of CVI were present in 45 patients $(71 \%)$. Compression therapy was used by $13 \%$ of the people entering the trial and a low sodium diet was used by $25 \%$.

We paid special attention to the use of drugs that are known to have oedema as a possible side-effect, there appaered to be no relevant difference between both groups regarding the use of those drugs (table 8.3 ).

The diuretics used by the patients at trial entry are presented in table 8.4. A distinction is made between different administration types: single preparation use, fixed-dose combination preparation use and use of single preparations together. The most frequently used diuretic drug in our patient group was hydrochlorthiazide, either alone or in combination with another diuretic (26 patients). Frusemide was the second most used drug (24 patients); one patient used both diuretics. 
Table 8.3. Use of co-medication in withdrawal group and control group at start of the experiment.

\begin{tabular}{|c|c|c|c|}
\hline & & $\begin{array}{l}\text { withdrawal } \\
\qquad \mathrm{n}=34\end{array}$ & $\begin{array}{l}\text { control } \\
a=29\end{array}$ \\
\hline $\begin{array}{l}\text { beta-blocking } \\
\text { drugs }\end{array}$ & $\begin{array}{l}\text { not used } \\
\text { used }\end{array}$ & $\begin{array}{c}34 \\
0\end{array}$ & $\begin{array}{c}28 \\
1\end{array}$ \\
\hline $\begin{array}{c}\text { calcium- } \\
\text { antagonists }\end{array}$ & $\begin{array}{l}\text { not used } \\
\text { used }\end{array}$ & $\begin{array}{l}32 \\
2\end{array}$ & $\begin{array}{l}26 \\
3\end{array}$ \\
\hline $\begin{array}{l}\text { ACE- } \\
\text { inhibitors }\end{array}$ & $\begin{array}{c}\text { not used } \\
\text { used }\end{array}$ & $\begin{array}{l}34 \\
0\end{array}$ & $\begin{array}{l}28 \\
1\end{array}$ \\
\hline $\begin{array}{c}\text { other } \\
\text { vasodilutors }\end{array}$ & $\begin{array}{l}\text { not used } \\
\text { used }\end{array}$ & $\begin{array}{l}32 \\
2\end{array}$ & $\begin{array}{r}26 \\
3\end{array}$ \\
\hline digitalis & $\begin{array}{l}\text { not used } \\
\text { used }\end{array}$ & $\begin{array}{l}31 \\
3\end{array}$ & $\begin{array}{l}29 \\
0\end{array}$ \\
\hline
\end{tabular}

\subsection{Patients who restarted diuretic therapy during the trial}

In this paragraph the patients who restarted using diuretics during the follow-up period are described. At start of the trial 34 patients stopped diuretic drug use, while 29 patients continued diuretic use as in the preceding period. Restarting diuretic therapy occurred in eight patients from the withdrawal group (from the control group none of the patients stopped diuretic use during the follow-up period). In table 8.5 characteristics of patients in whom diuretic therapy was restarted are presented. In three cases patients developed symptoms suggesting heart failure, making us decide to resume diuretic therapy (patients $D, E$ and $G$ ). Two of them (patients $D$ and E) showed increase of weight and oedema, complaints of fatigue and dyspnoea. Restarting diuretics relieved the problems within one day. One woman of 88 years (patient $G$ ) developed such strong oedema that we decided to resume diuretic therapy. Although she did not have complaints of dyspnoea or other symptoms of 
heart failure we did not want to take the risk of development of stronger fluidretention. Also in this case the symptoms quickly retumed to the level before the intervention.

Table 8.4. Diuretics used by the participants at start of the trial.

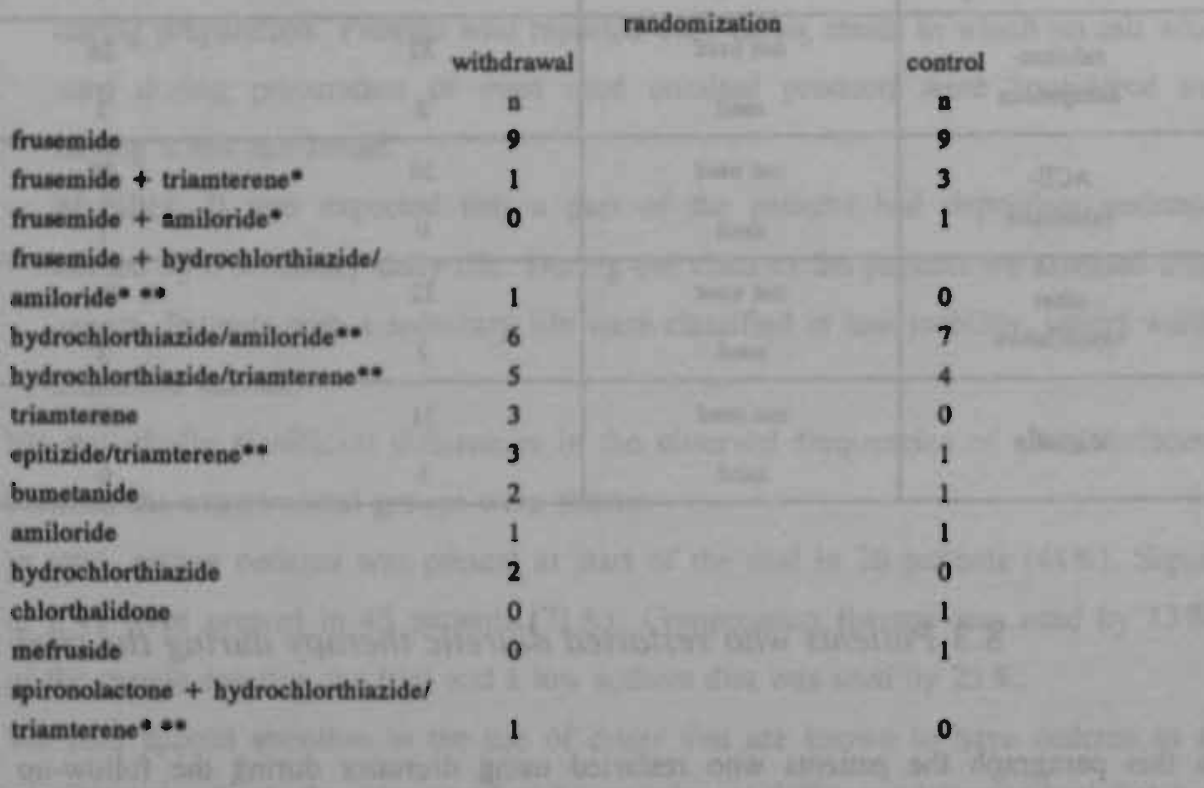

total

34

29

- some patients used two diureties

** fixed combination preparation.

One patient (B) showed after five weeks a systolic blood pressure reading of 220 mmHg which made us decide to resume diuretic therapy. Two patients ( $\mathrm{A}$ and $\mathrm{H}$ ) who initially agreed to cooperate with the tria! changed their minds within the first week. They reported being bothered by the visits for the measurement procedures and were worried about negative consequences of the withdrawal of diuretic use. One patient $(\mathrm{H})$ expressed strong feelings of being unwell, experienced increased trouble with incontinence of urine and insisted on resuming diuretic therapy; 
although strictly spoking there was no indication, diuretic use was restarted. Another patient (F) left unexpectedly for a holiday trip. Since she was afraid of developing stronger ankle oedema during the air trip she intended to make, she restarted diuretic use.

The mean age of patients in cases where withdrawal failed was 78 , while the mean age of patients in whom withdrawal was successful was 75 years. This difference appeared to be not significant.

After patients dropped out, no more follow-up measurements were obtained, thus in those cases data of the total six-week follow-up period were not available for analysis. The results in the following paragraphs are based on the 55 patients who completed the total follow-up period. The eight patients in whom diuretic therapy was restarted were excluded. Only the data concerning complaints of patients during withdrawal of diuretics are based on observations obtained from all participants.

\subsection{Complaints of patients during the trial}

In this paragraph a description is given of recorded complaints during follow-up. We recorded the complaints patients reported to us at the monitoring visits. Only complaints concerning shortness of breath and oedema were asked for explicitly. Other complaints were recorded after being mentioned spontaneously by patients. Complaints concerning oedema will be described in paragraph 8.7.

Table 8.6 shows the number of patients of each group reporting at least once during the follow-up period shortness of breath. The number of patients with complaints of dyspnoea seemed to be higher in the withdrawal group.

In table 8.7 complaints except dyspnoea or oedema are listed as reported by the patients during the follow-up period. Most complaints were recorded from patients in the withdrawal group. Some complaints could be explained by an altered balance of the salt and water homeostasis, for example bloated feelings, feelings of swollen eyes or face and nycturia. Also complaints concerning pain in the legs or knees seemed to occur somewhat more often in the withdrawa! group than in the control 
Table 8.5. Summary concerning patients in whom diuretic therapy was restarted. The data presented concerns age, gender, indication for diuretic use according to the general practitioner, co-morbidity of patients, type and dosage of used diuretic, number of the day when therapy was restarted, reason for restarting therapy and relevant complaints and symptoms at moment of restarting therapy.

\begin{tabular}{|c|c|c|c|c|c|c|c|c|}
\hline putiens & age & $\operatorname{sex}(I)$ & $\begin{array}{l}\text { indica-rion of } \\
\text { GP }\end{array}$ & co-morbid. & diwrestic (3) & $\begin{array}{l}\text { diny of } \\
\text { nestart } \\
\text { thenspy }\end{array}$ & $\begin{array}{l}\text { neapon } \\
\text { for } \\
\text { reanar }\end{array}$ & $\begin{array}{l}\text { examinationt } \\
\text { rener (5) }\end{array}$ \\
\hline$A$ & 78 & f. & ocdema & parkisis-anoists & $\begin{array}{l}\text { frus. } \\
40 \text { me/d }\end{array}$ & 2 & $\begin{array}{l}\text { coucern, } \\
\text { bochered } \\
\text { by measure-tnents }\end{array}$ & $\begin{array}{l}\text { no relevast } \\
\text { changen }\end{array}$ \\
\hline B & 83 & f. & lypert. & $\begin{array}{l}\text { pulm- } \\
\text { embolism }\end{array}$ & $\begin{array}{l}\text { trus: } \\
40 \mathrm{mg} / \mathrm{d}\end{array}$ & 30 & $\begin{array}{l}\text { SBP (4) } \\
220 / 95 \mathrm{mmH}^{2}\end{array}$ & $\begin{array}{l}1 \mathrm{~kg} \text { wght }+ \text {. } \\
\text { fatigue }\end{array}$ \\
\hline c & 81 & f. & oederna & parkin-sonism & $\begin{array}{l}\text { b-chl-th/ } \\
\text { triamt. } \\
75 \mathrm{mg} 2 / \mathrm{w} \\
\text { opiro-lact. } \\
25 \mathrm{mg} / \mathrm{d}\end{array}$ & = & $\begin{array}{l}\text { concern, } \\
\text { presuare of marroun- } \\
\text { dings } \\
\text { (connent) }\end{array}$ & $\begin{array}{l}\text { no relevant } \\
\text { charngea }\end{array}$ \\
\hline D & 67 & m. & aedema & COPD (2) & $\begin{array}{l}\text { bumet. } \\
2 \mathrm{mg} / \mathrm{d}\end{array}$ & 19 & $\begin{array}{l}\text { retention of iluid and } \\
\text { salt }\end{array}$ & $\begin{array}{l}\text { dyspnoea, wghtt. } \\
\text { Dedema, pulm. } \\
\text { erackelis }\end{array}$ \\
\hline
\end{tabular}




\begin{tabular}{|c|c|c|c|c|c|c|c|c|}
\hline parien? & age & $\operatorname{sex}(I)$ & $\begin{array}{l}\text { Indica-den of } \\
\text { GP }\end{array}$ & co-morbld. & disneric (3) & $\begin{array}{l}\text { dayy of } \\
\text { restars } \\
\text { therapy }\end{array}$ & $\begin{array}{l}\text { reason } \\
\text { for } \\
\text { nestary }\end{array}$ & $\begin{array}{l}\text { camikation } \\
\text { at } \\
\text { reatart (S) }\end{array}$ \\
\hline$E$ & 84 & 1. & $\begin{array}{l}\text { bypert. } \\
\text { cederna }\end{array}$ & & $\begin{array}{l}\text { h-chl-th/ } \\
\text { amiloride } \\
55 \mathrm{mg} 2 / \mathrm{w}\end{array}$ & 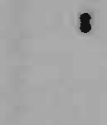 & $\begin{array}{l}\text { retention of fluid and } \\
\text { salt }\end{array}$ & $\begin{array}{l}\text { dyrenoea, wght, } \\
\text { codema pulm. } \\
\text { crackels }\end{array}$ \\
\hline $\mathbf{F}$ & 72 & f. & hypert. & & $\begin{array}{l}\text { b-chl-th/ } \\
\text { amiloride } \\
5 S \mathrm{mg} / \mathrm{w}\end{array}$ & 16 & $\begin{array}{l}\text { concern for } \\
\text { development of } \\
\text { oedema during } \\
\text { holiday }\end{array}$ & $\begin{array}{l}\text { no relevant } \\
\text { changes }\end{array}$ \\
\hline $\mathbf{6}$ & 58 & f. & oedema & & $\begin{array}{l}\text { frus. } \\
\text { triamt. } \\
40+50 \mathrm{mg} / \mathrm{d}\end{array}$ & 15 & $\begin{array}{l}\text { retentios of fuid and } \\
\text { salt }\end{array}$ & $\begin{array}{l}\text { strong oedema and } \\
\text { wght t. }\end{array}$ \\
\hline$H$ & 74 & c. & hypert. & & $\begin{array}{l}\text { bumel. } \\
1 \mathrm{mg} / \mathrm{d}\end{array}$ & 5 & $\begin{array}{l}\text { unwell- } \\
\text { feeling- complaints } \\
\text { of incon-tisence and } \\
\text { nycturis }\end{array}$ & $\begin{array}{l}\text { no relevant } \\
\text { cluanges }\end{array}$ \\
\hline
\end{tabular}

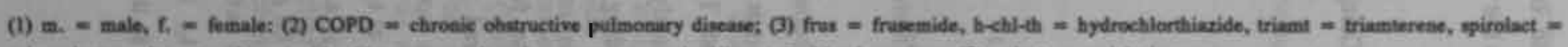
spirveolactone, bumet = bumetanide, Id meana per day, hw means per week; (4) systolic blood preanure; (5) waht $+=$ wreight increase. 
group. These complaints, however, were of a nature that could not clearly be attributed to the increase of oedema.

Table 8.6. Complaints of dyspnoea.

$\begin{array}{lrcr} & \begin{array}{c}\text { withdrawal } \\ \text { group }\end{array} & \begin{array}{c}\text { control } \\ \text { group }\end{array} & \text { total } \\ \text { dyspnoea } & 9 & 2 & 11 \\ \text { no dyspooea } & 25 & 27 & 52 \\ \text { total } & 34 & 29 & 64\end{array}$

$0.05<p<0.1$

\subsection{Compliance to the intervention}

To check whether the participants were compliant with the instructions to cease or continue diuretic use we collected urine samples for analysis on the presence of the diuretics used. Table 8.8 presents the results of these analyses. These are divided in positive, possibly positive and negative. Results were defined possibly positive when the diuretic drug was detectable in the urine but the concentration was too low for a definitive confirmation. The method we used was feasible for 53 of the patients who completed the follow-up. Two patients used diuretics (bumetanide and mefruside) which required a too complicated method of analysis. Therefore in these cases analysis was not executed. At $t_{\eta}$ one patient could not provide us with a urine sample: thus at $h$, one urine sample could not be determined.

At base line in 44 of 53 cases ( $83 \%$ ) presence of the expected diuretic could possibly or definitely be demonstrated. At $t_{2} 89 \%(23+24 / 53)$ of the cases matched closely the expected outcome; in the withdrawal group the compliance was at least $24 / 26$ (92\%). At $\mathrm{h}, 88 \%$ of the participants were found to be compliant with the instructions; in the withdrawal group this was at least $92 \%$. 
Table 8.7. Recorded complaints per patient other than dyspnoea or ankle oedema, during the follow-up period.

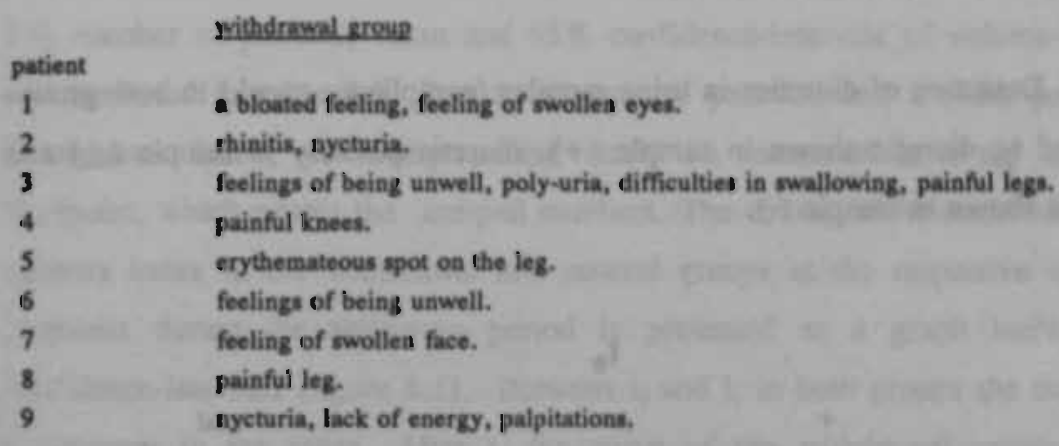

\section{sentrol exoup}

10

unwell, painful back, headache.

11

flu.

12 itching, redness, hot feeling of one leg.

\subsection{Course of oedema index after withdrawing diuretic drugs}

This paragraph describes the results of the objective assessment of the degree of ankle oedema during the trial. Firstly, we present crude analysis of the group means on the basis of the respective measurements on both extremities. Secondly, results are presented of a repeated measures analysing technique (BMDP SV) that gives the opportunity for including co-variables in the analysis and optimal interpretation in spite of missing data. Thirdly, we present an analysis when only the leg giving the most complaints is taken in account.

To measure in an objective way the degree of ankle oedema we applied a volumetric method (see 6.3.8). We calculated an index to express the relative changes in degree of oedema at the respective follow-up moments:

$\left[\mathrm{Vol}\left(\mathrm{L}_{\mathrm{L}}\right) \cdot \mathrm{Vol}\left(\mathrm{t}_{2}\right)\right] / \mathrm{Vol}\left(\mathrm{L}_{0}\right) * 100 \%=$ oedema index at $\mathrm{t}_{\mathrm{c}}$.

where: 
$\operatorname{Vol}(t)=$ (volume left foot + ankle $)+($ volume right foot + ankle) at $t$.

$\operatorname{Vol}\left(t_{0}\right)=($ volume left foot + ankle $)+($ volume right foot + ankle $)$ at $t_{0}$.

Table 8.8. Detection of diuretics in urine samples (compliance check) in both groups at $t_{0}, h$ and $h ;$ diuretic shown in sample $(+)$, diuretic possibly in sample $( \pm)$ and diuretic not shown in sample (-).

$\begin{array}{ccccc} & & \mathbf{C}_{0} & & \\ + & \pm & & \text { totad } \\ \text { withdrawal } & 18 & 2 & 6 & 26 \\ \text { control } & 22 & 2 & 3 & 27 \\ \text { total } & 49 & 4 & 9 & 53\end{array}$

$\begin{array}{ccccc} & & t_{2} & & \\ & + & \pm & - & \text { total } \\ \text { withdrawal } & 1 & 1 & 24 & 26 \\ \text { control } & 23 & 1 & 3 & 27 \\ \text { total } & 24 & 2 & 27 & 53\end{array}$

withdrawal

control

tota!

\section{0}

22

22

\section{$t_{1}$}

$\pm$

total

1 missing 
Oedema was measured at the start of the study ( $b_{0}$, baseline), on the second or third day of the first week $\left(t_{1}\right)$, on the fourth or the fifth day of the first week $\left(t_{2}\right)$ and thereafter once weekly for a total of six weeks $\left(t_{3}\right.$ to $\left.t_{7}\right)$ (paragraph 6.3.3).

The number of patients, mean and $95 \%$ confidence-intervals of volume-index at 4 are presented in table 8.9. Due to absence of patients, and a short period when instruments failed, not every patient could be measured at every observation timepoint, which causes the unequal numbers. The course of the mean values of the oedema index in the withdrawal and control groups at the respective observation moments during the follow-up period is presented as a graph including $95 \%$ confidence-intervals (figure 8.1). Between $L_{0}$ and $t_{1}$ in both groups the curve shows a decrease in the index. After $t_{1}$ the curve of the withdrawal group shows an ascending trend until $t_{4}$ when the maximum of $+3.5 \%$ is reached. After $t_{4}$ the curve shows a descending trend which continues until the last measurement. The curve of the control group shows a fluctuation between $0 \%$ and $-1.4 \%$, but does not show a significant increase or decrease over the complete follow-up period. From $t_{4}$ up to and including $t$ a significant difference between both group means can be shown.

Table 8.9. Calculated volume-index (mean and $95 \%$ confidence-interval) and number of patients at t for withdrawal-and control-group.

time

withdrewal-group yolume-index(\%)

- mean $95 \% \mathrm{Cr}$.

$\begin{array}{ccc}6 & 26 & 0 \\ t_{4} & 26 & -0.44 \\ 5 & 25 & 1.08 \\ 4 & 22 & 2.01 \\ 4 & 26 & 3.49 \\ 4 & 26 & 3.16 \\ 4 & 26 & 2.62 \\ 4 & 26 & 1.19\end{array}$

$(-1.53,0.65)$

$(-0.20,2.36)$

$(-0.26,-4.29)$

(1.80, 5.19)

(i.50, 4.82)

$(0.76,4.49)$

(-0.52, 2.91) control-group

yolume-index(\%)

$\begin{array}{ccc}\text { n } & \text { mean } & 95 \% \mathrm{Cl} . \\ 29 & 0 & \\ 29 & -1.27 & (-2.32,0.22) \\ 27 & -1.35 & (-2.64,0.06) \text {, } \\ 26 & -0.56 & (-1.88,0.77) \\ 29 & -1.18 & (-2.40,0.04) \\ 28 & -0.45 & (-1.71,0.81) \\ 28 & -0.84 & (-2.01,0.33) \\ 29 & -1.20 & (-2.37,-0.02)\end{array}$


Figure 8.1 Oedema index (mean and $95 \%$ confidence intervals) for both legs during the six week follow-up period: withdrawal group (O) and control group (").

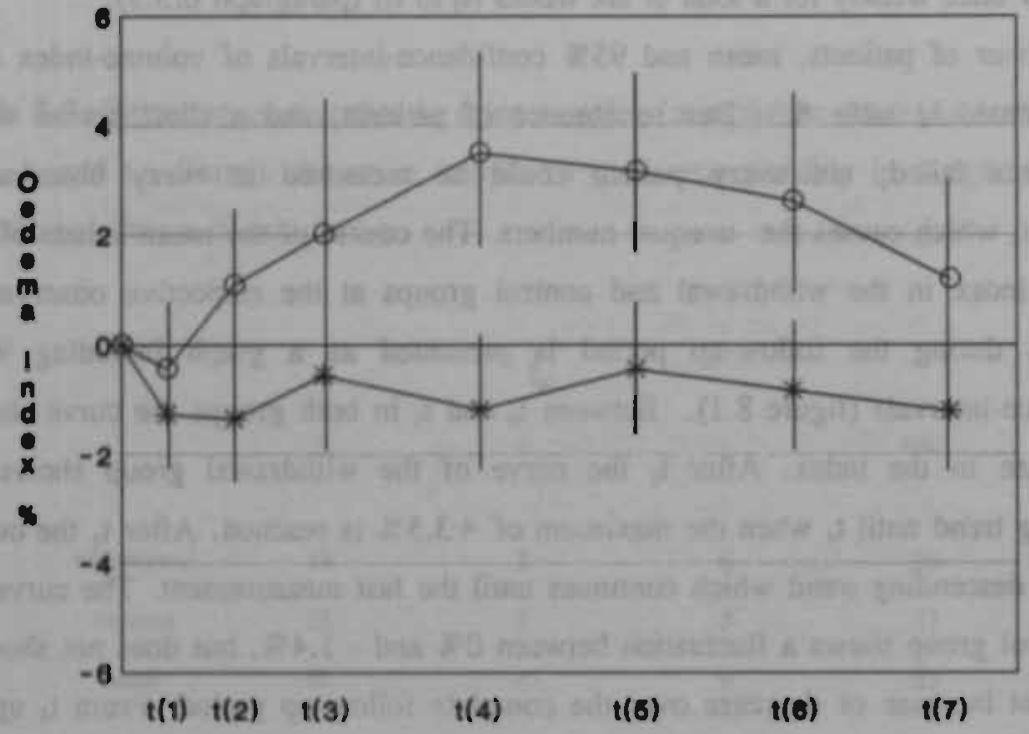

In order to control whether these results would still hold when account is taken of relevant co-variables and of the fact that some observations were missing, we used BMDP 5V. The following factors were checked as potential co-variables:

- Type of diuretic drug

Loop diuretics and other diuretics.

- Frequency of diuretic intake

One daily dose and less, than one daily dose.

- Mobility of the patient

Since we expected mobility of patients to have a reduction influence on oedema, patients who had a sedentary daily-life were defined as not mobile; others were defined as mobile.

- Time of day of the observation

We expected that ankle oedema would be more severe later in the day.

- Maximum day temperature, in the area of the location of observation We expected the oedema to be worse on "hot-days". 
- Symptoms of chronic venous insufficiency (CVI)

Patients with symptoms of CVI were expected to have stronger oedema than other patients; patients were categorized as presenting positive symptoms of CVI (at least one symptom except oedema) and no symptoms of CVI.

- Pitting oedema at base-line observation

Present or absent.

- Co-medication: Use of angiotensin converting enzyme inhibitors, beta-blockers, calcium re-uptake blockers other vasodilators or digitalis.

Not one of these variables appeared to have a significant effect on the estimation of the oedema index, if introduced as an independent co-variable in a full model. Consequently we decided to use the model as restricted to one independent variable, which represented whether the patient was allocated to the withdrawal group or the control group. When this model is used for the analysis, no significant difference in linear effect of the observation time between both groups is shown. However, a quadratic effect of the observation time clearly appears when both groups are compared (table 8.10). This gives a strong indication that the shape of the curves for both groups as constructed with the simple oedema index means is appropriate.

Table 8.10. BMDP SV analysis for time effect. The chosen independent variables with their estimated coefficients for the model to predict the oedema index curves for the withdrawal group and the control group.

$\begin{array}{lrrr}\text { parameter } & \text { estimate } & \text { Z-score } & \text { p-value } \\ & & & \\ \text { constant } & 0.010 & 1.77 & 0.08 \\ \text { withdrawal }^{*} & 0.017 & 3.05 & <0.01 \\ \text { time-linear } & 0.002 & 1.62 & 0.11 \\ \text { time-quadratic } & -0.002 & -5.07 & <0.01 \\ \text { withdrawat } \times \text { time-linear } & 0.001 & 1.40 & 0.16 \\ \text { withdrawal } x \text { time-quadratic } & -0.002 & -3.72 & <0.01\end{array}$

The banded covariance structure was chosen.

Each fixed effect of the model decomposed into single degree of freedom regression terms and covariates; is represented in the table.

"withdrawal: 1 = yes (withdrawal group), 0 = no (control group). 
In our population, a substantial group of patients reported having unilateral ankle oedema. We also constructed oedema index curves calculated on the basis of the leg that gave the most complaints according to the patient. Thus, in this situation:

$\left[\operatorname{Vol}\left(\mathrm{t}_{\mathrm{L}}\right)-\operatorname{Vol}\left(\left(\mathrm{t}_{0}\right)\right] / \mathrm{Vol}\left(\mathrm{t}_{0}\right) * 100 \%=\right.$ oedema index at $(\mathrm{t})$

where:

Vol $\left(t_{2}\right)=($ volume foot + ankle $)$ at $\left(t_{0}\right)+($ volume foot + ankle $)$ at $\left(t_{2}\right)$.

Vol $\left(t_{0}\right)=($ volume foot + ankle $)$ at $\left(\mathrm{t}_{0}\right)+($ volume foot + ankle $)$ at $\left(t_{0}\right)$.

Now (volume foot + ankle) is the result of the measurement of the volume of the affected leg (the same leg for each patient at all subsequent measurements). In case of symmetric bilateral oedema the mean of the oedema index of both legs was used. This curve is presented in figure 8.2. For this approach too a BMDP SV analysis was done, with similar co-variables as in the analysis on the basis of both legs. Results showed no relevant differences with the earlier analysis.

Figure 8.2 Oedema index (mean and $95 \%$ confidence intervals) for the most affected leg during the six week follow-up period: withdrawal group $(0)$ and control group (*).

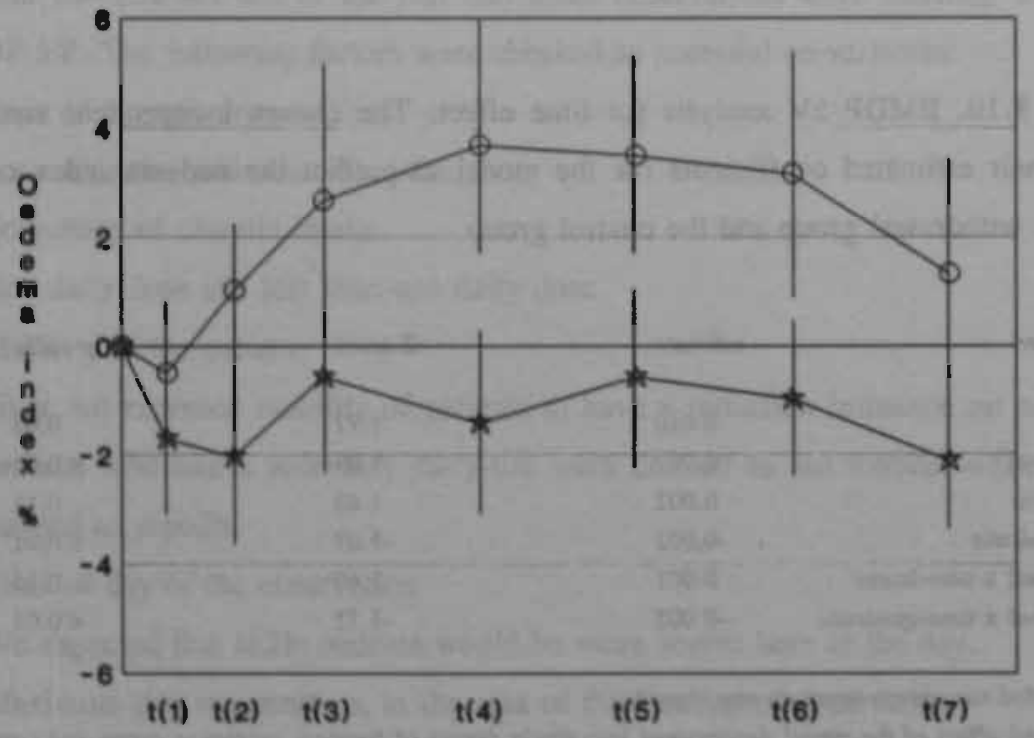




\subsection{Degree of oedema during the follow-up period}

As an alternative measure, in addition to volumetry, for the degree of oedema, we determined the extent of pitting-oedema at the follow-up visits. For the analysis we categorized the data into three groups:

"Appearance of oedema", if pitting-oedema in at least one leg was shown at 4 while at $t_{0}$ no pitting-oedema was found;

Table 8.11. Proportion of patients in withdrawal and control group with oedema appearing $(+)$, equal oedema $(=)$ and oedema disapearing $(-)$ at $t_{4}$ compared with $b_{0}$. (percentages do not always add up to $100 \%$ because effects of rounding) withdrawal group

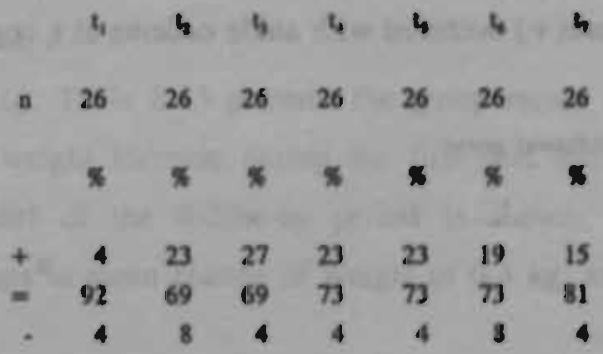

control group

$\begin{array}{rrrrrrrr} & 4 & 4 & 4 & 4 & 4 & 4 & 4 \\ 5 & 29 & 28 & 29 & 29 & 28 & 29 & 29 \\ 5 & 5 & 8 & 5 & 5 & 5 & 5 \\ + & 10 & 7 & 7 & 3 & 4 & 4 & 3 \\ = & 72 & 68 & 69 & 8 & 75 & 75 & 72 \\ - & 17 & 25 & 24 & 14 & 21 & 21 & 24 \\ * \quad & .61 & .14 & .07 & .04 & <.05 & .09 & .18\end{array}$

- Fisher-exact test, number of $(+)$ againat number of others, withdrawal group compared with control group at 1 , two-tailed $p$ value. 
"Equal oedema", if at both $b_{0}$ and $t_{4}$ no pitting-oedema in either leg was found or when at both 6 and 4 pitting-oedema was observed in at least one of the legs;

"Disappearance of oedema", if pitting-oedema in at least one leg was shown at $t_{0}$ while at $\mathrm{t}_{\mathrm{S}}$ no pitting-oedema was found.

Table $\mathbf{8 . 1 1}$ presents the results, which show that the difference between both groups concerning the appearance of oedema reaches a maximum at 4.

The subjective complaints of oedema were also recorded. At every measurement patients were asked whether they experienced more or less oedema compared to the previous observation visit. We divided the answers of the patients in the categories less oedema $(-)$, same oedema $(=)$ and more oedema $(+)$.

Table 8.12. Proportion of patients who reported being less $(-)$ equally $(=)$ or more $(+)$ bothered with ankle oedema at $t_{i}$ comparing to $t_{(i-1)}$.

withdrawal group

\begin{tabular}{|c|c|c|c|c|c|c|c|}
\hline & $t_{1}$ & $t_{2}$ & t, & 4 & ts & 4 & $b_{1}$ \\
\hline n & 26 & 26 & 26 & 26 & 26 & 26 & 26 \\
\hline & ж & $\%$ & \% & \% & $\%$ & ж & 5 \\
\hline+ & 4 & 39 & 27 & 15 & 8 & 23 & 0 \\
\hline$=$ & 85 & 58 & 65 & 65 & 85 & 69 & 96 \\
\hline . & 11 & 4 & 8 & 19 & 8 & 8 & 4 \\
\hline
\end{tabular}

control group

\begin{tabular}{|c|c|c|c|c|c|c|c|}
\hline & $t_{1}$ & $t_{2}$ & h & 4 & ts & 4 & $b_{y}$ \\
\hline $\mathbf{n}$ & 29 & 28 & 29 & 29 & 28 & 29 & 29 \\
\hline & $\%$ & 5 & $\pi$ & \% & $x$ & \% & x \\
\hline+ & 7 & 7 & 7 & 21 & 11 & 14 & 10 \\
\hline$=$ & 79 & 93 & 86 & 62 & 82 & 75 & 83 \\
\hline • & 14 & 0 & 7 & 17 & 7 & 11 & 7 \\
\hline 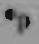 & 1.0 & $<.01$ & .07 & .73 & 1.0 & .49 & .24 \\
\hline
\end{tabular}

- Fisher-exact test, number of $(+)$ against number of others, withdrawal group compared with control group at $t_{0}$ two-tailed $p$ value. 
Table 8.12 represents the results as proportions of patients giving an answer in one of those categories. Only at $t_{2}$ is a significant difference between both groups noticed.

\subsection{Weight, peak flow and blood pressure during follow-up}

The trends in weight, peak flow and blood pressure during the follow-up period in both groups are represented as the means of the differences between the observations at $t_{4}$ and $t_{0}$. In case of the weight measurement, the observation at $t_{1}$ instead of $t_{0}$ was used as reference since in some occasions measurements at $t_{0}$ were carried out with a different pair of scales than at the following measurement moments, which could lead to incomparable results.

Weight difference $(\Delta \mathrm{W})$ was calculated as:

$\Delta W$ at $t_{i}=\left(\right.$ weight at $\left.t_{i}\right)-\left(\right.$ weight at $\left.t_{1}\right)$. Table 8.13 presents the group means of $\Delta W$ at $\mathrm{h}_{\mathrm{i}}$. In the withdrawal group a weight increase during the first part and a weight decrease during the second part of the follow-up period is shown. A significant difference between both groups in mean change of weight of $0.4 \mathrm{~kg}$. and $0.7 \mathrm{~kg}$. appears at $t_{2}$ and $t_{3}$.

Table 8.13. Mean of AW (kg.) of both groups at $\mathrm{s}$.

$\begin{array}{lrrrrrrr}\text { group } & b_{2} & \text { b } & 4 & b_{3} & 4 & h \\ \text { withdrawal } & & & & & & \\ \text { control } & 0.4 & 0.6 & 0.3 & 0.3 & 0.3 & 0.0 \\ & 0.0 & -0.1 & -0.1 & -0.2 & -0.2 & -0.1\end{array}$

- Significant difference between group means at t, $(p<0.05$ )

Peak flow difference $\triangle \mathrm{PF}$ was calculated as:

$\triangle P F$ at $t_{\mathbf{i}}=$ (peak flow at $\mathbf{i}_{\text {) }}$ - (peak flow at $\mathrm{b}_{0}$ ).

Due to problems of some patients using the Mini-Wright peak flow meter, in some instances no proper peak flow measurement was obtained. 
Table 8.14. Mean of $\triangle \mathrm{PF}(\mathrm{L} / \mathrm{min}$.) of both groups at 4 .

$\begin{array}{lrrrrrrr}\text { group } & t_{4} & b & t_{3} & 4 & \text { b } & 4 & h \\ \text { withdrawal } & 16 & 11 & 10 & 1 & 20 & 25 & 27 \\ \text { control } & 3 & 9 & 8 & 22 & 19 & 26 & 21\end{array}$

No significant difference between group means.

Table 8.14 gives the group means of $\triangle \mathrm{PF}$ at $\mathrm{t}_{\mathrm{i}}$ revealing no significant changes in peak flow between the two groups.

Diastolic blood pressure difference ( $\triangle \mathrm{DBP})$ was calculated as:

$\triangle D B P$ at $4=\left(\right.$ diastolic blood pressure at $\left.\mathrm{t}_{\mathrm{f}}\right)$ - (diastolic blood pressure at $\left.\mathrm{b}_{0}\right)$. Table 8.15 showi the group means of $\triangle D B P$ at $t_{t}$ changes could not be shown to be significantly different.

Table 8.15. Mean of $\triangle D B P(\mathrm{mmHg}$ ) of both groups at $\mathrm{t}$.

group

withdrawal

control

$$
t_{1} b_{2} t_{4} b_{4} 4
$$

$$
\begin{array}{rrrrrrr}
-0.1 & -0.8 & 1.8 & -0.8 & -0.3 & -0.8 & -0.3 \\
-3.2 & -2.8 & -1.5 & -4.4 & -4.0 & -5.3 & -4.2
\end{array}
$$

No significant difference between group means.

8.9 Influence of withdrawing diuretics on electrolytes, haematocrit. creatinine and urea.

The blood concentration of the electrolytes sodium, potassium and magnesium were determined at $t_{0}$ and $\mathrm{h}_{\mathrm{f}}$. As can be read from table 8.16 both mean sodium and potassium level increased in the withdrawal group, while no significant change was observed in the control group. The magnesium level showed no significant change in the follow-up period in either group. 
Table 8.16. Mean level of sodium, potassium and magnesium $(\mathrm{mmol} / \mathrm{l})$ in both groups at $t_{0}$ and $h_{h}$.

\begin{tabular}{|c|c|c|c|c|c|c|c|}
\hline \multicolumn{2}{|r|}{$y$} & \multicolumn{3}{|c|}{6} & \multicolumn{3}{|c|}{ h } \\
\hline & & " & mean & SE & n & mean & SE \\
\hline \multirow{2}{*}{ sodium } & withdrawal & 26 & 142 & .52 & 26 & $143^{\circ}$ & $3 n$ \\
\hline & eontrol & 27 & 142 & 51 & 28 & $142^{*}$ & .40 \\
\hline \multirow{2}{*}{ potassium } & withdrawal & 26 & 4.3 & .10 & 26 & 4.6" & .06 \\
\hline & coutrol & 27 & 4.3 & .08 & 28 & $4.3^{\prime \prime}$ & . 예 \\
\hline \multirow{2}{*}{ magnexium } & withdrawal & 25 & .83 & .02 & 26 & .83 & .02 \\
\hline & control & 26 & .83 & .01 & 26 & .84 & .02 \\
\hline
\end{tabular}

At $h("$ and *"), mean sodium and potassium level showed significantly higher mean values in the withdrawal group.

Creatinine, urea and haematocrit were also measured in blood samples at $b_{6}$ and $t_{7}$. The results of these measurements are presented as group means at both time-points in table 8.17. Although the change cannot be shown to be significantly different when comparing both groups, the mean creatinine leve! in blood samples of patients who ceased diuretic drugs showed a stronger decrease than the mean level in the control group. The ratio creatinine/urea, calculated as a measure for hydration, showed no significantly different changes over the follow-up time period. The same was true for haematocrit.

\subsection{Questionnaires about quality of life and functional status}

The results of our concise quality of life measurements are presented in table 8.18 Patients' answers were scored on a 5-point scale (see appendix 1). We used the mean score for each question separately as a measure for comparing both groups at $t_{0}$ and $t_{7}$ and calculated the mean difference in score for each group between $t_{0}$ and $t_{7}$ 
Table 8.17. Mean level of creatinine $(\mu \mathrm{mol} / \mathrm{l})$, urea (mmol/1), and haematocrit (\%) in both groups at $\mathrm{t}_{0}$ and $\mathrm{t}_{\mathrm{F}}$.

\begin{tabular}{|c|c|c|c|c|c|c|c|}
\hline \multicolumn{2}{|c|}{ 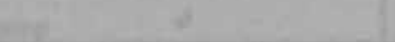 } & \multicolumn{3}{|c|}{6} & \multicolumn{3}{|c|}{4} \\
\hline & a & n & mean & SE & a & mean & SE \\
\hline \multirow[t]{2}{*}{ creatinine } & withdrawal & 26 & 83 & 4.56 & 25 & 75 & 4.10 \\
\hline & control & 26 & 83 & 4.98 & 26 & 80 & 3.72 \\
\hline \multirow{2}{*}{ urea } & withdrawal & 26 & 7.6 & 0.38 & 27 & 7.0 & 0.44 \\
\hline & control & 28 & 6.9 & 0.36 & 26 & 7.1 & 0.28 \\
\hline \multirow{2}{*}{$\begin{array}{l}\text { haemato- } \\
\text { crit }\end{array}$} & withdrawal & 22 & 41 & 0.91 & 24 & 42. & 0.71 \\
\hline & eontrol & 25 & 42 & 0.56 & 27 & 42 & 0.44 \\
\hline
\end{tabular}

No significant difference for group meana was shown between both groups at both time points.

use of in order to measure possible effects caused by the intervention. Strictly speaking,the mean score is not appropriate since the variables are of the ordinal type. However, in our view the type of analysis we used will give the least information loss, and is suitable assuming that the scale reaches the properties of an integer variable. This approach was also used for the functional status measurements (see appendix 2) with outcomes presented in table 8.19. No significant difference between both groups could be shown for any question, neither at one and the same observation time nor with regard to the differences between $t_{0}$ and $t_{7}$.

\subsection{Post-experimental follow-up}

To get an idea whether patients would persist in not using diuretics after the trial, a non-experimental follow-up procedure was carried out. In table 8.20 figures are presented concerning the use of diuretics of the participating patients at least half-ayear after the end of the trial. In the category of patients who were using diuretics, 
Table 8.18. Mean score in both groups on 'quality of life' questions at $t_{0}$ and $\mathrm{t}_{\mathrm{T}}$.

\begin{tabular}{|c|c|c|c|c|c|c|c|}
\hline \multirow{2}{*}{ 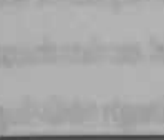 } & \multirow{2}{*}{ instotins } & \multicolumn{3}{|c|}{6} & \multicolumn{3}{|c|}{4} \\
\hline & & - & mean & SE & $\mathbf{n}$ & mean & SE \\
\hline \multirow{2}{*}{ bealth } & withdrawal & 24 & 2.3 & 0.11 & 24 & 2.3 & 0.11 \\
\hline & control & 29 & 2.3 & 0.12 & 29 & 2.2 & 0.12 \\
\hline \multirow{2}{*}{ happiness } & withdrawal & 24 & 2.5 & 0.17 & 24 & 2.3 & 0.13 \\
\hline & control & 29 & 2.2 & 0.14 & 20 & 2.1 & 0.11 \\
\hline \multirow{2}{*}{ satisfac-tioa } & withdrawal & 24 & 2.0 & 0.15 & 24 & 2.0 & 0.10 \\
\hline & control & 29 & 2.0 & 0.13 & 29 & 1.9 & 0.07 \\
\hline \multirow{2}{*}{$\begin{array}{l}\text { quality } \\
\text { of life }\end{array}$} & withdrawal & 23 & 3.6 & 0.26 & 23 & 3.4 & 0.16 \\
\hline & control & 26 & 3.7 & 0.19 & 27 & 3.8 & 0.18 \\
\hline
\end{tabular}

No significant difference was shown between both groups, neither in mean scores at each observation time nor for mean differences between scores at 6 and $h_{5}$.

Table 8.19. Mean score in both groups on 'Nelson's functioning score questions' at 6 and $h$.

\begin{tabular}{|c|c|c|c|c|c|c|c|}
\hline \multirow{2}{*}{\multicolumn{2}{|c|}{ wat fis ald }} & \multicolumn{3}{|c|}{6} & \multicolumn{3}{|c|}{ b } \\
\hline & & a & mean & SE & a & mean & SE \\
\hline \multirow{2}{*}{ physical } & withdrawall & 24 & 2.7 & 0.20 & 24 & 2.6 & 0.22 \\
\hline & control & 28 & 2.3 & 0.16 & 29 & 2.4 & 0.16 \\
\hline \multirow{2}{*}{ mental } & withdrawal & 24 & 2.4 & 0.22 & 21 & 2.1 & 0.19 \\
\hline & control & 29 & 2.3 & 0.21 & 28 & 2.5 & 0.20 \\
\hline \multirow{2}{*}{$\begin{array}{l}\text { daily } \\
\text { activities }\end{array}$} & withdrawal & 24 & 2.0 & 0.23 & 27 & 2.0 & 0.23 \\
\hline & control & 29 & 1.9 & 0.16 & 28 & 1.6 & 0.15 \\
\hline \multirow{2}{*}{ social } & withdrawal & 24 & 1.3 & 0.13 & 23 & 1.3 & 0.11 \\
\hline & control & 29 & 1.5 & 0.16 & 28 & 1.5 & 0.16 \\
\hline
\end{tabular}

No significant difference was shown between both groups neither concerning mean scores at each observation time nor for mean differences between scores at $\zeta$ and $h$. 
the patients who had restarted diuretic use during the trial are included. In the control group only three patients had stopped diuretic use after the trial. Two patients of the control group reduced their diuretic use to sporadic use or at most three doses per week. In the withdrawal group three patients, although having restarted, were using diuretics less frequently than before the trial.

Table 8.20. Use of diuretics in both groups half-a-year after the end of the withdrawal trial.

\begin{tabular}{l|c|r|r|r|r|} 
& \multicolumn{9}{c|}{ use of diuretics } \\
& use & less & no use & unknown & total \\
\hline withdrawal group & 18 & 3 & 11 & 2 & 34 \\
eontrol group & 23 & 2 & 3 & 1 & 29 \\
total & 41 & 5 & 14 & 3 & 63 \\
\hline
\end{tabular}

Fisher-exact test, proportion "no use" in withdrawal group (11/34) compared to proportion "no use" in control group $(3 / 29)$, two-tuiled $p=0.07$.

The reasons for restarting diuretic therapy in the 13 patients who recommenced diuretic use after the trial are summarized in table 8.21. The reasons for restart in the eight patients in whom diuretic use was recommenced during the trial, have already been mentioned in paragraph 8.3 .

The moment of restarting diuretic use after the trial is summarized in table 8.22.

Health problems, other than ankle oedema or hypertension, that occurred after the end of the trial in the patients who had participated in the withdrawal group were as follows:

- One female patient, 71 years of age, died from a myocardial infarction half-ayear after the end of the trial.

- One female patient, aged 78 , had transient symptoms of a minor stroke without disturbances persisting. The initial indication for diuretic use had been, in addition to ankle oedema, hypertension. However, during the trial her blood pressure never exceeded $160 / 95 \mathrm{~mm} \mathrm{Hg}$. A year after the symptoms of the stroke she was in good health, not hypertensive and still did not use diuretic 
drugs (nor other antihypertensive drugs).

- One patient, who was already disabled before the trial because he had previously broken his left and his right hip, had fallen and broke one hip again.

- One patient who suffered from chronic obstructive pulmonary disease had an exacerbation more than a year after the trial. At that time his attending lung specialist prescribed diuretics again.

Table 8.21. The reasons for restarting diuretic use

in the 13 patients, who had succeeded in not using diuretics during the six-week trial but restarted afterwards, (between brackets, patients who restarted diuretics but less than they initially used):

indication

number of patients

\begin{tabular}{lc}
\hline ankle oedema & $5(2)$ \\
bypertension & $3(1)$ \\
dyspnoea(COPD") & 1 \\
unknown & 1 \\
\hline
\end{tabular}

total

13

- patient with chronic obstructive pulmonary disease

Table 8.22. The moment of restarting to use diuretics

in the 13 patients who had succeeded in not using fiuretics during the six-week trial but restarted afterwards:

moment of restart after the trial

as soon as the trial was finished

within 1 month

2 to 3 months

more than 6 months

unknown

total

number of patients

3

5

3

1

1

13 
In the control group the following events were recorded:

- One patient was admitted to hospital on suspicion of a small myocardial infarction which at moment of follow-up had no short term serious consequences.

- One patient had fallen and suffered a vertebral (osteoporotic) fracture.

- One patient had an operation for dorsal nerve root compression.

The blood pressure of the nineteen patients who had hypertension as additional indication for diuretic use was again measured at least 3 months after the end of the trial period. Nine patients had participated in the control group and 10 patients in the withdrawal group. Three months after the trial, 13 patients used diuretic drugs. One of these patients had also been prescribed another anti-hypertensive drug. Six patients did not use diuretic drugs any more. However, one of them was prescribed another anti-hypertensive drug. Excluding the two patients who had started with another anti-hypertensive drug, the mean diastolic blood pressure of patients using diuretics was $87.4 \mathrm{~mm} \mathrm{Hg}$. The mean diastolic blood pressure of the patients not using diuretic drugs any more was $80.8 \mathrm{~mm} \mathrm{Hg}$.

\subsection{Discussion}

Our study shows that withdrawing of diuretic drugs in elderly long-term users is feasible in a selected population. In 26 of 34 patients diuretics were withdrawn successfully during a period of six weeks.

However, in 8 patients the withdrawal failed, in four cases because of medical reasons in spite of our thorough selection procedure. Since we provided the patients with a monitoring system that consisted of frequent house-visits and clear jnstructions when to enlist medical help, no serious consequences occurred in those cases.

In four cases, reasons other than medical forced us to resume diuretic therapy. In those cases patients felt less well or were worried about negative consequences of the withdrawal of the diuretic drugs although they were told that their use of 
diuretics was not based on an accepted indication. Patients seemed to be attached to the treatment and argued that they felt well and felt that they were being helped by using the drug. In their view there were no serious adverse effects, and they were reluctant to change their situation.

The randomization procedure of the trial appeared to have worked out satisfactorily. The allocation to the withdrawal group or control group per practice was balanced. Concerning major characteristics of patients for which we compared both groups after randomization, no statistically significant differences between the withdrawal and control groups were shown. Due to the relatively low number of patients, the power of the statistical tests is low; thus differences between both groups cannot be excluded. On the other hand, we tested for each category separately - thus repeated testing occurred. In such a situation finding a significant difference for at least one category is not inconceivable; however, this was not the case.

In general, the fact that the trial was performed with a relatively low number of patients has the consequence of low power in most significance tests.

As explained in paragraph 5.7 and 6.3 .1 we did not opt for a double-blind trial. Thus the subjective data are to be considered as gross effects where no distinction between exclusive drug effects and other effects can be made. Probably complaints expected or feared by the investigator, the patients, or both were recorded more frequently in the withdrawal group than in the control group. However, it can be expected that the practitioner will be confronted with the same complaints when the withdrawal of diuretics is performed in the daily (non-experimental) situation. Overestimation of complaints that could be a result of fluid retention, could occur since during the trial we were keen on the early identification of patients $\mathbf{u}$ risk of developing congestive heart failure especially in the withdrawal group. As shown in table 8.6, complaints of dyspnoea were indeed more frequently recorded in the withdrawal group. However, these complaints were, except in the two cases of patients who dropped out because of strong fluid retention, never of a serious nature and at physical examination never accompanied with increased breath frequency or auscultatory abnormalities. Other complaints which can be expected as a consequence of fluid retention that were recorded in patients who stopped diuretic 
use, such as weight increase, bloated feelings, swollen eyelids or face, or even fatigue, were observed several times in the withdrawal group and not in the control group.

The fact that the complaint of painful legs was found more often in the withdrawal group is difficult to explain. This is especially since most patients located the pain at other places in their legs than the ankles or feet where oedema might cause pais. Probably it is a coincidental observation. In future studies it would be advisable to pay speciall attention to this complaint.

The compliance to the instructions whether to stop or continue diuretic use appeared to be quite satisfactory. Most unexpected outcomes could be explained by the situation that some patients used less than one daily dose, since our detection method was not sensitive enough to detect a diuretic taken more than 24 hours before sampling. A comparable situation exists when the urine was sampled just before intake of diuretics. This happened in some patients and was due to the fact that we could not instruct the patients openly to sample the urine some time after diuretic intake (we were worried that they would then guess the reason for the urine investigation which would make the compliance control unreliable). When we take this inte consideration, the compliance control showed very acceptable results.

Based on the volumetric measurements, our results give strong, indications that in those patients who stayed in good clinical condition, ankle oedema after six weeks of withdrawal showed no relevant increase compared to the level measured at baseline.

However, a temporary rebound effect of increasing oedema is shown when results of the withdrawal group and control group are compared. This effect reached a peak with a mean increase of the oedema index of $3.5 \%$ in the third week after withdrawal of diuretics. After this period the oedema decreased gradually until the sixth week. Although in the sixth week a smal! significant difference between both groups is still present, the shape of the curve leads us to expect that this difference would disappear within a few weeks.

The data concerning the observations of pitting oedema show a similar trend. The subjective data obtained from the patients also show an increase in complaints concerning oedema during the initial weeks. However, in contrast to the oedema 
index and degree of pitting oedema, the decrease of oedema after 4 cannot be confirmed by the patient opinions recorded. This might be due to the fact that the patient observations are recorded as relative changes with the directly preceding measurements, while the other observations, oedema index and degree of pitting oedema, were related to the baseline measurements. Relatively small decreases of oedema over one week might not be noticed by the patients. On the other hand this result can be an indication that from the point of view of the patients, diuretic withdrawal caused an increase in oedema that did not disappear during the follow-up period. The BMDP 5V repeated measures analysis procedure gave a strong confirmation concerning the convex shape of the curve that describes the oedema index of the withdrawal group. This procedure also provided evidence that the difference between the mean oedema index of both groups showed no linear increase with time over the complete follow-up period. Of the co-variables we recorded, type of diuretic drug, dosage of diuretics, mobility of the patient, time of day of the observation, maximum day temperature at observation day, symptoms of CVI at baseline, co-medication and degree of pitting oedema at baseline, not one could be shown to have a significant influence on the oedema index.

The conclusions concerning the course of the oedema index are based on data in which the volume measurements of both legs are used. This approach is preferred because diuretics will have an influence on both legs since they are administered systemically. However, as shown in paragraph 8.6 , there seems to be no important difference whether only the most affected leg, or both legs are taken in account.

The trend in the weight of patients who stopped diuretic use follows the same pattern as the oedema index. During the first two weeks the weight increased while it decreased subsequently. This might be very well explained by the rebound phenomenon that has been described as an effect of withdrawal of diuretics.(1)(2)

During the follow-up peak flow measurements showed no significant differences between the control group and the withdrawal group. If fluid retention occurs as a rebound phenomenon, this might influence the pulmonary circulation with consequently a decrease of lung function, which should be detected by a decreased 
peak flow. This could not be confirmed by our results. However, we cannot exclude any difference between the withdrawal group and the control group.

Peak flow measurements are known to have a wide inter-patient variability but can be used in the monitoring of lung function in individual patients. Results are rather dependent on the skills of patients how to perform the measurement.(3) In the control group a gradual increase of the peak flow seemed to occur. Since the lung function in those patients is not expected to alter, rising peak flow measurements might be a consequence of gradual increase in skills. This effect may influence the follow-up results of peak flow measurements. In our view this pleads for the thorough training of patients in the use of the mini-Wright peak flow meter prior to base line measurements. This would have a positive influence on both research and the practical use of the peak flow meter.

A major use of diuretics is the treatment of hypertension.(4) However, some: studies have shown that the withdrawal of diuretics in patients treated for hypertension does not always lead to an increase of the blood pressure. $(5)(6)(7)(8)(9)(10)$ This observation has no clear explanation. An important explanation suggested is that in some patients the initial decision for starting the treatment could have been made on insufficient grounds. Then therapy is started on the basis of a coincidental high blood pressure reading in patients who do not normally have an elevated blood pressure. When treatment is stopped in those patients, blood pressure seems to be normalized and probably will not rise.(11) In our population in which 19 patients had hypertension as additional indication for diuretic use (10 in the withdrawal group and 9 in the control group) no significanit difference between both groups concerning the course of the mean blood pressure could be shown, which gives strong indications that in our population the withdrawal of diuretics, on the average had no significant increasing effect on the diastolic blood pressure.

The influence of diuretic drugs on electrolytes is also well known. The primary effect of diuretics is a loss of sodium and water in the body, but diuretics also affect other electrolyte levels in plasma. A loss of sodium, potassium (except in potassiumsparing diuretics) and magnesium is described. Hyponatraemia, hypokalaemia and 
hypomagnesaemia can be consequences of use of diuretics (chapter 2). In our study population, at baseline mean blood levels of sodium, potassium and magnesium were equal in both experimental groups. At $\mathrm{b}$, both mean sodium and potassium level in the withdrawal group had increased and differed significantly from the levels in the control group. The mean blood level of magnesium showed no change in the withdrawal group and a small increase in the control group. However, at $h_{7}$, group means were not significantly different. The expected influence on magnesium level was not shown in our population. While it has been suggested that better evaluation of magnesium state might be done on the basis of muscle biopsy, in our opinion this technique fell outside the research methods.(12) In conclusion although the withdrawal showed some effects on electrolyte levels, in our group the degree to which electrolyte levels were influenced by stopping diuretic use seems to be limited.

Although both mean creatinine level and urea level showed a decrease in the withdrawal group when baseline levels are compared with levels at the end of the trial, the influence of diuretic withdrawal on creatinine and urea was not demonstrated to be significant in our study population. This is also the case for our measures of hydration: both creatinine/urea ratio and haematocrit showed no significant difference, either between both groups at $b$ and $t$, nor between mean differences over the follow-up period for both groups. Although the measures of hydration used should be considered as indications rather than hard measures, in our view this finding indicates that the occurrence of dehydration caused by use of diuretic drugs is not usual in the population we investigated.

In order to investigate whether diuretic withdrawal would have an influence on quality of life of patients and their functional status, we performed interviews at baseline and at the end of the trial (for questionnaires: see appendix). Both on the quality of life questionnaire and the functional status questionnaire no significant changes of diuretic withdrawal could be shown. Thus diuretic withdrawal over a period of 6 weeks neither increases nor decreases the perceived quality of life and functional status in our study.

Half-a-year after the trial it appeared that the majority of patients had resumed use 
of diuretic drugs, at least $62 \%$. However, it seems worthwhile that still $32 \%$ of the patients were not using diuretic drugs any more.

The frequency of restarting diuretics in the patients who were withdrawn diuretics during the trial is high, despite the fact that after six weeks of withdrawal the oedema was not worse in most patients than at baseline. This may indicate that patients in most cases perceived a benefit from the use of diuretics and did not experience strong disadvantages or troublesome side effects. From another point of view it might illustrate the attachment of patients to the habit of diuretic use. In this context again extra care may be advocated in the decision to start with diuretic therapy for the complaint ankle oedema if no hard indication exists. The chance thatt patients will adhere to diuretic therapy for a long period is substantial and withdrawal is shown to be difficult.

Concerning the events after the trial it should be taken into account that the groups are too small to draw conclusions with any statistical confirmation. The events we recorded are not unexpected because of the mean age of the population in which the investigation was performed. Still the events should be reported as we cannot exclude the possibility that the withdrawal of diuretics may have had an influence on their occurrence. One patient in the withdrawal group who had hypertension as an additional indication suffered a short time after the trial from symptoms of a stroke that, fortunately, were relieved within a week. Persistent symptoms did not develop in the following year. It is important to note in this case that the blood pressure readings during the trial would under normal care not have given reason for prescribing anti-hypertensive drugs.(13)

Another patient who had participated in the withdrawal group and did not use diuretics after the trial died from a myocardial infarction. There was no history of hypertension or angina pectoris. Thus it is not likely that this event would not have occurred if diuretics had still been used, however certainty cannot be obtained in this case. In the control group too one patient suffered from chest pain which may have been caused by a myocardial infarction although admission to the cardiology ward in hospital did not yield clear evidence of a myocardial infarction. However, since the follow-up had no experimental design and the groups are small, statistical evidence 
for differences between the long-term outcomes of the control group and the withdrawal group cannot be obtained.

Valid evidence concerning differences in outcome between the control group and withdrawal group concerning the long-term blood pressure level also cannot be obtained. The mean blood pressure of those not taking any more diuretics three months after the trial was lower than the blood pressure of those taking diuretics. It is likely that selection has took place in these patients. Patients with a high blood pressure were prescribed diuretics again while patients with a low pressure were not in need of diuretics any more. Still our findings show similar results with the trial undertaken by Kruijsdijk et al.(9) If diuretics are withdrawn in patients who use diuretics for hypertension, but who do not have hypertension at the moment of withdrawal, in a substantial proportion of the patients the blood pressure does not rise to a level that forces anti-hypertensive therapy to be restarted. 


\section{References}

1. MacGregor OA, Markandu ND, Roulston JE, Jones JC, de Wardener HE; Is "idiopathic" oedema idiopathic? Lancet 1979; 1: 397-400.

2. MacGregor OA, Taker PRW, de Wardener HE; Diuretic-induced oedema, Lancet 1975; 1: 489-492.

3. Veen van WA. De bruikbaarheid van de piekstroombepaling voor de tuisarts. Huisarts Wet 1982; (nuppl HOP 6): 69.75.

4. Anonymus. Tractus Uropoèticus Diuretica. In: Nelemans FA ed. Farmacotherapeutisch Kompas. Amstelveen: Centrale Medisch Pharmaceutische Commissie van đe Ziekenfondsraad, 1989: 362-5.

5. Burr ML, King S, Davies HEF, Pathy MS. The effects of discontinuing long-term diuretic therapy in the elderly. Age Ageing 1977; 6: 38-45.

6. Portnoi VA, Pawlsos LG. Abuse of diuretic therapy in nursing homes. I Chron Dis 1981: 34: 363-5.

7. Myera GM, Weingent ME, Fisher RH, Oryfe CI, Shulman HS. Unnecessary diuretic therapy in the elderly. Age Ageing 1982; 11:213-21.

8. Tageart A. MeDevitt DG. Diuretic withdrawal, a need for caution. Curr Med Res Opin 1983; 8: 501-8.

9. Koopmana RTCM. Gribnau FWI. Langdurige diureticumbehandeling bij verpleeghuisbewoners. Is atoppen mogelijk? Tijachr Gerontol Geriatr 1988; 19: 55-60.

10. Walma EP, Hoen AW, Prins A, van der Does E. Het staken van langdurige diuretica-medicatie bij 65-plussers in een huisartspraktijk. Huisarts Wet 1992; 34: 105-8.

11. Krujisdijk M van. Hypertensie opniew gemeten [Dissertatie]. Nijmegen: Katholieke Universiteit to Nijmegen, 1991.

12. Dyekner $T$, Wester PO. Plasma and skeletal musele electrolytes in patients on long-terin diuretic therapy for arterial bypertension and/or congestive heart failure. Acta Med Scand 1987; 222: 231-6.

13. Binabergen If van, Orundmejier HCLM, Hoogen JPH van den, Kruijsdijk M van, Prins M, Ree JW van, Thomas S. Hypertensie, NHG-standaard. Huisarts Wet 1991; 34: 389-95. 
CHAPTER 9

General discussion 
10:

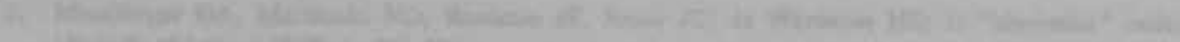

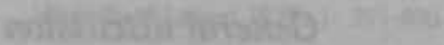

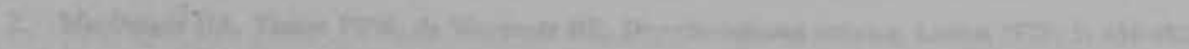

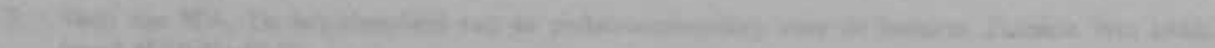

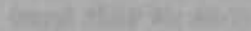

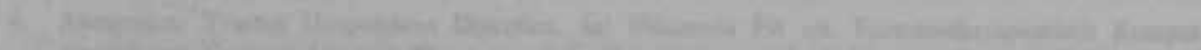

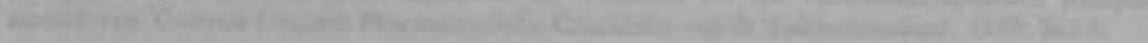

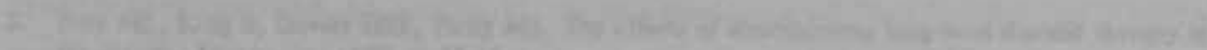

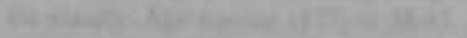

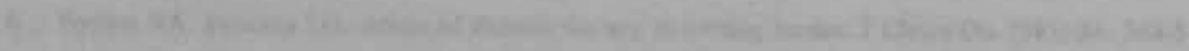

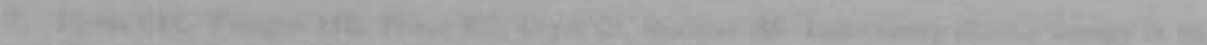

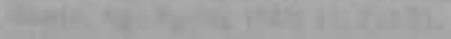

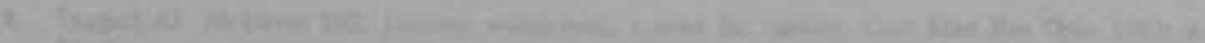
Anich

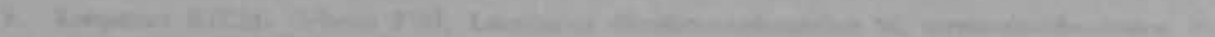

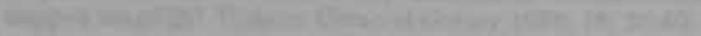

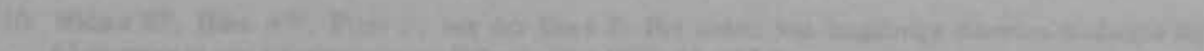

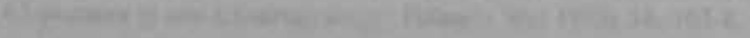

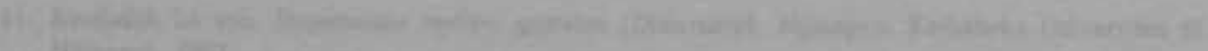

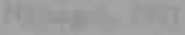

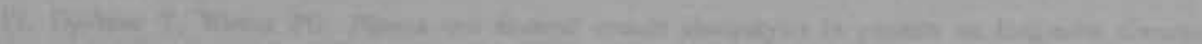

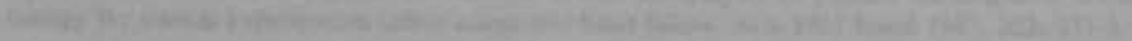

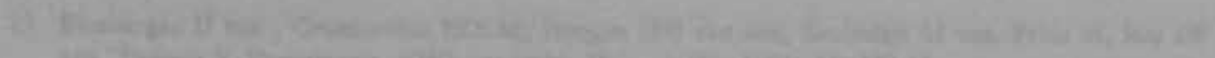

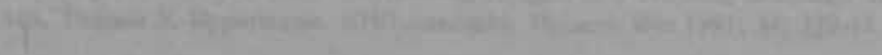


It is often stated that the use of diuretic drugs by a high percentage of the elderly is undesirable because of the risk of adverse effects and interactions with other drugs.(1)(2)(3) Several investigators have advocated that in elderly patients who use diuretics chronically, withdrawal is safe and adequate in many circumstances.(4-10) Complaints of ankle oedema without symptoms of cardiac, hepatic or renal failure, are controversial as an indication for chronic diuretic use of elderly patients. Trying to withdraw diuretics that are used in such circumstances therefore seems worthwhile. However, so far no research has been undertaken to investigate the effects of withdrawal in this situation. This is of particular interest for general practice, since prescription of drugs to the elderly often goes via the general practitioner.(11) In day-to-day care it is he or she who decides about continuation or withdrawal of chronically used drugs.

\subsubsection{Diuretic withdrawal studies}

A study was made of the literature regarding the withdrawal of diuretics from elderly patients. All studies except one conclude that withdrawal of diuretics drugs in elderly patients is safe and appropriate if there are no indications for heart, liver or kidney insufficiency or hypertension.(2-10) However, we conclude on the basis of our review that there are still uncertainties concerning, the safety' of withdrawal, especially when performed in general practice. Concerning the effect of withdrawal on ankle oedema, ne study fulfilled to all methodological criteria for sufficient. evidential proof and moreover, results are inconsistent. 


\subsubsection{Questionnaire on treatment of ankle oedema}

In the elderly the most likely cause of chronic ankle oedema in absence of symptoms of cardiac, hepatic or renal failure, is venous insufficiency.(12)(13) Venous insufficiency is a controversial indication for diuretic use.(14) Whether prescription of diuretic drugs would be initiated by physicians for ankle oedema caused by venous insufficiency, was investigated by means of a mail questionnaire. We concluded that $40 \%$ of the doctors questioned would prescribe diuretics in the case presented.

On the basis of the questionnaire we postulated that a number of physicians estimated the risk of heart failure too high in a patient presenting the complaint ankle oedema; this might provide an additional explanation for the high prescription rate of diuretics. However, on basis of the prevalence study and the selection procedure for the trial we concluded that only a small minority of patients with the indication of heart failure for diuretic use, actually used them for the symptom ankle oedema while the diagnosis of heart failure could not be confirmed. Thus the importance of unnecessary diuretic use resulting from this kind of prescription of diuretics that is quite often mentioned in geriatric literature could ultimately not be confirmed by our research.(2)(12)

\subsubsection{The prevalence study}

By means of the selection method for the trial we were able to make a description of some important characteristics of patients aged 65 years or older who were prescribed diuretic drugs.

A low number of patients appeared to be eligible for participation in the trial. Only $17 \%$ of the patients that were using diuretics for ankle oedema or the indication heart failure appeared eligible for diuretic withdrawal. On the one hand, the problem of misuse of diuretics for ankle oedema appeared to be not as widespread as concluded on basis of literature and previous research. On the other hand, many patients had relative or hard "indications", sometimes merely on the basis of 
uncertainty, for the continuation of diuretic treatment. This illustrates that if a patient is using diuretics, it can be difficult to decide to cease the diuretic therapy. Reasons to continue therapy often are present or cannot be excluded. Therefore a thorough consideration should be made about the strength of the indication before prescribing diuretic therapy. Once diuretics are prescribed, they are not easily stopped.

\subsection{S The withdrawal trial}

The withdrawal trial that we performed led to the following results. On the basis of the clinical course of the patients who completed the full protocol we conclude that withdrawal of diuretic drugs in patients using diuretics because of ankle oedema leads to a temporary increase in oedema. The process seems to be reversible in patients in good clinical condition. In the trial, six weeks after the cessation of diuretic therapy, the oedema had almost reached the starting level and was still decreasing. Further, in contrast to previous reports, we conclude that in most cases rebound oedema does not last about three weeks but rather reaches a peak after three weeks.

During the 6-week follow-up diuretics had to be restarted in 8 of the 34 patients in whom diuretics had been experimentally withdrawn. In three of those patients symptoms of heart failure made it necessary to restart diuretic therapy. In one case an elevated systolic blood pressure and in three cases the patients' wishes, in absence of strict medical reasons, were reasons for restarting, diuretic therapy.

Concerning the long-term effects of withdrawal, uncertainty' remains. On the basis of our experiment no conclusions may be drawn. However, if the results of previous research are considered, in combination with our findings indications are very strong that withdrawal of diuretics should only be performed after thorough consideration and under adequate medical monitoring. 


\subsection{Methodology}

\subsubsection{The literature review method}

Diuretic withdrawal studies in the elderly were reviewed and judged on their validity. Although we were primarily interested in research about this subject in general practice, we reviewed articles based on research in other settings as well, since all investigations except one had not taken place in general practice. The articles were judged qualitatively on their methodological validity using criteria advocated by Sackett al.(15) The choice of criteria for this purpose is arbitrary. We have chosen Sackett's criteria since his work on clinical epidemiology is widely recognized. The use of a more quantitative method, which is sometimes advocated, was not chosen.(16) Using a quantitative or semi-quantitative method is disputable in the case of a variety of clinical settings and study populations. Moreover, the use of weights (attributed to the fulfilment of certain criteria) might introduce subjectivity, rather than contribute to objectivity. Different: weights are to be assigned to different criteria, and the score on those criteria is dependent on subjective judgements.

\subsubsection{The questionnaire}

A mail guestionnaire was used to investigate whether general practitioners would prescribe diuretic drugs for ankle oedema without symptoms of cardiac, hepatic or renal failure.

A drawback of using a questionnaire is that it measures competence and not performance; it measures what doctors think they should do and not what they really do in day-to-day practice.(17) It is rather widely known that the use of diuretics in oedema caused by venous insufficiency is not a therapy of choice. Thus it could be expected that our estimation on the basis of the questionnaire gives an underestimation of the percentage of physicians who would prescribe diuretics for oedema caused by venous insufficiency in the daily routine situation. 
Patients were recruited for the trial in an active way. For the participation of patients in a clinical trial, one is usually dependent on patients consulting their doctor with the health problem of interest. The object of our research, withdrawal of diuretics, needed another approach. We expected that patient recruitment, depending on a selection by doctors from patients consulting for a repeat prescription for diuretics, would not be efficient for our research. We decided to select the patients in an active way. Our method started from patients of 65 years or older, using diuretic drugs. In this population patients were to be found who were eligible for diuretic drug withdrawal. If another strategy had been used, the research questions might only be answered after considerably more effort. An important advantage of the method we used is that we were able to perform a transversal study of all elderly patients recorded as using diuretics in the participating practices. Indications for diuretic use and type of prescribed diuretics could be recorded in this way.

We cannot be $100 \%$ certain that we identified each patient from all participating practices of 65 years or older who used diuretics. Some patients might have received a prescription that was not recorded in the computer of the computerized practices, or others may have been clients from pharmacists that did not participate in the study. However, no important difference showed up between our figures for prevalence for chronic diuretic use and those from earlier studies.

\subsubsection{Design of the trial}

The fact that the intervention investigated concerns the withdrawal of a therapy instead of starting a therapy implies some difficulties and peculiarities that make this kind of research different from common research on the efficacy of an intervention.

Especially for research on withdrawal of diuretic therapy, it should be kept in mind that the therapy is prescribed for a range of indications. In common research, interventions for one specified indication at a time are compared. For propeip analysis of a withdrawal intervention, the different indications should be considered 
separately. In our diuretic withdrawal project we have chosen the indication ankle oedema without symptoms of cardiac, hepatic or renal failure since this is the most controversial indication for long-term diuretic use.

In common drug research, the efficacy per particular substance is investigated. In the case of the chronic use of diuretics for ankle oedema, various diuretic substances and brands are used. Ideally the effect of withdrawal per substance should be investigated.

This causes an important problem. Since there is such a wide variety of diuretics prescribed, it would hardly be possible to select a group of patients using the same diuretic, that is large enough to perform a trial with sufficient power for sound conclusions. We have chosen to include all patients irrespective the kind of diuretic drug they were using. Conclusions are based on the total group. In a multi-variate analysis we checked afterwards for the influence of the class of diuretics on the outcome (loop diuretics versus all other diuretics). No statistically significant difference in effect on the outcome between both types of drugs was found. The power of the trial is for such a sub-analysis rather low because of the small number of patients in each group. Thus it cannot be excluded that the type of diuretic may be of influence on the outcome.

Performing a placebo-controlled withdrawal trial has methodological drawbacks. For proper comparability the withdrawal intervention should be compared with "inactive" withdrawal, which is not possible. Thus one is obliged to study only the net (pharmacological) drug effect in which placebo is compared with active therapy. In that case the withdrawal consists of stopping the active drug withour patients being certain of the fact that the drug has been stopped or continued. The effects of the manifest act of withdrawing are not studied in that case. The other option to study the effects of a withdrawal intervention is to compare a group in which withdrawal is openly executed, with a group in which the therapy is simply continued. Then a gross effect can be measured. In this case the effect of the act of withdrawal and the chemical effect of the withdrawal of the drug under study are studied in combination. This has the disadvantage that it is difficult to distinguish the contribution of each component to the total effect. If subjective measures are 
important outcomes of a trial, this can be a drawback. However, in case of 'hard' outcome measures the problem is of less importance, especially if there are no plausible theoretical indications that a mental component has important influence on the given outcome measure.(18) This was the case concerning the volumetrie measurements of oedema in the trial we performed. Furthermore, the problem is less important if the drug under study cannot be bought freely in the drugstore. Finally, it is important that we checked the patient-compliance by testing urine samples, with satisfactory results.

The choice of a volumetric measurement as most important outcome measure for our trial was determined by the fact that we were primarily interested in the degree of oedema that patients would develop after withdrawal of diuretic therapy. Volumetric measurements guaranteed the most objective and precise way available to determine changes in oedema.(19) Although sometimes clinically better applicable, other ways of determining oedema lack sufficient precision, or are too expensive or complicated. The additional subjective methods we used in our trial, clinical judgement (presence of pitting oedema) and subjective patient judgement (complaints of oedema) provided results that confirmed the objective volume measurements.

The length of the follow-up period was chosen on the basis of literature in which a rebound effect of diuretic withdrawal of 3 weeks was mentioned. To work with a safe margin we choose a follow-up period of 6 weeks. Since the first objective of our study was to investigate the effects. of withdrawal, and not whether withdrawal could be achieved for a substantial period of time, a limited period was appropriate. A major advantage of a limited period was that this period was acceptable for participants. Most patients were reassured in the knowledge that the trial had a limited period. We suppose that a longer experimental period would have led to more effort being required to find cooperative patients and more effort to keep the patients motivated to complete the full follow-up period. After the trial we had to conclude that although we had chosen a margin of $100 \%$ the follow-up period was too short to describe the complete rebound effect. At the last follow-up observation moment a falling trend was still observed in the oedema index curve, that had not yet reached the baseline level. However, the observed trend indicates rather strongly 
that, on average, oedema will return to baseline level after a period of about 6 weeks.

\subsection{Recommendations for further research}

We obtained very strong indications for a rebound phenomenon, of fluid retention after withdrawal of diuretic drug therapy, in patients using diuretics for ankle oedema without symptoms of cardiac, hepatic or renal failure. It might be possible to get more specific knowledge about the exact length of the phenomenon if a trial with a longer follow-up period is carried out. Furthermore it might be important to investigate whether there are differences between specific diuretics in the course of the rebound phenomenon.

Another important but difficult issue is the uncertainty about effects on mortality after withdrawal of diuretic drugs. On the one hand warnings about adverse effects of chronic diuretic use in the elderly are repeatedly found in medical literature.(1)(2)(3) On the other hand, both from the review on the literature (chapter 3) and from our findings at the non-experimental follow-up, uncertainties remain about the safety of diuretic withdrawal in the long-term. To obtain more certainty about this problem, a withdrawal trial with more participants and a longer follow-up period is needed. But where lies the burden of proof? Is it to be proved that chronic diuretic use is harmless even when the indication fot use is relatively weak? Or should it be proved that withdrawal is safe in patients using them for a weak indication? Independent of the answer on the first question, we think that it is important for clinical practice to know when it is safe and appropriate to withdraw diuretics if patients are using them for weak indications.

More in general, we think that there is a need for further development of methodology to investigate withdrawal of therapies and drugs. As already mentioned in the methodological discussion, we have treated withdrawal methodologically as if it were an intervention. The normal randomized controlled design is, however, not perfectly suitable for the withdrawal situation. Problems arise in forming 
homogenous groups, the control intervention (placebo withdrawal) and the analysis. Proper methodological tools should be developed further to be able to investigate in a sound way, withdrawal of therapies.

\subsection{Recommendations for clinical practice}

We conclude that withdrawal of diuretic drugs can be done safely in general practice in those elderly patients who are prescribed diuretics for ankle oedema and who have no symptoms of present hypertension, cardiac, renal or hepatic failure. A careful monitoring of the patients in the first weeks after withdrawal is of great importance. Most patients will develop an increased oedema in the first week. However, after six weeks, oedema will be back at base-line level. Those patients might continue without diuretics, while keeping them under close observations seems advisable.

In spite of careful selection, some patients appeared to be still at risk of deterioration in our trial. Those patients were identified in an early stage after withdrawal. In dayto-day practice careful monitoring after withdrawal can ensure that diuretic restart takes place, if complaints of dyspnoea d' effort develop together with weight and oedema increase.

In a considerable group of patients, withdrawal of diuretics might be possible. However, relative contra-indications for withdrawal are often present. This was in important reason for the relatively low proportion of diuretic using patients who could participate in the trial. It seems that a contra- indication for withdrawal can easily be found in many patients, which often makes withdrawal difficult. This will contribute to the situation that a high proportion of elderly patients are using diuretic drugs chronically and that the percentage of diuretic drug users increases with advancement of age. To prevent this situation, it seems important that diuretic drugs are only prescribed for strong indications. If prescribed, it might be usefull to apply a restricted period after which reconsideration for the use should be made.

In general, we think that there are arguments for a rule that not only instructions for 
using a drug should be provided with every drug, but also instructions for withdrawal of the drug. Doctors should be able to know when and how to cease chronic therapy in a safe way and what they can expect in case of withdrawal. 
1. Need we poison the elderly so often? (editorial). Luncet 1988: ii: 20-2.

2. Diuretica in the elderly [editorial]. Br Med J 1978; is 1092-3.

3. MacLennaa WJ. Diuretics in the elderly: how safe? [editorial]. Brit Med J 1988; 296: 1551.

4. Burr ML, King S, Davies HEF, Pathy MS. The effects of discontinuing long-term diuretic therapy in the elderly. Age Ageing 1977; 6: 38-45.

5. Portnoi VA, Pawlson LG. Abuse of diuretic therapy in nursing homes. J Chron Dis 1981; 34: 363-5.

6. Myers CM, Weingert ME, Fisher RH, Oryfe CI, Shulman HS. Unanecesuary diuretie therapy in the elderly. Age Ageing 1982; 11: 213-21.

7. Taggart N. MeDevitt DG. Diuretic withdrawal, a need for caution. Curr Med Res Opin 1983; 8: $501-8$.

8. Koopmans RTCM. Gribnau FWI. Langdurige diureticumbehandeling bij verpleeghuisbewoners. Is stoppen mogelijk? Tijdschr Gerontol Geriatr 1988; 19: 55-60.

9. Walma EP, Hoes AW, Prins A, van der Does E. Het staken van langdurige diuretica-medieatie bij 65-plussers in een huisartspraktijk. Huisarts Wet 1992; 34: 105-8.

10. Wilson IA, Thompson D, MacLennan WJ, Marshall 1. Stasis oedema in the elderly: Are diuretics necessary? Gerontology 1991; 37: 289-92.

11. Cartwright A, Smith C. Elderly people, their medicines, and their doctors. London: Routledge, 198I.

12. Wilcock GK, Gray INM, Pritchard PMM. Oedema of the nnkles. Geriatric Problems in General Practice. 1st ed. Oxford: Oxford University Press, 1982: 64-7.

13. Westerhof PW. Klinische manifestaties van hartziekten. In: Dunning AJ, Meijler FL, Verheugt APM, eds. Nederlands Leerboek der Cardiologie. 2th ed. Utrecht: Bohn, Scheltema en Holkema, 1983: 199-228.

14. Anonymus. Tractus Uropoèticus Diuretica. In: Nelemana FA ed. Farmacotherapeutisch Kompas. Amstelveen: Centrale Mediech Pharmaceutische Commissie van de Ziekenfonderaad, 1989: 362-5.

15. Sackett DL, Haynes RB, Tugwell P. Clinical Epidemiology: A basic science for clinical medicine. Boston: Little, Brown and Company, 1985.

16. Ter Riet G, Klejinen Y, Knipschild P. De meta-analyse als review methode. Huisarts Wet 1989; 32: $176-81$.

17. Rethana J, Leeuwes $Y$ van, Drop R, Vleuten $C$ van der, Sturmans F. Competence and Performance: Two Different Concepts in the Assessment of Quality of Medical Care. Fam Pract 1990; 7: 168-74.

18. Knottnerus IA, Volovies A. Medische statistiek en onderzoek in de huisartsgeneeskunde. Utrecht: NHO, 1990.

19. Thulesius O, Norgren L, Gjoeres JE. Foot-volumetry, a new method for pbjective assessmeat of edema and venous function. Vasa 1973; $2: 325-29$. 


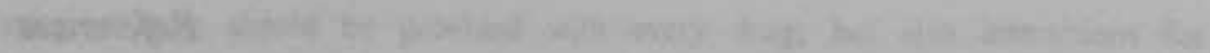

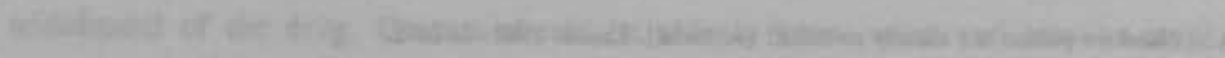

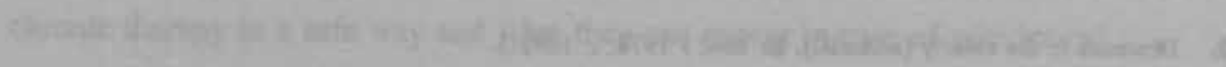

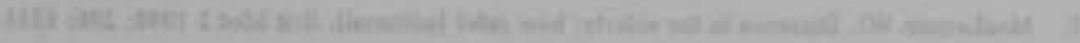

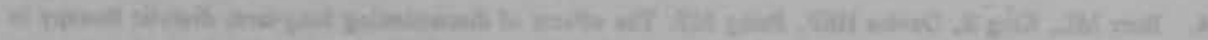

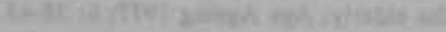

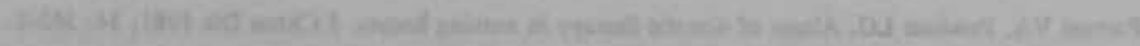

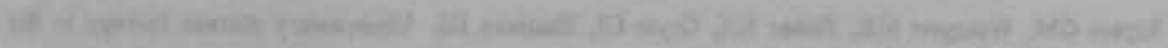

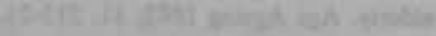

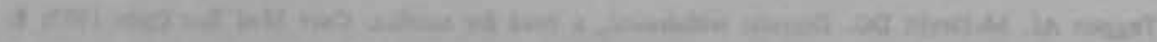
antath

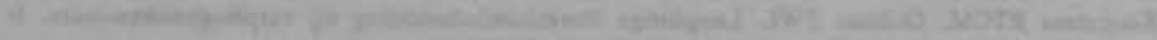

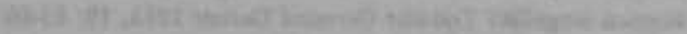

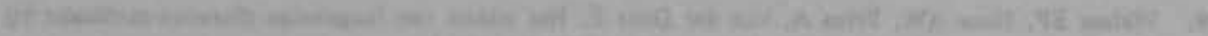

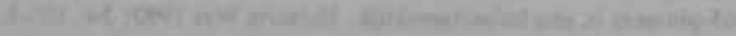

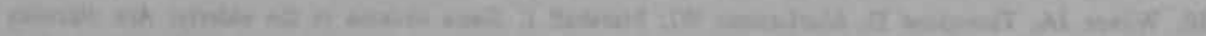

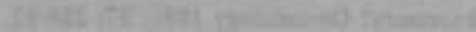

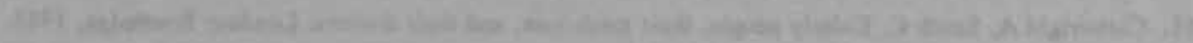

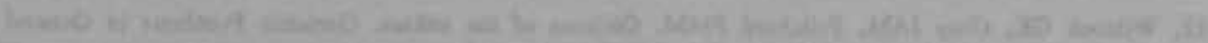

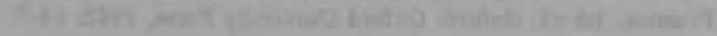

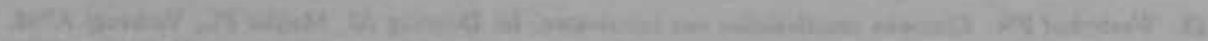

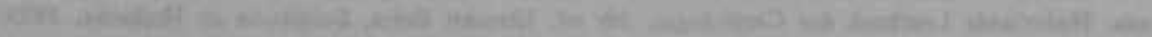
triastis

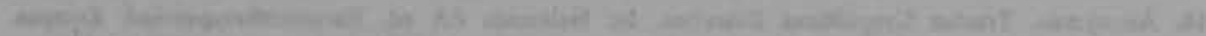

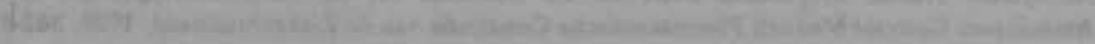

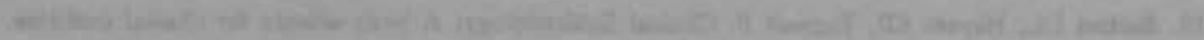

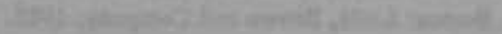

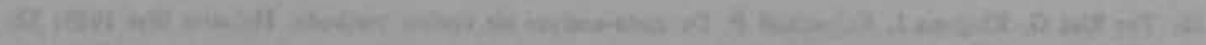
In:

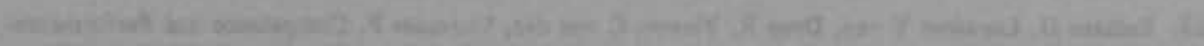

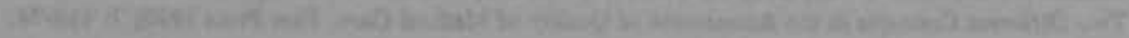

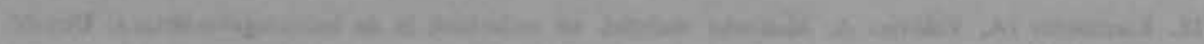
Bovit Dest

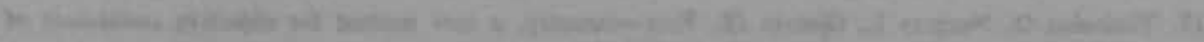

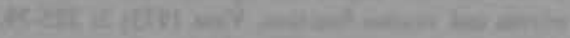


Chapter 10

Summary

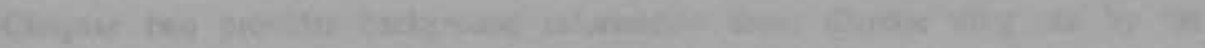
Lititain 
The first chapter describes the purpose and the background of this thesis. In addition, the research questions that were formulated are provided.

The GP must often decide whether to stop or continue drugs that are used chronically. However, in contrast with starting of therapies, little is known about the effects of withdrawal of many therapies. In this context, diuretic drugs prescribed for ankle oedema are of interest. There is, morover, noticable concern aboult unnecessary use of diuretics by elderly patients. In the medical geriatric literature it has been advocated that withdrawal of diuretics in elderly patients can be appropriate, in such circumstances as when patients are using diuretics for ankle oedema, given that the oedema is not caused by candiac, renal or hepatic insufficiency. However, whether this opinion is also held in general practice is not clear. This study therefore focussed on general practice. The central objective of the work in this thesis was to determine the effects of withdrawal of diuretic drugs which are used by elderly patients for ankle oedema without symptoms of cardiac, hepatic or renal insufficiency.

Chapter two provides background information about diuretic drug, use by the elderly.

The high rate of prescription of drugs to elderly patients is a subject of concern. Patients can suffer undesirable consequences such as side-effects or interactions with. other drugs. In this light diuretics are of particular interest. In the Netherlands, almost one in every five people of 65 years of age or older uses diuretic drugs.

The diuretics used nowadays were introduced in the late 1950s and early 1960s. Their major effect is the promotion of water and salt diuresis. The main indications are the treatment of oedema (including pulmonary oedema) and hypertension. Many side-effects of diuretics have been described, especially disturbances in the water and electrolyte balance. Rebound oedema after withdrawal of diuretics has been. reported.

Ankle oedema seems to be an important reason for use of diuretics. If the ankle 
oedema is caused by cardiac, hepatic or renal failure the use of diuretics is normally useful. However, if the oedema is caused by venous insufficiency, then the use of diuretics is controversial. If diuretics are used for this indication, withdrawal seems appropriate. Nevertheless, research purely on the effects of withdrawal of diuretic drugs in elderly patients in the general practice population to whom diuretics were prescribed for ankle oedema has not taken place.

Chapter three presents a review on withdrawal trials of diuretic drugs. On the basis of literature, we determined whether the withdrawal of diuretic drugs in general practice is safe and adequate in elderly patients using chronic diuretics who do not have high blood pressure or symptoms of cardiac, hepatic or renal failure.

Literature published in English and Dutch was screened. Seven studies on withdrawal of diuretic drugs in elderly patients who had used diuretics chronically have been reviewed. The studies are assessed on their methodological validity on the basis of criteria for usefulness of interventions of Sackett et al. Consensus on the methodological judgement was sought between two observers on all criteria after independent assessment. Relevant outcomes of individual studies are reported in the review. If appropriate, further statistical assessment was carried out. Pooling of data was not performed because of relevant differences between the studies.

No study fulfilled the methodological criteria for a clear judgement whether diuretic withdrawal is safe and useful in the population of interest. Although the authors in the reported studies advocate that withdrawal of diuretics can be safe and appropriate in a number of situations, questions remain not only as to the long-term effects on mortality and congestive heart failure, but also as to short term effects on the degree of ankle oedema.

Chapter four presents an investigation to determine whether diuretics would be prescribed for ankle oedema in absence of symptoms of cardiac, hepatic or renal failure. We used a questionnaire survey to obtain information on the opinions of Dutch general practitioners about the differential diagnosis and treatment of ankle oedema in the elderly. In the questionnaire we presented the case of a 68 -year-old 
woman who complained of ankle oedema without any symptom or sign of heart failure. The questionnaire was sent to 200 Dutch general practitioners (response rate $64 \%)$. Venous insufficiency was mentioned by $86 \%$ and heart failure by $12 \%$ of the responders as most probable cause of the oedema. The treatment proposed by $59 \%$ was advice and/or compression therapy without drugs, while $40 \%$ would have prescribed diuretics.

Methodological issues of withdrawal are treated in chapter five. In contrast to the methodology for the investigation of starting therapies, the methodology of withdrawal research has hardly been developed. Methodological characteristics of a withdrawal trial are discussed.

Chapter six (Research methods) gives a detailed description of the design and the practical execution of the prevalence study, the withdrawal trial and the nonexperimental follow-up procedure.

The prevalence study was carried out in four successive phases:

(1) an investigation to identify thepatients aged 65 years or older, using diuretic drugs; (2) a patients' mail questionnaire; (3) a medical file investigation of patients who cooperated with the questionnaire; (4) an inclusion procedure, the definitive selection of patients eligible for the trial.

A randomized controlled design was chosen for the trial. During a period of six weeks, a group of patients eligible for diuretics withdrawal were followed. In the intervention group diuretic use ceased at start of the experimental period, while the control group continued to use the diuretics. The main outcome measure was the relative change in volumetric determined ankle oedema.

After the trial a non-experimental follow-up procedure was organized. At least half a year after the last trial measurement, we checked whether, why and since when diuretics were used and in addition whether important medical events had happened.

Chapter seven presents the results of the prevalence study. We were able to screen the population in fifteen practices on the criteria: aged 65 years or older and being 
prescribed diuretic drugs. We traced 1202 patients who met those criteria. On the basis of data from six computerized practices, we found a prevalence rate of $17 \%$ in the age group 65 years or older having been prescribed diuretic drugs in the preceding half year. On being asked, $40 \%$ of the patients reported using diuretics, for hypertension and $39 \%$ for swollen ankles. Those patients' doctors stated that in $55 \%$ of the cases prescription of diuretics was for hypertension, in $23 \%$ for heart failure and in $13 \%$ for ankle oedema. After selection we could trace 383 patients who appeared to use diuretics for ankle oedema. Ultimately in only 66 cases did stopping; diuretics for the trial appear to be possible without any contra-indication. The most frequent contra-indication found was the risk of developing heart failure after withdrawing diuretic therapy. Furthermore, additional use of diuretics for hypertension was an important reason for exclusion. Thus it appeared to be difficult to find patients where it was clearly indicated to withdraw diuretics on the basis of the criterion: diuretic use for ankle oedema without symptoms of heart, hepatic or renal failure.

We conclude that each doctor should make a thorough evaluation of the necessity of diuretic therapy before prescribing diuretics since withdrawal of the therapy will at the very least be complicated by several contra-indications, even when the diuretics are used for a relatively weak indication such as ankle oedema.

Chapter eight describes the results of the withdrawal trial. Eventually 63 patients were enrolled in the trial. The withdrawal group consisted of 34 patients and the control group of 29 patients. In eight patients the withdrawal failed, in four cases due to medical reasons in spite of our thorough selection procedure. In 26 of 34 patients diuretics were withdrawn successfully during a period of six weeks. Rebound ankle oedema occurred causing a temporary increase of $3.5 \%(95 \%$ confidence interval $1.8 \%-5.2 \%$ ) in the mean oedema index. The peak level was reached in the third week, after which the oedema appeared to be returning to baseline level.

Half-a-year after the trial it appeared that the majority of patients had resumed use of diuretic drugs $(62 \%)$. 
Concerning the long-term effect of withdrawal, uncertainty remains. In the nonexperimental follow-up period, one patient died from a myocardial infaretion, while another suffered from symptoms of a stroke, which did not persist. Both had participated in the withdrawal group. One patient who had participated in the control Broup suffered from symptoms of a myocardial infarction. However, since the follow-up had no experimental design no evidence for differences between both groups concerning any long-term effect could be obtained.

Our study shows that withdrawing diuretic drugs in elderly long-term users is feasible in a selected population. On the basis of the clinical course of the patients who completed the full protocol in the withdrawal trial, we conclude that withdrawal of diuretic drugs in patients using diuretics because of ankle oedema leads to an increase of oedema which is only temporary. The process seems to be reversible in patients in good clinical condition.

Chapter nine (the general discussion) reviews the main findings and discusses the research methods that we applied. In addition recommendations for further research and clinical practice are provided.

A small number of patients appeared to be eligible for withdrawal of diuretics in the trial. The problem of misuse of diuretics for ankle oedema seems not as widespread as was concluded on the basis of literature and previous research. In addition only a minority of the patients selected were eligible for withdrawal, given that they had no 'contra-indications' for cessation of diuretic therapy.

We obtained evidence that withdrawal of diuretic drugs does not lead to a permanent increase of oedema. A temporary rebound oedema must be expected. However, uncertainty remains regarding the long-term effects of withdrawal, both on the basis of the literature review and our experiment. We conclude that withdrawal of diuretics should only be performed after thorough consideration and under adequate medical monitoring.

Further research might find answers on such issues as:

- the difference between various types of diuretics, regarding magnitude and the duration of the rebound effect, and 
- the long-term effects of continued withdrawal.

In future doctors will face more and more situations in which patients are using all kinds of therapies chronically. Further research is necessary to obtain knowledge about the possibility and the effects of withdrawal of therapies.

Several issues for which well defined guidelines exist in common intervention trials need reconsideration in withdrawal trials. Further development of the investigation methods for withdrawal is required.

\section{Samenvatting}

In hoofdstuk één worden kort het doel en de achtergrond van dit proefschrift beschreven. Bovendien worden de afzonderlijke vraagstellingen behandeld.

De huisarts wordt regelmatig geconfronteerd met de keuze geneesmiddelen die chronisch gebruikt worden opnieuw voor te schrijven of te staken. In tegenstelling tot het starten, is er weinig bekend over effecten van het staken van allerlei therapieên. Diuretica voorgeschreven als behandeling van enkeloedeem zijin van belang in dit opzicht. Er bestaat zorg over onnodig diuretica gebruik door ouderen. In de geriatrische literatuur wordt het staken van diuretica in een aantal situaties aanbevolen, onder andere wanneer patiênten diuretica gebruiken vanwege enkeloedeem, waarbij geen tekenen zijn van decompensatio cordis, lever- of nierfalen. Of dit ook geldt voor de situatie in de huisartspraktijk is niet duidelijk. De centrale doelstelling van het onderzoek beschreven in dit proefschrift is na te gaan wat het effect is van het staken van diuretica, bij patiênten die diuretica gebruiken vanwege enkeloedeem waarbij geen sprake is van decompensatio cordis, lever- of nierfalen.

Hoofdstuk twee bespreekt het gebruik van diuretica door ouderen.

Het grote aantal van ouderen die geneesmiddelen gebruiken, is een punt van zorg. Patiènten kunnen getroffen worden door ongewenste effecten als bijwerkingen of interacties met andere geneesmiddelen. Diuretica zijn in dit opzicht van belang. In 
Nederland gebruikt bijna $20 \%$ van de mensen van 65 jaar en ouder een diureticum.

De momenteel gebruikte diuretica werden geintroduceerd in de late jaren vijftig en de vroege jaren zestig. De belangrijkste indicaties zijn, de behandeling van oedemen (inclusief longoedeem) en hypertensie. Vele bijwerkingen van diuretica zijn beschreven, in het bijzonder stoornissen in de water en zout balans. Het ontstaan van "rebound" oedeem na het staken van diuretica is gerapporteerd.

Enkeloedeem lijkt een belangrijke reden te zijn voor het gebruik van diuretica. Wanneer enkeloedeem het gevolg is van decompensatio cordis, lever- of nierfalen kunnen diuretica geindiceerd zijn. Als het oedeem echter het gevolg is van veneuze insufficiēntie, dan is het toepassen van diuretica controversieel. Wanneer diuretica in deze situatie gebruikt worden, lijkt stoppen zinvol. Er is echter geen onderzoek gedaan naar de effecten van het staken van diuretica in deze omstandigheid bij patiënten in de huisartspraktijk.

Hoofdstuk drie geeft een overzicht van klinische trials waarin het staken van diuretica werd onderzocht. Op basis van de literatuur probeerden wij te bepalen of het staken van diuretica in de huisartspraktijk, veilig en zinvol is, bij ouderen die diuretica langdurig gebruiken zonder symptomen van hypertensie, decompensatio cordis, lever- of nierfalen te hebben. Engels- en Nederlandstalige literatuur werd gescreend. Zeven onderzoeken naar effecten van het staken van diuretica bij ouderen die langdurig diuretica gebruikten werden geanalyseerd. De onderzoeken werden beoordeeld op hun methodologische validiteit op basis van de criteria van Sackett et al. Na eerst een onafhankelijk oordeel gevormd te hebben, werd door twee beoordelaars consensus gezocht over het al of niet voldoen van de studies aan de vooraf gedefinieerde criteria. Relevante resultaten van de studies worden beschreven in het overzicht. Indien zinvol werd nadere statistische analyse verricht van de gegevens uit de studies. De gegevens werden niet ge-pooled vanwege relevante verschillen tussen de studies onderling.

Geen enkel onderzoek voldeed aan de methodologische criteria om op volledig betrouwbare gronden te kunnen oordelen of het staken van diuretica veilig en nuttig is in de betreffende populatie. De auteurs van de onderzochte studies geven aan dat 
het staken van diuretica veilig en nuttig kan zijn in een aantal situaties. Er blijven echter vragen open over de lange termijn effecten op zowel de mortaliteit als, decompensatio cordis, maar ook over het directe effect op enkeloedeem.

In hoofdstuk vier wordt cen studie beschreven waarin werd onderzocht of diuretical voorgeschreven worden voor enkeloedeem in afwezigheid van symptomen van decompensatio cordis, lever- of nierfalen. Om inzicht te krijgen in de mening van Nederlandse huisartsen over differentiële diagnose en de behandeling van enkeloedeem bij een oudere patiënt(e) werd een enquête verricht aan de hand van een gefingeerde ziektegeschiedenis van een 68-jarige patiēnte met enkeloedeem zonder duidelijke aanwijzingen voor een hartziekte. De enquête werd aan 200 huisartsen gestuurd ("respons rate" $64 \%$ ). Veneuze insufficiêntie werdl door $86 \%$ en decompensatio cordis door $12 \%$ van de respondenten als meest waarschijnlijke oorzaak genoemd. De voorgestelde behandeling was in $59 \%$ niet medicamenteus (o.a. houdingsadvies met eventueel compressie therapie); $40 \%$ zou al of niet als ondersteuning diuretica voorschrijven.

In hoofdstuk vijf worden methodologische aspecten van het onderzoek van het staken van een behandeling belicht. In tegenstelling tot de methodologie van het onderzoeken van het gaan behandelen met nieuwe therapieên, is de methodologie van het onderzoeken van het staken van behandelingen nauwelijks ontwikkeld.

In hoofdstuk zes (methoden) worden het design en de uitvoering van de prevalentie studie, de stop-trial en de daaropvolgende niet experimentele follow-up procedure behandeld.

De prevalentie studie werd vitgevoerd in 4 opeenvolgende fases: (1) een inventarisatie om patiënten in de praktijken te vinden van 65 jaar en ouder die een diureticum g̨ebruikten; (2) een enquête onder de patiênten; (3) een medisch dossier onderzoek van de patiễnten die hun medewerking gaven via de enquête; (4) een inclusie procedure waarin de definitieve selectie van patiênten voor deelname aan de trial plaatsvond. 
De trial werd uitgevoerd volgens een gerandomizeerd gecontroleerd design. Gedurende een periode van zes weken werden patiēnten waarbij het staken van diuretica zinvol werd geacht, gevolgd. De interventiegroep bestond uit patiēnten waarbij diuretica werden gestaakt, terwijl de controlegroep bestond uit patiěnten die hun diureticagebruik continueerden. De belangrijkste vitkomstmaat was de verandering in de mate van enkeloedeem.

$\mathrm{Na}$ de trial werd een niet experimentele follow-up procedure uitgevoerd. Minimaal een half jaar na laatste meting voor de trial, werd nagegaan of, waarom en sinds hoelang diuretica werden gebruikt. Bovendien werd de ziektegeschiedenis van de patiènten in de periode volgend op de trial nagegaan.

De resultaten van de prevalentie studie worden gepresenteerd in hoofdstuk zeven. De praktijkpopulatie van 15 huisartspraktijken was gescreend op de criteria: leeftijd 65 jaar of ouder en het gebruik van diuretica. We spoorden 1202 patiênten op die voldeden aan deze criteria. Op basis van gegevens uit de zes geautomatiseerde praktijken die deelnamen aan de trial, vonden we een prevalentie van $17 \%$ voor het diuretica gebruik in de groep 65 jaar en ouder. Veertig procent van de patiènten die meewerkten aan onze enquête gaf aan de diuretica te gebruiken wegens hoge bloeddruk, 39\% gebruikte diuretica wegens enkeloedeem. Reden voor het voorschrijven van diuretica aan deze patiēnten was volgens hun artsen: in $55 \%$ van de gevallen hypertensie, in $23 \%$ decompensatio cordis en in $13 \%$ enkeloedeem. Na selectie, vonden wij 383 patiênten die diuretica gebruikten vanwege enkeloedeem. Uiteindelijk voldeden slechts 66 patiēnten aan alle criteria om de diuretica te staken voor de trial. De meest voorkomende "contra-indicatie" voor het stoppen van diuretica was het risico op decompensatio cordis na staken. Daarnaast was de combinatie van de indicatie hypertensie naast de indicatie enkeloedeem, een belangrijke reden waarom diuretica niet gestaakt konden worden in het kader van onze trial. Het bleek dus moeilijk om patiênten te vinden waarbij het duidelijk geindiceerd was de diuretica behandeling te staken op grond van het criterium: diuretica gebruik vanwege enkeloedeem zonder symptomen van hart-, lever- of nierfalen. 
Wij concluderen dat alvorens diuretica voor te schrijven, een zorgvuldige afweging gemaakt zou moeten worden over de doelmatigheid daarvan. Het blijkt dat er vaak contra-indicaties zijn voor het staken van de diuretica als ze eenmaal gebruikt worden, zelfs in het geval van een relatief zwakke indicatie als enkeloedeem.

In hoofdstuk acht beschrijven we resultaten van de stop-trial. Uiteindelijk werden 63 patiēnten opgenomen in de trial. De stopgroep bestond uit 34 , de controlegroep uit 29 patiênten. Bij acht patiēnten mislukte de poging de diuretica te staken. In vier gevallen vanwege duidelijke medische redenen, ondanks onze zorgvuldige selectie. Bij 26 van de 34 patiênten werden de diuretica succesvol gestopt gedurende een periode van 6 weken. Er trad een tijdelijk rebound oedeem' op waarbij het oedeem gemiddeld $3.5 \%$ toenam $(95 \%$ betrouwbaarheids-interval $1.8 \%-5.2 \%$ ). Gemiddeld werd in de derde week na het staken van de diuretica, de sterkste mate van rebound oedeem gemeten. Daarna nam het oedeem af naar de uitgangswaarde.

Ben half jaar na de trial bleek $62 \%$ van de patiênten waarbij diuretica gestaakt waren toch weer diuretica te gebruiken.

Er blijft onzekerheid bestaan over de lange termijn effecten van het staken van diuretica. In de periode na de trial, overleed 1 patiênt aan een myocard infarct, terwijl een andere patiễnt een tijdelijke periode met symptomen van een CVA doormaakte. Beide hadden deelgenomen in de stopgroep. Een patiēnt die deelgenomen had in de controle groep werd opgenomen in het ziekenhuis vanwege symptomen van een myocard infarct. Vanwege de niet experimentele opzet van de follow-up kunnen hier geen harde conclusies, aan verbonden worden ten aanzien van verschillen tussen de stopgroep en de controlegroep.

Ons onderzoek toont aan dat het staken van diuretica bij, ouderen die ze langdurig gebruiken uitvoerbaar is in een geselecteerde populatie. Op basis var de patiênten fie de volledige experimentele periode doorliepen, concluderen wij dat het staken van diuretica bij patiěnten die ze gebruiken wegens enkeloedeem zonder symptomen van hart-, lever- of nierfalen leidt tot cen slechts tijdelijke toename van het oedeem. Het proces lijkt reversibel bij patiēnten in een goede klinische conditie. 
In hoofdstuk negen worden de belangrijkste bevindingen herhaald en de onderzoeksmethoden besproken. Bovendien worden aanbevelingen voor de praktijk en toekomstig onderzoek vermeld.

Bij slechts weinig patiēnten bleek stoppen van diuretica in de trial toepasbaar. Het probleem van onnodig diuretica gebruik voor enkeloedeem lijkı niet zo omvangrijk als op basis van de literatuur en eerder onderzoek was geconcludeerd. Bovendien hadden veel patiènten die in de eerste instantie geselecteerd waren voor de trial toch een "contra-indicatie" voor het staken van diuretica. Wij verkregen sterke aanwijzingen dat het staken van diuretica niet leidt tot een belangrijke blijvende toename in de mate van enkeloedeem. Wel moet rekening gehouden worden met een tijdelijke toename van het oedeem. Er blijft echter onzekerheid over de lange termijn effecten van het staken, zowel op basis van de literatuurstudie als op basis van de trial die wij verrichtten. We concluderen dat het staken van diuretica alleen onder adequate medische begeleiding zou moeten plaatsvinden.

Toekomstig onderzoek zou duidelijkheid kunnen brengen in kwesties als:

- verschillen wat betreft sterkte en duur van het rebound effect tussen verschillende diuretica;

- de lange termijn effecten van het staken van diuretica.

In de toekomst zullen artsen meer en meer geconfronteerd worden met situaties waarin patiënten langdurig behandeld worden. Nader onderzoek van de mogelijkheid tot, en de effecten van staken van behandelingen verdient aanbeveling. Allerlei methodologische richtlijnen die geschikt zijn voor onderzoek naar effecten van het instellen van een therapie, zijn niet rechtstreeks, toepasbaar op onderzoek van het staken van een therapie. Verdere ontwikkeling van methodes voor onderzoek naai het staken van therapiežn lijkt daarom zinvol. 


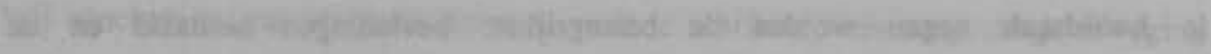

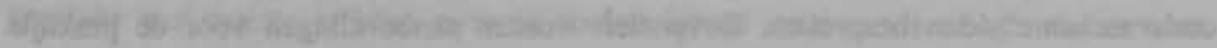

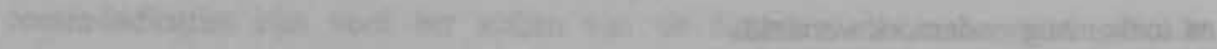

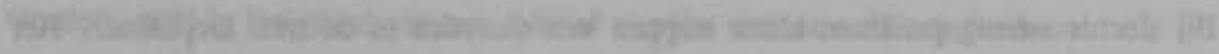

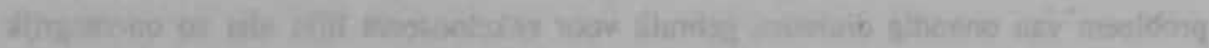

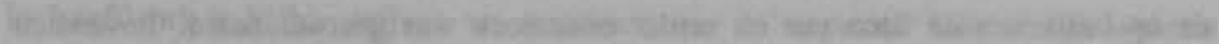

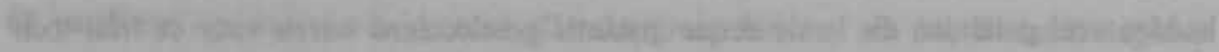

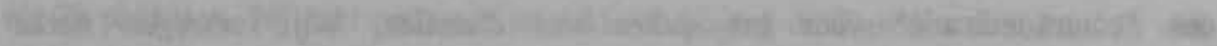

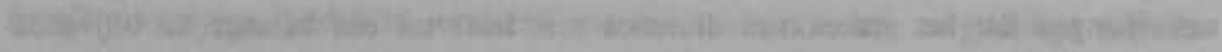

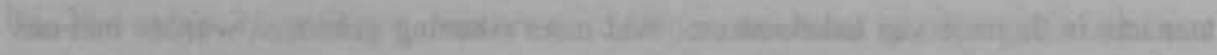

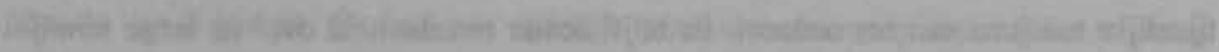

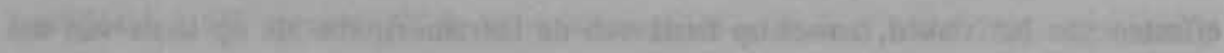

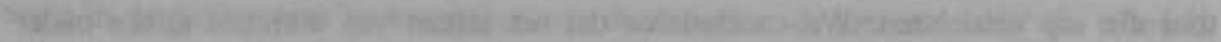

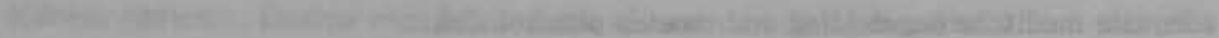

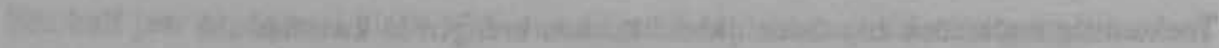

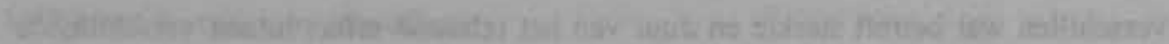

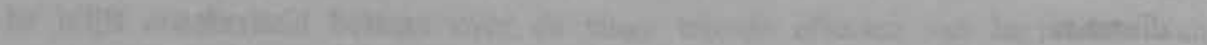

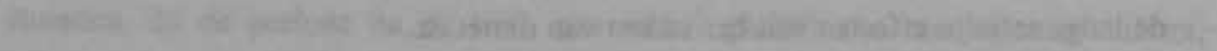

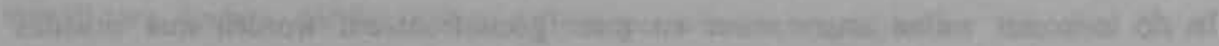

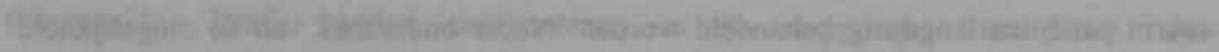

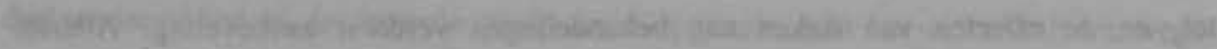

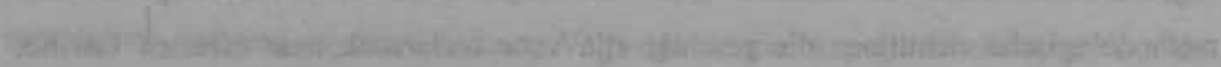

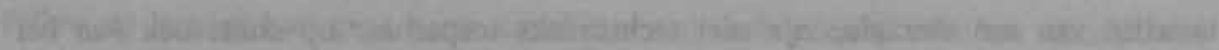

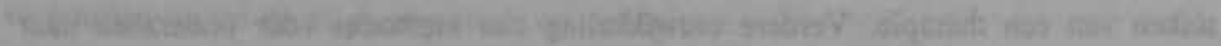

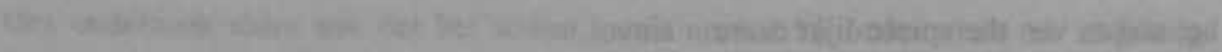

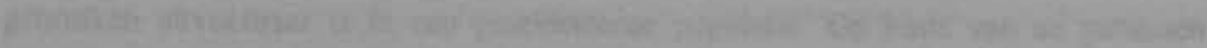

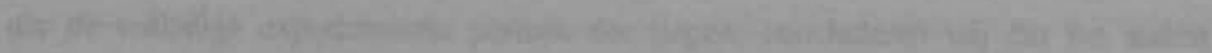

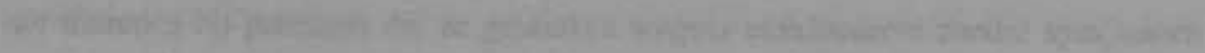

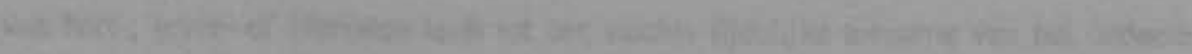

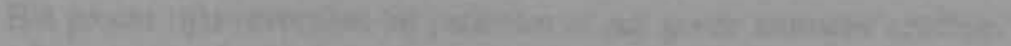


Appendix 1 Questionnaire for concise quality of life measurement

\section{Bow would you judge your health?}

- very well

o well

- moderate

- bad

- very bad

2 How happy were you in the past few weeks?

- very happy

- happy

- not happy/not unhappy

- unhappy

o very unhappy

3 How satisfied were you in the past few weeks?

- very satisfied

- satisfied

- not satisfied/not dissatisfied

- dissatisfied

- very dissatisfied

4 One can have an idea about the quality of for example fruits or wine; it is also possible to have an idea about one's quality of life. This can be high, low or somewere in berween. Could you give a judgement about your quality of life in the past few weeks by putting a cross on the line below?

Lowest quality highest quality 
Appendix 2 Questionnaire for functional status score

1 Judgement about limitations of physical fitness

o unlimited/no problem

o a little/slightly

- moderate/some

- much/quite a bit

- always/serious

2 Judgement about feelings

- unlimited/no problem

- a little/slightly

- moderate/some

- much/quite a bit

- always/serious

3 Judgement about limitations of daily activities

- unlimited/ne problem

- a little/slightly

- moderate/some

- much/quite a bit

- always/serious

4 Judgement about limitations of social gctivities

- unlimited/no problem

o a little/slightly

- moderate/some

- much/quite a bit

- always/serious 
Jan-Willem de Jonge was born on May 31st, 1958 in Warder, the Netherlands. He finished his secondary education ("Atheneum beta") at the "Rijksscholengemeenschap Noord-Kennemerland" in Alkmaar in 1978. After completing 14 month' military service in 1979, he studied maritime engineering in Delft. From 1980 to 1988 he studied medicine at the University of Amsterdam. Subsequently he worked for four years on $\mathrm{PhD}$, research at the Department of General Practice of the University of Limburg. In 1992 he started training as a General Practitioner. 


\section{Dankwoord}

Op deze plaats wil ik iedereen bedanken die cen bijdrage heeft geleverd aan de totstandkoming van dit proefschrift. Soms wordt beweend dat onderzoekswerk een eenzame bezigheid is, het beeld van de onderzoeker in de ivoren toren doemt dan op. Ik denk dit niet voor elk onderzoek opgaat. Uit het onderstaande moge blijken hoeveel mensen mij op een of andere wijze hebben geholpen.

Allereerst de patiënten, die bereid waren mee te werken aan een medisch onderzoek waarbij hen niet veel meer in het vooruitzicht gesteld kon worden dan dat zij een geneesmiddel niet meer hoefden te gebruiken. Hun medewerking en gastvrijheid was formidabel.

Met zijn onstuitbare enthousiasme en werkkracht heeft André Knottnerus mij van het begin tot het einde geweldig gestimuleerd. Ik denk met plezier terug aan de vele uren die aan overleg besteed werden.

Wim van Zutphen kon helaas de definitieve afronding van dit project waarvan hij projectleider was niet meer meemaken. Zijn onvoorwaardelijke steun zal ik niet snel vergeten.

Ad de Bruijne was de geestelijke vader van het idee dat in deze dissertatie is uitgewerkt. Daarnaast heeft hij mij wegwijs gemaakt in het gebruik van de "PC". Ik heb daar in de loop van het, onderzoek veel plezier van gehad.

Harry Struijker Boudier heeft zowel in de aanloopfase als bij de verslagleggingsfase yan het project belangrijke adviezen gegeven.

Gerda van der Pol heeft met haar adequate optreden een essentiēle bijdrage geleverd aan de data verzameling en verwerking. Zij combineerde in eén persoon de: kwaliteiten van dokters-assistente en research-assistente.

Trudy Seegers zorgde voor op maat gesneden oplossingen ten behoeve van de geautomatiseerde gegevens verwerking. Daarnaast heefit zij vaak geholpen bij praktische problemen zoals het opstellen vari onderzoeksformulieren en het formuleren van instructies voor artsen en patiēnten. Bovendien heeft zij mij wegwijs gemaakt in het werken met de "VAX" en het hanteren van het programma "BMDP". Bob Wilkinson heeft fantastisch werk verricht door mijn Engelse teksten zeer. 
zorgvuldig, te redigeren. Zelfs mijn tabellen en getallen waren niet veilig voor zijn kritisch oog.

Paul Höppener zorgde voor de programmatuur om in de Micro-His praktijken de prevalentie studie efficiênt te kunnen uitvoeren. Hij nam deze taak op zich, terwijl hij druk bezig was met zijn eigen proefschrift. Bovendien bood hij de gastvrijheid om in zijn eigen praktijk de eerste ronde van de trial te laten uitvoeren. Bijgestaan an bijgestuurd door zijn praktijk-assistente Pia Cuypers kon ik deze belangrijke fase van het onderzoek op een relatief soepele wijze laten verlopen.

In de praktijk van Jan van Dongen werd proefgedraaid. De nodige avonden werden besteed aan het vinden van oplossingen voor de praktische problemen die opdoemden bij de uitvoering van de op papier zo mooie plannen.

Frits Ruyters heeft vele storingen in zijn werk door vragen en wensen mijnerzijds geduldig getolereerd en in de eindfase gezorgd voor goede communicatielijnen.

Wim Martens bood mij de gelegenheid ten tijde van het onderzoek ook ervaring op te doen in de dagelijkse huisartspraktijk. Zijn assistente, Patty Schijns becommentarieerde de instructieformulieren ten behoeve van de praktijk-assistentes.

Later, tijdens mijn assistentschap was Fred Willemsen zo flexibel om, wanneer nodig, mij de ruimte te geven om aan de afronding van dit proefschrift te werken.

De hulp van de meewerkende huisartsen was onontbeerlijk, zij boden de gastvrijheid om het onderzoek in hun praktijken uit te laten voeren. Bij het onderzoek waren betrokken de huisartsen: M. Op den Kamp, J. van Iersel, J. Sonke, J. van Putten, H. Schőnberger, H. Derkx, J. Sereever-Delahaye, A. Sereever, P. Wielders, A. Gielen, F. Verhaeg, B. v.d. Rijst, T. Krebber, R. de Jong, M. Huynen, E. Geraedts, G. Beusmans, W. Vierhout, R. van Well en H.Ypma. De assistentes uit deze praktijken zorgden in veel gevallen voor de eerste contacten met de patiēnten. Bovendien vervulden zij de rol van vraagbaak voor de deelnemers.

Verreweg de meeste apothekers in Maastricht waren zonder aarzelen bereid mee te werken aan het onderzoek. Van hen wil ik speciaal de heer Straver bedanken, hij heeft uitgezocht of onze plannen uitvoerbaar waren in de geautomatiseerde apotheek. Daarnaast werkten de volgende apothekers mee: C. Langen-Engel, R. Huijnen, J. Koomen, H. Geusgens, M. Schüsler-van Hees, Dhr. Martens, H. Willems, M. 
Jaspers-van Wouw, Mevr. Sijstermans, R. Oostwegel, Dhr. Theuns, E. van Thoor en F. Römkens.

Karin Aretz en Paula Rinckens fungeerden als contactpersoon bij de vakgroep tijdens de eerste helft van de dataverzamelingsperiode. In een later stadium heeft Sylvia Bours deze taak op zich genomen.

De medewerkers van het Diagnostisch Centrum Maastricht zorgden voor een adequate afhandeling van de benodigde laboratorium onderzoeken.

De medewerkers van de afdeling Klinische Farmacie van het AZM verzorgden de urine analyses ten behoeve van de compliance meting. Van hen wil ik met name H.J.G. Groothuijsen bedanken die de uitvoering en rapportage van dit werk onder zijn hoede nam.

Amold Kester droeg de nodige statistische verfijningen aan.

De "Gang" huisarts-medewerkers wil ik bedanken voor hun altijd collegiale opstelling. Vanaf het eerste moment voelde ik mij opgenomen tussen de onderzoekers en docenten van de Maastrichtse Vakgroep. Bij hen kon ik altijd vooir formeel of informeel overleg terecht. Floor Martens, Marijke Perquin, Geert-Jan Dinant, Michiel Cornel en Piet Portegijs waren fijne kamergenoten tijdens mijn aanstelling bij de vakgroep.

De voltallige "KKP" club bedank ik voor de fijne tijd in het hart van Maastricht, waarin op een plezierige en stimulerende manier werd samengewerkt.

René Kocken regelde soepel de zo broodnodige financiële zaken voor dit onderzoek. Tijdens de planningsfase gaven Hans Fiolet, Ton Gorgels, Luc v. Bortel, Arnold Vulto en Frans v.d. Horst mij waardevolle adviezen.

Fedde Spoel zorgde vliegensvlug voor een mooie lay-out. Guus varı Rooy maakte een passende omslag.

De mensen van Thesis-publishers hebben er uiteindelijk voor gezorgd dat de tekst in bockvorm kon verschijnen.

En tenslotte Esther, zij maakte zonder aarzelen de overstap mee van Amsterdam naar Maastricht. Als wij weer eens tegen familie of vrienden zeurden dat wij niet op een uitnodiging in konden gaan, kon ik haar gelukkig meestal de schuld geven vanwege haar werkzaamheden. Overigens zorgde zij daarmee voor een goed 
inkomen zodat ik me met mijn "AIO" hobby kon bezig houden. 


\section{Diuretic drug cessation in general practice.}

\section{Withdrawing diuretic drugs prescribed for ankle oedema.}

\section{Jan-willem de Jonge}

The General Practitioner must often decide whether to stop or continue drugs that are used chronically. However, in contrast to the starting of many therapies, little is known about the effects of their withdrawal. In this context, diuretic drugs prescribed for ankle oedema are of interest. There is noticeable concern about unnecessary use of diuretics by elderly patients. A number of studies reported in the medical geriatric literature have advocated that withdrawal of diuretics in elderly patients can be appropriate in certain circumstances, such as when patients are using diuretics for ankle oederna, given that the oedema is not caused by cardiac, renal or hepatic insufficiency. What are the effects if diuretics are withdrawn in these circumstances? This work presents a study in this field.

Jan-Willem de Jonge studied medicine at the University of Amsterdam, the Netherlands. He trained in the field of clinical epidemiology while he worked as a junior researcher at the Department of General Practice at the University of Limburg, Maastricht, the Netherlands.

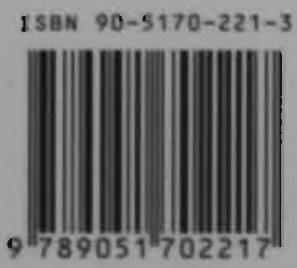

NUGI $741 / 746$ 